\title{
Extreme Weather and the Reproductive Success of a Long-lived Pelagic Seabird
}

\author{
Bryony Baker
}

\begin{abstract}
A thesis submitted to the University of Gloucestershire in accordance with the requirements of the degree of MSc by Research in the School of Natural and Social Sciences
\end{abstract}

December 2019

Word count: 21,609 


\section{Abstract}

Seabirds are in decline globally and climate change is likely to increase the pressure on already struggling species. The indirect effects of climate change are widely studied, they have been shown to have a significant effect on both seabird survival and reproductive success, but the direct effects are less well understood. Climate predictions suggest that one of the direct effects, extreme weather, is predicted to increase in both frequency and intensity.

Skomer Island is the largest Manx Shearwater colony in the world and the population has been increasing over recent decades, but the specific effects of extreme weather on reproductive success are unknown.

This study compared the effects of average and extreme weather conditions on Manx Shearwater reproductive success, taking into account the effect of known breeding pairs and the potential effects of individual experience. It also considered the effect of inter-specific competition between shearwaters and Atlantic puffins on shearwater reproductive success.

This study found that colony-level reproductive success showed no significant trend over the study period of 1995-2019, however fledging success showed a significant decline. When individual-level analysis was carried out no such trend was found: experienced breeders may be more likely to successfully raise a chick. Extreme weather was shown to have significant effects on reproductive success at the individual-level, particularly on fledging success, but this did not cause a significant decrease in fledging success over the study period.

Population estimates show that shearwaters are increasing on Skomer and it is clear that weather, extreme or not, is not currently the most significant factor in determining reproductive success of Manx Shearwaters. This study also found no evidence that puffins are influencing the reproductive success of Manx Shearwaters on Skomer Island.

The effects of climate change, indirect and direct, will interact and have many complex effects, especially if predictions regarding future climate change are met. Extreme weather and the effects of demography can only be studied where longterm datasets exist, therefore projects such as this are vital for ongoing seabird research and conservation. 


\section{Declaration}

I declare that the work in this thesis was carried out in accordance with the regulations of the University of Gloucestershire and is original except where indicated by specific reference in the text. No part of the thesis has been submitted as part of any other academic award. The thesis has not been presented to any other education institution in the United Kingdom or overseas. Any views expressed in the thesis are those of the author and in no way represent those of the University.

Signed

Date $20 / 12 / 2019$

doi: 10.46289/DP88BR12 


\section{Acknowledgements}

I would like to thank the Wildlife Trust of South and West Wales and JNCC for allowing me to use data collected on both Skomer and Skokholm Islands. This research was only possible due to the long-term data collected by them and over 25 years by the Edward Grey Institute and University of Gloucestershire. Particular thanks to Chris Perrins for providing data not available elsewhere. Thank you to the Met Office for providing weather data.

I couldn't have done it without my supervisors. Thank you to Anne, for making me see things from a different perspective and think outside of my own frame of reference, you were right, it's not the puffin's fault! To Matt, without whom this would literally not have been possible. Thank you for taking me on, for giving me so many opportunities outside of this research, for employing me and allowing me to get out of the office, for being so supportive and not letting me succumb to doubt and low confidence. I could not have asked for a better supervisor.

I have met so many people in the last 2 years whom I am so lucky to call my friends. My island girls who dragged me through my Skomer season and have let me gate crash their university on numerous occasions, you inspire me. The Skomer staff and

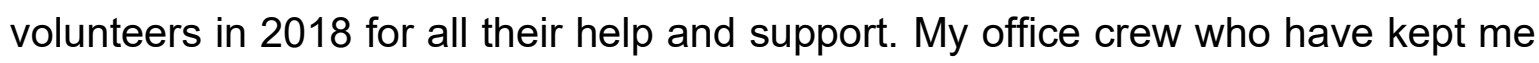
going and supported me in the best way possible, with chat, biscuits and tea breaks! To my wonderful family, thank you for the support and the stability, for providing two lovely homes and a limitless supply of food. Finally, to Lewis, for putting up with the highs and lows and making me happy, even after a day of stats. 


\section{Contents}

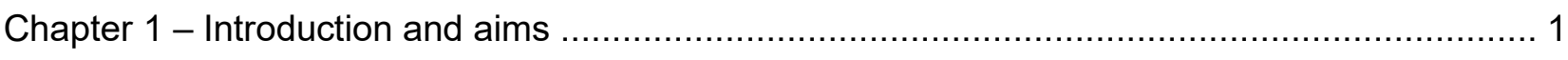

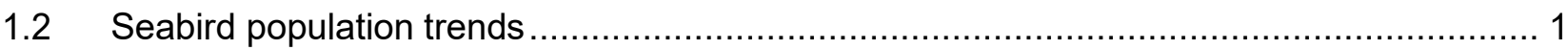

1.2.1 UK seabird populations - status and trends ................................................. 2

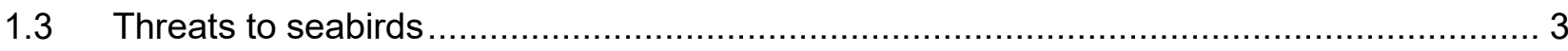

Threat Type of threat Effect on seabirds Examples of research ….............................. 4

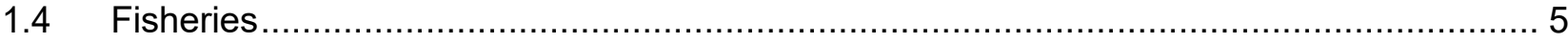

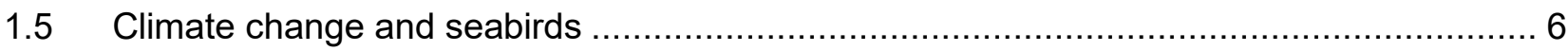

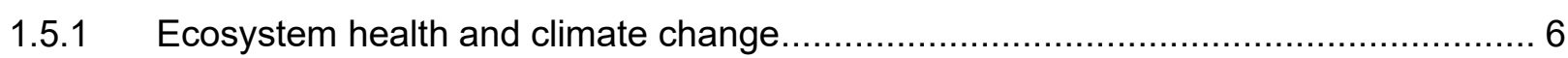

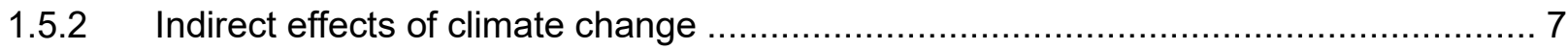

1.5.3 Direct effects of climate change: weather .................................................... 9

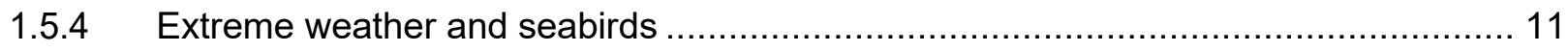

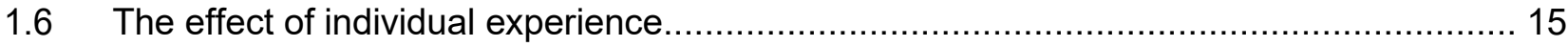

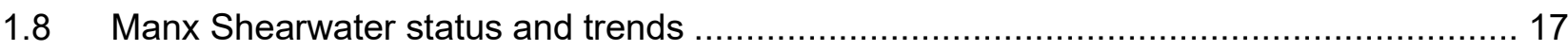

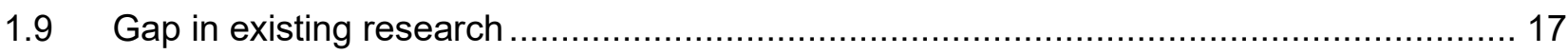

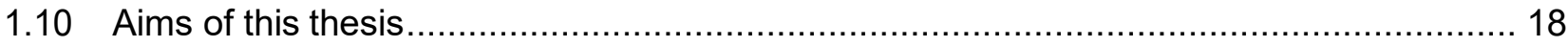

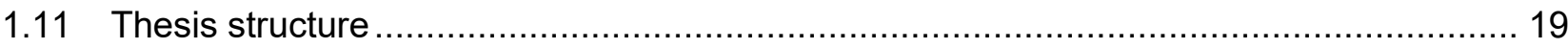

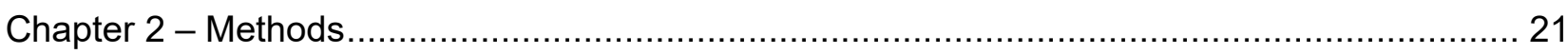

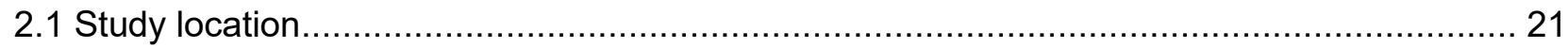

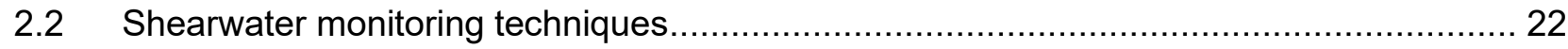

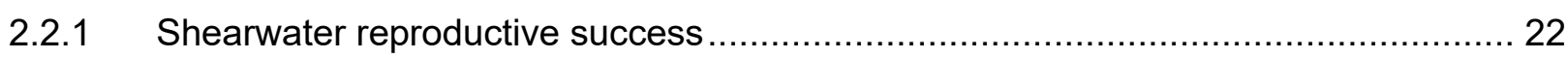

2.2.2 Components of reproductive success ............................................................... 23

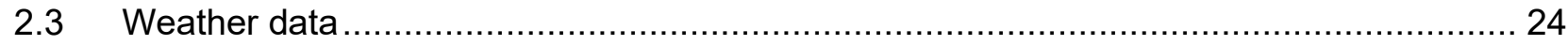

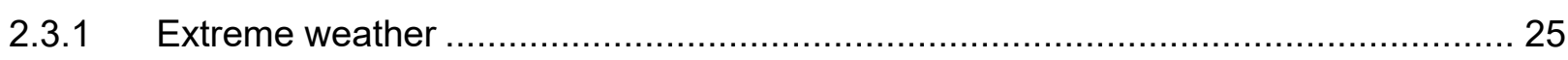

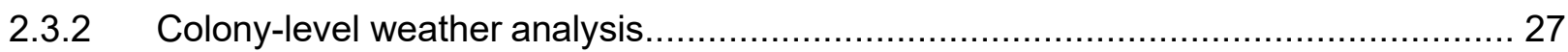

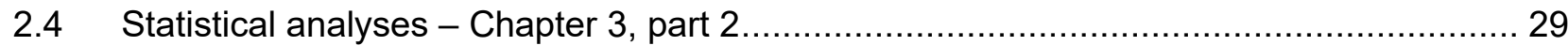

2.4.1 Individual-level weather analysis .............................................................. 29

2.4.2 Hypothesis-driven weather variables for a mixed model ................................... 30

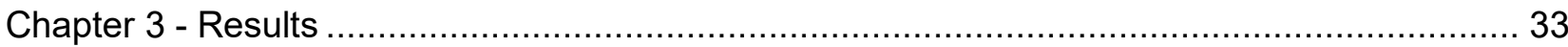

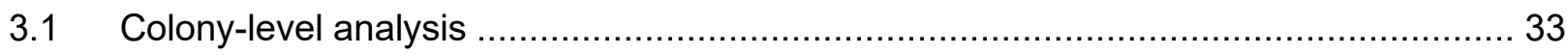

3.1.3.4 Hypothesis-driven weather analysis ...................................................... 40

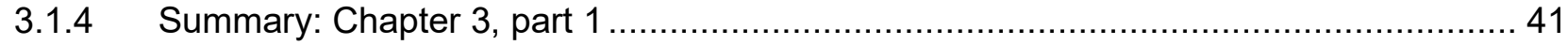

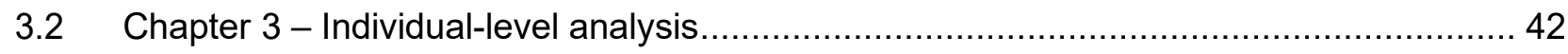

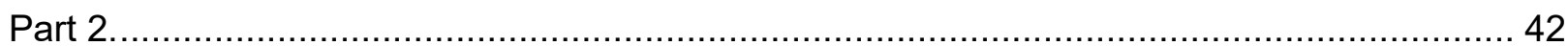

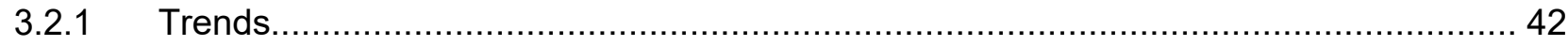

3.3 Individual-level average weather analysis .......................................................... 44

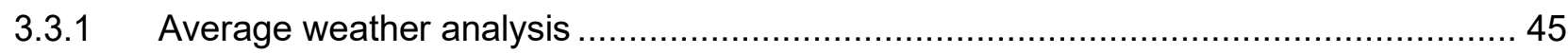

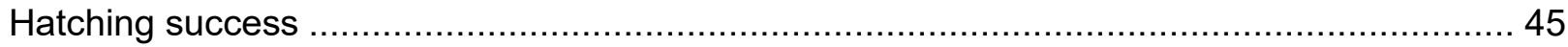

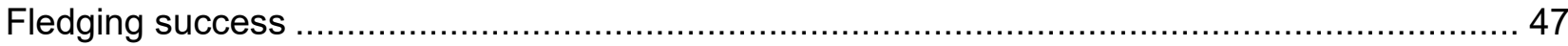

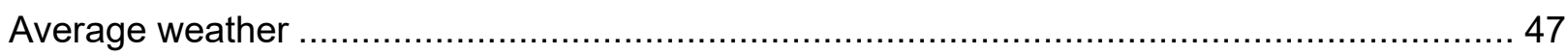

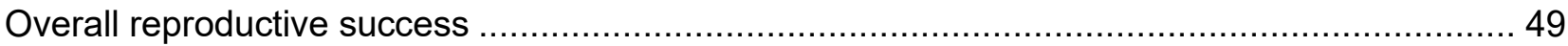


Average weather

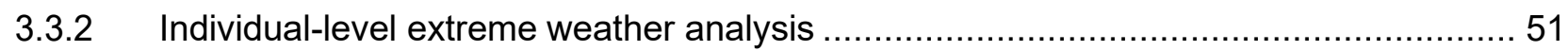

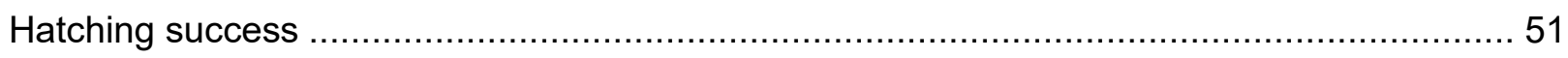

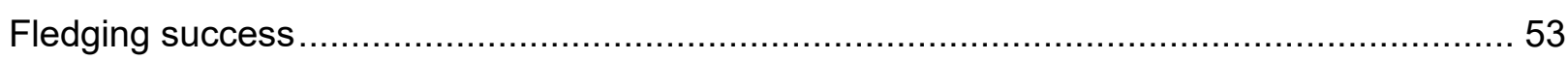

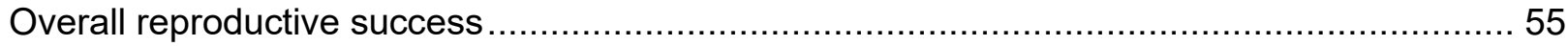

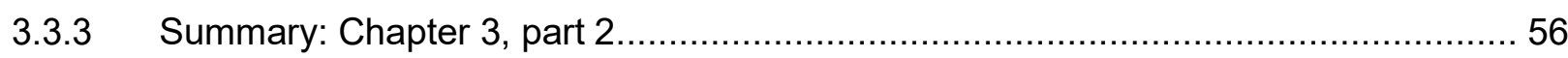

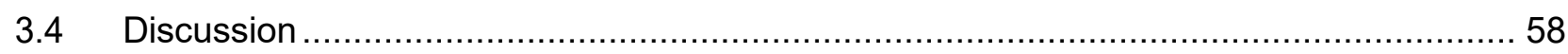

3.4.1 Demographic effects on reproductive success ............................................... 59

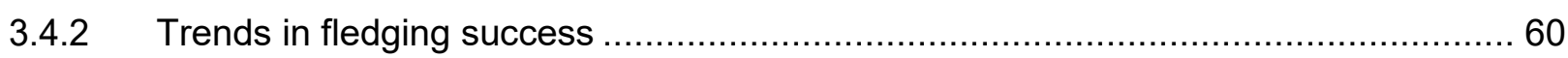

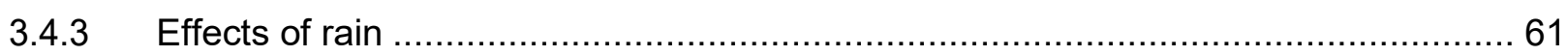

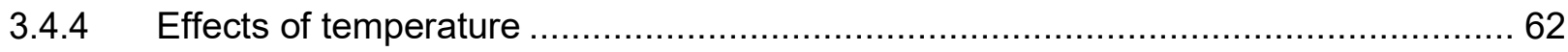

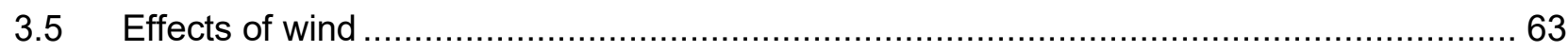

Chapter 4 - Competition and Puffins on Skomer........................................................... 65

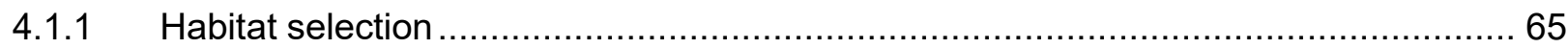

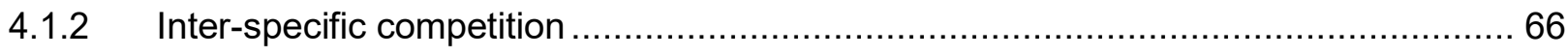

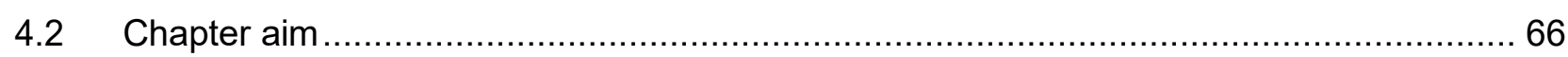

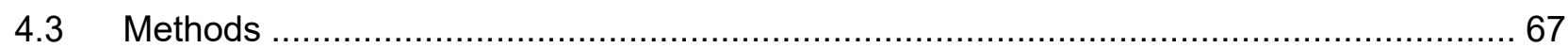

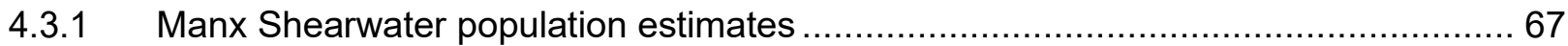

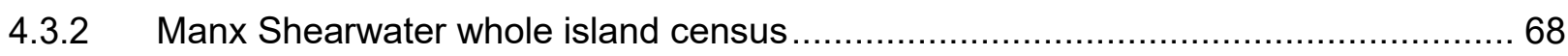

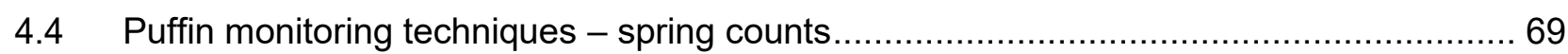

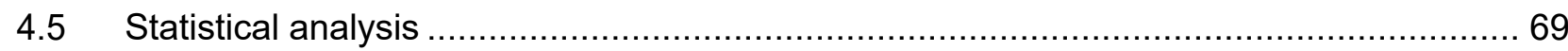

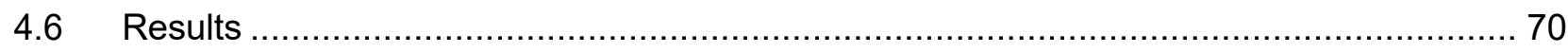

4.6.1 Comparison with another colony ................................................................... 70

4.6.1 Shearwater and puffin population trends on Skomer Island ................................ 72

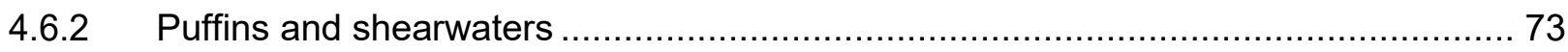

4.6.3 Manx Shearwater whole island census ............................................................ 76

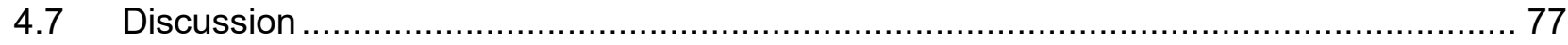

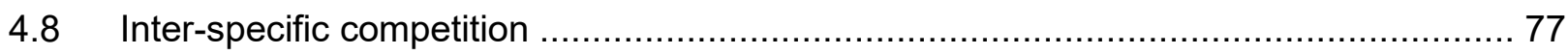

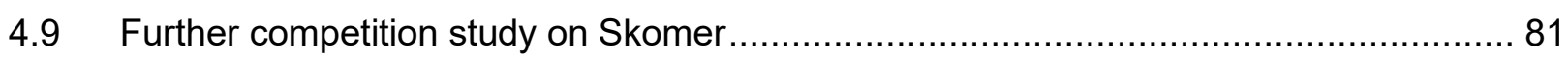

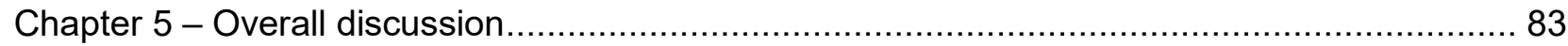

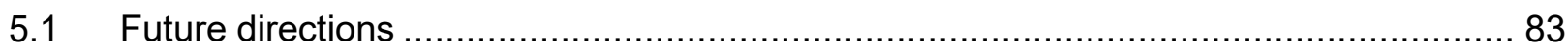

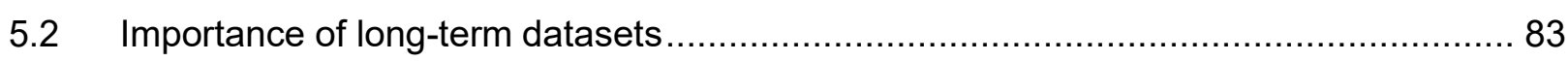

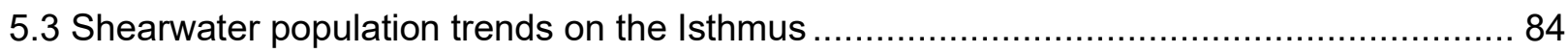

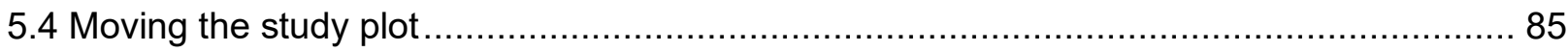

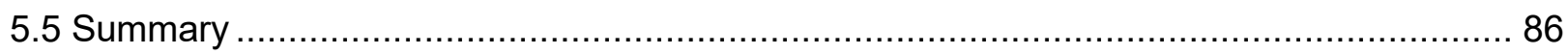




\section{List of Figures}

Figure 1 Global seabird population trends 1950-2010, Paleczny et al. 2015 .......... 2

Figure 2. The study site, Skomer Island .................................................... 21

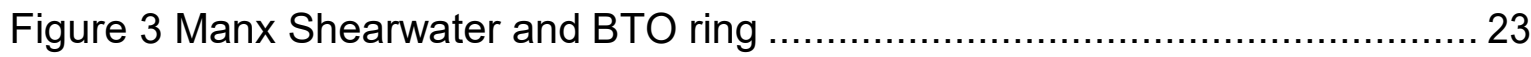

Figure 4 Manx Shearwater reproductive success 1995-2019 ............................. 34

Figure 5 Colony-level reproductive success of Manx Shearwaters 1991-2019..... 35

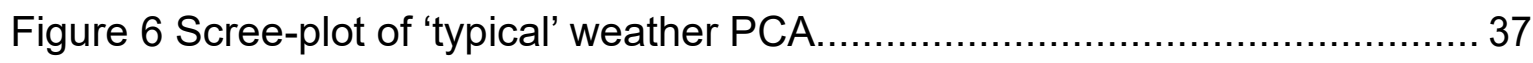

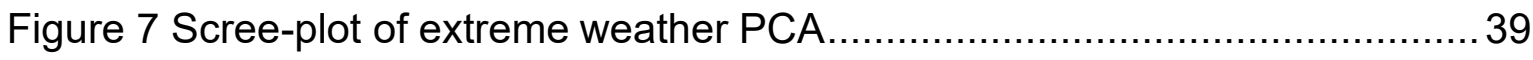

Figure 8 Relationship between Manx Shearwater overall reproductive success and the number of dry days during the fledging period ..............................................4 40

Figure 9 Individual-level reproductive success of Manx Shearwaters 1995-2019.44

Figure 10 Comparison of reproductive success between two islands, Skomer and Skokholm

Figure 11 Manx Shearwater population estimates for Skomer Island between 1998 and 2019

Figure 12 Total Skomer Island puffin population estimates counted on one spring

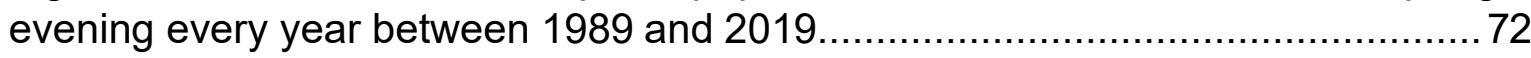

Figure 13 Manx Shearwater tape playback plots A to S.................................. 74

Figure 14. Manx Shearwater coastal and inland playback responses................... 75

Figure 15 Boxplot: population variation between 18 Manx Shearwater sample plots and colour coded by location 


\section{List of Tables}

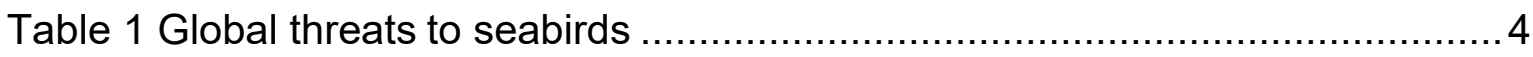

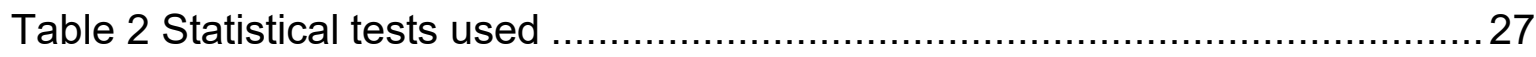

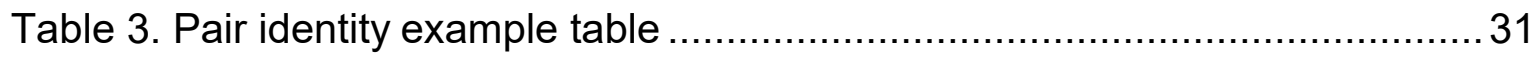

Table 4 Manx Shearwater reproductive success GLM .................................... 36

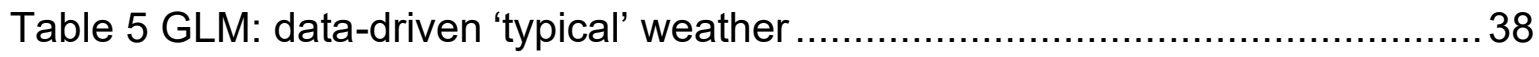

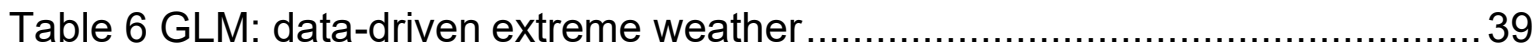

Table 7 GLM: Hypothesis-driven extreme weather .................................... 41

Table 8 Summary of trends in individual-level reproductive success over time..... 43

Table 9 GLMM: Average weather and hatching success ............................... 46

Table 10 GLMM: Average weather and fledging success ............................. 48

Table 11 GLMM: Average weather and overall reproductive success .................50

Table 12 GLMM: Extreme weather and hatching success ............................... 52

Table 13 GLMM: Extreme weather and fledging success .............................. 54

Table 14 GLMM: Extreme weather and overall reproductive success .................56 


\section{Chapter 1 - Introduction and aims}

The climate is changing, and the effects of this change are being manifested around the world in many forms such as temperature fluctuation, sea-level rise, habitat degradation and weather variability (Croxall et al. 2012; Milne et al. 2009). Currently, climate change is affecting $27 \%$ of all seabird species both in terms of survival and reproductive success, both directly and indirectly (Dias et al. 2019; Mitchell et al. 2020). The level of threat posed by climate change / extreme weather is only exceeded by that of introduced predators and bycatch, with $>20 \%$ of all seabirds facing all three threats (Dias et al. 2019). The indirect effects of climate change have been well-studied, including in the UK, and are largely mediated through changes in the food web (Mitchell et al. 2020; Riou et al. 2011). However, it is the direct effects such as extreme weather that are becoming more prominent in climate change research (Jentsch et al. 2007).

Manx Shearwaters, Puffinus puffinus, are medium-sized, migratory shearwaters (Brooke 1990). They breed mainly on small islands, with around $90 \%$ of the total population breeding in the UK and Ireland (Brooke 1990). Population trends are generally unknown, but it is thought that the greatest threats facing Manx Shearwaters are climate change and pressure from the fishing industry (Burthe et al. 2014; Mitchell et al. 2020). It may be the case that the indirect effects of climate change will be the most significant factor in terms of population persistence in all seabirds, including shearwaters, but it is important to understand the direct effects as well.

\subsection{Seabird population trends}

Seabirds as a group are declining rapidly, there are proportionally more seabird species in decline than in any other comparable group (Croxall et al. 2012; Dias et al. 2019). Of 346 seabird species in the world, $5 \%$ are critically endangered, $28 \%$ are globally threatened and a further $10 \%$ are near threatened, Fig. 1 (Croxall et al. 2012; Dias et al. 2019; Paleczny et al. 2015).The outlook for pelagic seabirds, such as shearwaters, is poor even when compared with coastal seabirds (Croxall et al. 2012). Pelagic species generally have lower fecundity (smaller clutch sizes), often small population sizes and a tendency to nest in a small number of dense colonies, but also due to the significant threats that exist to seabirds at sea (Croxall et al. 2012). 


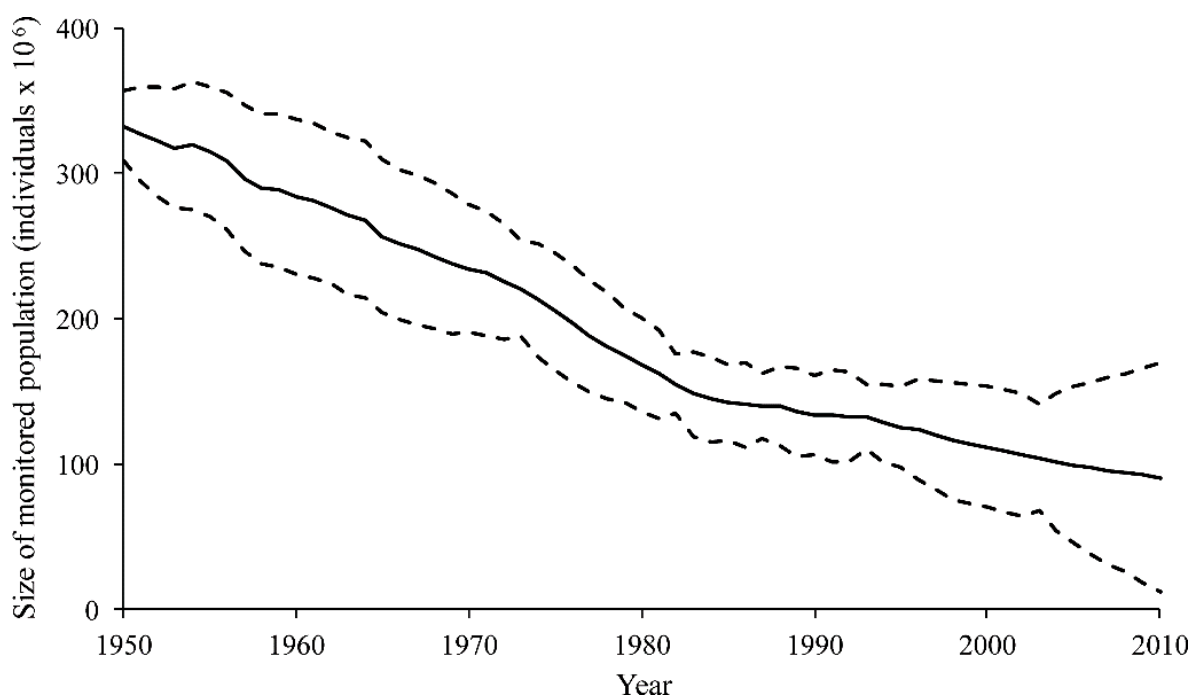

Figure 1 Global seabird population trends 1950-2010, Paleczny et al. 2015

Over 60 years 324 seabird species have shown an overall decline of $69.7 \%$

\subsubsection{UK seabird populations - status and trends}

UK and Ireland's breeding seabird populations are of international importance. Around eight million seabirds of 25 different species breed in the United Kingdom, including $90 \%$ of the world's Manx Shearwaters, $68 \%$ of Northern Gannets (Morus bassanus) and $60 \%$ of Great Skuas (Stercorarius skua) (Mitchell et al. 2004). The UK fulfils all the requirements for large and varied seabird populations, including varied coastal habitats, a highly productive marine environment, a rich food source in the form of fisheries bycatch and discards and little to no pressure from hunting (Lloyd et al. 2010; Mitchell et al. 2004).

The last UK wide census of seabirds was undertaken as part of the Seabird 2000 project between 1998 and 2002. The project counted all breeding seabird species in Britain and Ireland comprising 3,200 colonies of 25 different species (Mitchell et al. 2004). This census found that seabirds in the UK have increased from around five million in 1969-70 to almost eight million in 1998-2002, although not all species had increased, some have been facing serious declines (Mitchell et al. 2004).

Since the Seabird 2000 census some seabird species have continued to decline, most significantly Arctic Skua (Stercorarius parasiticus) and Black-legged Kittiwake (Rissa tridactyla) which have declined $64 \%$ and $44 \%$ respectively (JNCC 2016). But there are differences between colonies, although some species are declining nationwide (kittiwakes) some species such as Atlantic Puffins (Fratercula arctica) are increasing at a considerable rate at some colonies such as Skomer Island, whilst declining in others such as in Shetland (Stzubbings et al. 2018; Perkins et al. 2018). 
It is thought declines are being driven by a lack of prey caused by increased sea surface temperatures, something that seems to be having a greater impact in the North Sea, (Mitchell et al. 2004; Frederiksen et al. 2007) and will be discussed later in this thesis 1.4.1.

\subsection{Threats to seabirds}

The trend of seabird declines is being driven by many varied and complex issues, and although many pressures are universal, some species are more vulnerable to certain threats. Globally the three threats which are having the greatest impact upon seabirds are invasive species, bycatch and climate change, more than $20 \%$ of all species are affected by these threats alone (Dias et al. 2019). What is more concerning is that many species are facing multiple threats simultaneously, with $46 \%$ of all species facing at least three different threats (Dias et al. 2019). Climate change is considered to be the most important drivers of seabird population declines in the UK, with Manx Shearwaters thought to be most vulnerable to the effects of climate and overfishing (Burthe et al. 2014; Mitchell et al. 2020). These threats will be dealt with in detail, sections 1.4 and 1.5 (Burthe et al. 2014). Table 1 addresses the other major threats to seabirds worldwide, some of which are a very real threat to population persistence. 


\section{Threat Type of threat Effect on seabirds Examples of research}

\begin{tabular}{|c|c|c|c|}
\hline \multirow{3}{*}{$\begin{array}{l}\text { Invasive } \\
\text { and non- } \\
\text { native } \\
\text { species }\end{array}$} & \multirow{3}{*}{$\begin{array}{l}\text { Rodents, } \\
\text { domesticated } \\
\text { animals, introduced } \\
\text { non-natives }\end{array}$} & Predation & \multirow{3}{*}{$\begin{array}{l}\text { Courchamp et al. 2003; Crawford et al. 2018; Dias et al. } \\
\text { 2019; Monteiro et al. 1996; Peeler and Murray 2004; } \\
\text { Read and Fernandes 2003; Roos et al. 2018; Stone et } \\
\text { al. 1994; Veitch et al. 2019; Wikelski et al. } 2004\end{array}$} \\
\hline & & Spread of disease or parasites & \\
\hline & & Trampling by livestock & \\
\hline
\end{tabular}

Plants

Impact natural nutrient cycles

Destabilise ground
Allison and Vitousek 2004; Liao et al. 2008; Monteiro et al. 1996; Rodriguez 2006; Veitch et al. 2019

\begin{tabular}{|c|c|c|c|}
\hline \multirow[t]{7}{*}{ Pollution } & Biological & Escapes and effluent from fisheries & $\begin{array}{l}\text { Jensen et al. 2010; Peeler and Murray 2004; Read and } \\
\text { Fernandes } 2003\end{array}$ \\
\hline & \multirow[t]{3}{*}{ Chemical } & Pesticides & \multirow{3}{*}{$\begin{array}{l}\text { Crawford et al. 2018; Monteiro et al. 1996; Oudi et al. } \\
\text { 2019; Peeler and Murray 2004; Read and Fernandes } \\
2003\end{array}$} \\
\hline & & Antibiotics from fisheries & \\
\hline & & Oil spills & \\
\hline & \multirow[t]{2}{*}{ Physical } & Plastic & \multirow{2}{*}{$\begin{array}{l}\text { Avery-Gomm et al. 2018; Lebreton et al. 2018; Wilcox } \\
\text { et al. } 2015\end{array}$} \\
\hline & & Other rubbish & \\
\hline & Light & $\begin{array}{l}\text { Artificial light from cities and offshore } \\
\text { vessels }\end{array}$ & $\begin{array}{l}\text { Dias et al. 2019; Monteiro et al. 1996; Oro et al. 2005; } \\
\text { Syposz et al. } 2018\end{array}$ \\
\hline \multirow[t]{3}{*}{$\begin{array}{l}\text { Human } \\
\text { exploitation }\end{array}$} & Hunting/egging & Adult and chick mortality, egg loss & $\begin{array}{l}\text { Boersma et al. 2002; Crawford et al. 2018; Croxall et } \\
\text { al. 2012; Dias et al. 2019; Monteiro et al. } 1996\end{array}$ \\
\hline & \multirow[t]{2}{*}{ Colony disturbance } & Human population expansion & \multirow{2}{*}{$\begin{array}{l}\text { Dias et al. 2019; Monteiro et al. 1996; Thomas et al. } \\
\text { 2017b }\end{array}$} \\
\hline & & Tourism & \\
\hline
\end{tabular}




\subsection{Fisheries}

Bycatch, the capture of a non-target species, from long-line fisheries is thought to be responsible for the deaths of up to 320,000 seabirds per year, with the majority of these being albatrosses, petrels and shearwaters (Anderson et al. 2011; Clay et al. 2019; Croxall et al. 2012; Lewison et al. 2004). It is thought that for some species affected it is having an unsustainable effect their populations and in the last ten years the number of species affected has increased by $25 \%$ (Anderson et al. 2011; Dias et al. 2019). After introduced species, bycatch has the highest overall impact on seabird population across the World, large- and small-scale fisheries are contributing to the declines of many species $>80$ and $>40$ species respectively (Dias et al. 2019). There are several innovative techniques being used to combat the effects of bycatch, such as Hookpods, weighting of branch-lines, placing LEDs on nets or using orange coloured gillnets (Hanamseth et al. 2018; Jiménez et al. 2018; Mangel et al. 2018; Sullivan et al. 2018). These technologies are already reducing the amount of bycatch; however, this is not having enough of an impact for some species and more needs to be done (Clay et al. 2019).

Overfishing now affects 22 species of seabird around the world, an increase of nearly 55\% since 2010 (Dias et al 2019). Overfishing happens across the globe and aside from crashes in fish stocks, has wide-ranging impacts on the functioning of the whole marine ecosystem (Daskalov et al. 2007; Scheffer et al. 2005). It is estimated the $40.4 \%$ of the annual global marine catch is bycatch with much of this being discarded back into the sea (Davies et al. 2009). Although this practice removes millions of fish from the food chain it can directly and indirectly benefit seabird populations, in the North Sea alone this industry may support up to 6 million seabirds and the fishing of large predatory species can relieve predation pressure on smaller prey species (Camphuysen and Garthe 2000; Davies et al. 2009; Montevecchi 2002).

There are examples of reduced reproductive success in seabirds as a result of fisheries, although the effects vary between species and results can be conflicting. Frederiksen et al. (2008b) found that when a sand lance (Ammodytes marinus) fishery was open in the North Sea, kittiwake productivity was reduced, although four species of diving seabird were unaffected. In Norway, the overfishing of Herring (Clupea harengus) in the 1960s was linked to the reproductive failure and subsequent population decline of Atlantic Puffins over several years (1975-1991) 
(Anker-Nilssen and Røstad 1993). Frederiksen et al. (2004) suggested that the presence of a sand eel (Ammodytes marinus) fishery had a negative impact on kittiwakes breeding in the North Sea between 1991-1998, although it is also suggested that this may have been a natural fluctuation in sand eel stocks (Camphuysen and Garthe 2000).

Fisheries cause pollution when detritus and waste from offshore and coastal farms leach into the surrounding areas spreading disease to wild fish, causing build ups of nutrients from waste food and possibly leaking chemicals into the environment (Peeler and Murray 2004; Read and Fernandes 2003; Thomas et al. 2017b). Escaped individuals can spread disease and establish wild populations in areas where they are not native which could have consequences up and down the food chain (Jensen et al. 2010). Increasing demand for farmed fish is leading to large areas of important coastal and mangrove habitat being taken over for aquaculture which can be devastating for local ecosystems (Thomas et al. 2017b). Fisheries are the single most significant contributor to plastic pollution in the oceans, with at least $46 \%$ of all plastic the ocean being traced back to fisheries, items such as lost nets and fishing gear (Lebreton et al. 2018).

\subsection{Climate change and seabirds}

\subsubsection{Ecosystem health and climate change}

Across the World animal and plant species are facing widespread threats and declines with the current trend calling scientists to name this as the $6^{\text {th }}$ mass extinction event in the planet's history (Ceballos et al. 2017). Under the current minimum climate change scenario, almost a fifth of animal and plant species will be "committed to extinction" by 2050 and in a sample of 27,600 species, $32 \%$ are decreasing (Ceballos et al. 2017; Thomas et al. 2004). Climate change is one factor that is contributing to this crisis, and recent events such as unprecedented flooding and wildfires across several continents are a result of the recently named "climate emergency" (Ripple et al. 2019). Rising temperatures (both ambient and sea) are causing ice caps and glaciers to melt, which will lead to freshwater shortages but also cause sea levels to rise (Milne et al. 2009). Increased levels of carbon dioxide in the atmosphere are causing ocean acidification, and extreme weather events will increase in severity and frequency (Cohen et al. 2018; Hoegh- Guldberg et al. 2007; Pachauri and Reisinger 2007; Solomon et al. 2007; Walther et al. 2002). Climate 
change is not the only threat, rising human populations are having significant impacts, including habitat destruction, pollution, exploitation and introduction of nonnative species (Croxall et al. 2012).

Our oceans in particular are under huge pressure from anthropogenic activities, and the effects are made more problematic to understand due to the difficulties associated with studying species at sea. Species that are apex predators in this environment, such as seabirds, are excellent indicators of the health of our marine ecosystems given that their populations rely on bottom-up processes for regulation, see section (Aebischer et al. 1990; Piatt et al. 2007; Schreiber and Burger 2001).

Climate change is and will continue to have effects on seabirds across the globe (Jenouvrier 2013). It has been suggested that the most widespread effects of climate on marine ecosystems appear to be indirect, this effect seems to be largely mediated through the food web (Lynam et al. 2017; Walther et al. 2002). Some of the most studied examples of this involve increases in sea surface temperature (hereafter SST), the influence of the North Atlantic Oscillation (NAO), and EI Niño events.

There is growing evidence regarding direct impacts of weather: winter storms causing seabird wrecks (the mass stranding of dead or moribund birds), heavy rainfall inundating burrows and wind influencing foraging behaviour (Camphuysen and Garthe 2000; Daunt et al. 2006; Mitchell et al. 2020; Thompson and Furness 1991). Where seabirds are facing increasing pressure through multiple other threats, the impacts of extreme weather may become more important and a tipping point may be reached (BirdLife International 2017; BirdLife International 2016).

\subsubsection{Indirect effects of climate change}

\subsubsection{Sea surface temperature}

In the UK SST has increased by between 0.1 and 0.5 degrees Celsius per decade in the past 30 years, up to 6 times greater than the global average, this is anticipated to continue with predictions suggesting the temperature will increase by between two and four degrees by 2100 (Dye et al. 2013; Trenberth et al. 2007). Such increases will affect all ocean species and ecosystem services such as carbon dioxide absorption, oxygen production and the cycling of nutrients will be altered (Richardson and Schoeman 2004). 


\subsubsection{How does sea surface temperature affect the food web?}

Global warming has already caused ambient and SST to increase, and this has already influenced the nutrient cycling in the oceans. Increased temperatures have increased stratification which not only reduces primary productivity, but increased early stratification has already been linked to decreasing productivity of kittiwakes in the UK (Carroll et al. 2015).

This reduction in primary productivity affects the abundance and distribution of phytoplankton and zooplankton, on which the entire food chain is based (Capuzzo et al. 2018). Increased temperatures have been associated with reduced size of zooplankton, a key prey item for small fish, and the northwards movement of warm water associated species which are less nutritionally valuable and occur in reduced numbers (Frederiksen et al. 2006; Graham and Harrod 2009; Macdonald et al. 2015)

\subsubsection{Species distribution and abundance}

SST is predicted to increase differentially across latitudes, causing biogeographical shifts in terms of distribution and abundance of some marine species, these have already been documented between 1960 and 2005 (Beaugrand and Kirby 2018; Trenberth et al. 2007). As such the primary and secondary productivity of these regions will vary and cause changes in the spatial distribution of plankton and species such as small fish on which seabirds feed (Daunt and Mitchell 2013; Richardson and Schoeman 2004). A vital prey species for many species, the lesser sand eel, Ammodytes tobianus (hereafter sand eel), has been shown to have a negative relationship with increased SST, both in terms of recruitment and total biomass (Daunt and Mitchell 2013; Carroll et al. 2015). Some warm water species, such as the snake pipefish, Entelurus aequoreus, may fill the same niche or outcompete northern ones but may not be as nutritionally beneficial to top predators such as seabirds (Daunt and Mitchell 2013; Harris et al. 2008).

Not all areas are controlled through bottom up processes. Southern areas such as the Celtic Sea, Irish Sea and English Channel are not thought to be as sensitive to the effects of climate change on lower trophic levels as areas such as the North Sea (Lauria et al. 2013; Macdonald et al. 2015). Despite an increase in SST of 0.6 $\pm 0.02^{\circ} \mathrm{C}$ there was only a very weak effect on plankton and the food web as a whole (Lauria et al. 2012). In the North Sea zooplankton abundance is positively correlated 
with SST but no such relationship was found in Celtic Sea, Irish Sea and English Channel (Beaugrand and Reid 2003; Lauria et al. 2013).

As well as various regions experiencing diverse effects different species of seabird are more or less sensitive to climate effect. Furness and Tasker (2000) showed that species with high foraging costs, limited diving ability, inadequate time to spare for extended foraging, restricted foraging range and reduced plasticity in prey selection were the most likely to be negatively affected by climate change.

\subsubsection{Manx Shearwaters and SST}

Herring (Clupea harengus) and Sprat (Sprattus sprattus) are both key prey items for Manx Shearwaters and both have important populations in the Celtic Sea (Brooke 1990; Lauria et al. 2012). Herring vary greatly between years in terms of abundance, but in the period between 1986 and 2007 showed no clear population trend, this may be due to the more resilient nature of seas in this part of the UK to climate change (Lauria et al. 2012; 2013; Graham and Harrod 2009). This study links with a paper published by Riou et al. (2011) which showed that anthropogenic warming was negatively affecting Manx Shearwaters on Skomer Island indirectly through changes in SST and prey quality. During the years of study, fledging mass of chicks was significantly lower than in previous years, this was related to increased SST in the preceding winter (Riou et al. 2011). Adult birds swapped foraging strategy and spent longer feeding at sea, likely caused by a shift in prey distribution (Riou et al. 2011).

It is important to note that increased SST is not negatively affecting all species, and even within species there are opposing trends at different colonies (Carroll et al. 2015; Frederiksen et al. 2007; Grémillet and Boulinier 2009; Sandvik et al. 2005). However, there are studies that have showed that some species are not sufficiently able to adapt their foraging behaviour, alter their prey selection or change their timing of breeding to meet the ongoing changes in the food web (Keogan et al. 2018; Rindorf et al. 2000).

\subsubsection{Direct effects of climate change: weather}

Indirect effects of climate change mediated through the food web, changes in timing of peak food abundance and distribution of prey may have a more important effect in the long-term persistence of seabird populations (Grémillet et al. 2008; Hipfner 2008; Santora et al. 2009). However, the direct effects of changing weather systems 
are thought to be substantial in hampering population recovery and are having significant short-term effects (Daunt et al 2006; Frederiksen et al. 2008a; Newell et al. 2015).

\subsubsection{Extreme weather}

Many studies into the effects of climate change have focussed on the long-term changes in terms of average increases and decreases in temperature, rainfall and wind as these are much easier to measure and analyse (Jentsch et al. 2007; Oro et al. 2005). Although there are obvious trends in average weather patterns, rare and extreme events are often not identifiable in this sort of analysis (Easterling et al. 2000; Hanna et al. 2017).

Recording extreme events that occur within a short time frame is much more difficult than measuring a trend or a longer event such as a heatwave or drought, and currently there is not sufficient technology available across the world to document these phenomenon thoroughly enough to identify or predict trends (Jentsch et al. 2007). This is compounded by the natural variability in weather systems, which may mask the changes in these rare events (Hanna et al. 2017). Although they are more difficult to measure because of their infrequency and transience a study by Jentsch et al. (2007) concluded:

"Intensification of weather extremes is currently emerging as one the most important facets of climate change".

At current levels it is unlikely that extreme weather events will be the most significant factor for seabird population survival, however these events will have major shortterm effects and may over time reduce the resilience of populations and constrain their ability to rebound or increase (Jentsch et al. 2007; Mitchell et al. 2020). Therefore, if predictions are correct and extreme events continue to increase in frequency and severity the impacts may be significant.

\subsection{What is an 'extreme' weather event and what are the trends?}

Increasing temperatures have other impacts aside from sea surface and ambient temperature. Hurricane occurrence has increased, rainfall is becoming more unpredictable and storm frequency and severity is increasing, all of these impacts can be attributed to anthropogenic atmospheric warming (Cohen et al. 2018).

Arctic warming in particular has been associated with increases in extreme weather in the Northern hemisphere, both Europe and more significantly the east coast of 
America have experienced severe winter weather in recent years (Cohen et al. 2018). In addition to more unpredictable winter weather, the UK has since 2009, experienced record-breaking monthly rainfall records as well as extreme summer rains and flooding (Hanna et al. 2017).

By definition, extreme weather events are rare. Their occurrence would normally coincide with the $10^{\text {th }}$ or $90^{\text {th }}$ percentile (Jenouvrier 2013), however many studies have predicted that these extremes will continue to become more regular (Cohen et al. 2018; Palmer and Räisänen 2002). The study of extreme events has grown significantly in recent years, with one in five published experimental climate change studies focussing on extreme events which eludes to their growing significance (Jentsch et al. 2007).

\subsubsection{Extreme weather and seabirds}

\subsubsection{Mass mortality}

Due to their life-history traits (i.e. being long lived), seabird population growth rates have been shown to be more significantly impacted by adult survival than reproductive success (Sæther and Bakke 2000; Wooller et al. 1992).

Seabird wrecks occur as a consequence of environmental or anthropogenic events and result in mass strandings of dead or moribund birds (Camphuysen and Garthe 2000). Wrecks are most commonly caused by storms, oil spills, extreme weather and food availability (Camphuysen and Garthe 2000; Morley et al. 2016; Louzao et al. 2019). Weather related mortality is caused by cold stress, exhaustion and starvation; either as birds have difficulty foraging, are blown away from feeding grounds or fish shoals become scattered, all causing increased metabolic costs (Blake 1984; Bugoni et al. 2007; Camphuysen and Garthe 2000; Louzao et al. 2019; Morley et al. 2016).

In the UK there have been four major wrecks in recent times, autumn 1969 (Irish Sea), 1983 (east coast), 1994 (east coast) and 2014 (English Channel) (Birkhead 2014; Morley et al. 2016). In 1969 at least 12,000 seabirds died after storms inhibited their foraging causing starvation, the effect was felt on Skomer where the following summer the breeding population of guillemots was reduced to around 2,000 pairs from an estimated 100,000 in the 1930s, the lowest count ever recorded (Birkhead 2014). The 1983 wreck resulted in the largest number of dead auks ever being recovered on UK coastlines, 31,600 (Underwood and Stowe 1984). This wreck, and the more recent 2014 event, both followed periods of stormy weather in important 
overwintering areas, off the south west of the UK and northern France (Birkhead 2014). With extreme weather predicted to increase, the occurrence of storms and extreme wind and wave events are likely to become more regular, both in summer and winter.

Seabird life history has been demonstrated to allow for breeding failure in order to prioritise adult survival, suggesting that adult survival has a more significant impact on population dynamics than reproductive success in any given year (Jenouvrier 2013; Nevoux et al. 2010; Sæther and Bakke 2000). This strategy is advantageous in many respects but in a changing environment where adult survival may be impacted by more frequent and extreme winter weather, seabird populations may suffer (Mitchell et al. 2020).

\subsubsection{Weather and foraging}

Adverse weather conditions, such as storms, rain and wind, have been proven to affect the foraging ability of some seabird species (Daunt et al. 2006; Finney et al. 1999; Morley et al. 2016; Taylor 1983). Some species are more sensitive to the effects of weather during foraging, e.g. guillemots as they forage beneath the surface and have to forage every 3 to 4 days (Morley et al. 2016). Surface feeders such as terns and kittiwakes can also be negatively affected by wind speed and sea state, which can make it more difficult to catch fish beneath the surface (Taylor 1983).

Burrows provide a stable environment in terms of temperature and humidity and reduce the risk of predation by aerial predators such as gulls, this allows both Manx Shearwater parents to forage (Brooke 1990; Kaiser and Forbes 1992; Kulaszewicz and Jakubas 2018). This strategy potentially allows adults' foraging trips to extend further from the colony (Shoji et al. 2015; Gray and Hamer 2001). Trips can last as long as eleven days so shearwaters can reach sites that offer greater reward in terms of food availability and avoid areas where weather conditions are not favourable (Gray and Hamer 2001; Guildford et al. 2008). They capture prey beneath the surface using plunge diving or plunge pursuit which allows them to reach that may be out of reach of other species such as kittiwakes (BirdLife International 2016).

All species of seabird are susceptible to be being displaced in gales and storms. Smaller seabirds such as auks may be more significantly affected by these events as they can only store a small amount of fat and must feed every 3-4 days, 
consequently, they are often the most common group of birds found dead or stranded after storms (Louzao et al. 2019; García-Barón et al. 2019)

Adverse weather conditions may affect the foraging success of a variety of seabirds, therefore increased extreme and inclement weather may affect the ability of birds to provide enough food for their chicks or even ensure their own survival.

\subsubsection{Weather and productivity}

During the winter seabirds can evade storms and extreme weather by migrating, however during the breeding season seabirds are tied to the colony and their chicks increasing their vulnerability (Weimerskirch and Prudor 2019; Wolfaardt et al. 2012). Extreme events at or near the colony are not currently as much a cause for concern as events that cause mass adult mortality. However, if as predicted, extreme weather events, storms, cyclone and hurricanes continue to increase in frequency and severity this may become much more of a concern in terms of their impact on adult survival.

\subsection{Cliff-nesting species}

Heavy precipitation and windy conditions are of particular significance to chicks in exposed nests, e.g. kittiwakes and albatrosses (Cleeland et al. 2020). Young chicks only have downy feathers and when these get wet there is a significant risk of chilling (Kennedy 1970). When chicks get chilled they must increase their metabolic rate to maintain their body temperature, consequently they require more food to sustain other functions such as growth (Kildaw 1999). Wind can exacerbate the effect of rain by accelerating chilling, however wind chill in the absence of rain can also cause this phenomenon (Kildaw 1999). One study has shown that kittiwake chicks in areas exposed to updrafts experienced reduced growth rates; this was likely to have been caused by increased costs of thermoregulation (Kildaw 1999).

\subsection{Burrow-nesting species}

Burrow nesting holds several advantages over nesting on open sites such as cliffs, chicks have a more stable environment and therefore will expend less energy on thermoregulation (Bancroft et al. 2005). However, in extreme cases burrows can be a disadvantage, during periods of heavy precipitation burrows can become flooded and heat waves can lead to heat stress (Chambers et al. 2011). Burrow flooding, and its impact on chick thermoregulation, has been documented as a cause of chick and egg mortality in many species, including penguins, shearwaters and storm- 
petrels (Bancroft et al. 2005; Boersma and Rebstock 2014; Chambers et al. 2011; Huntington et al. 1996; Fagundes et al. 2016; Serventy and Curry 1984).

A study conducted by Thompson and Furness (1991) investigated the impacts of rainfall on population dynamics of Manx Shearwaters on Rum: colony productivity was directly affected by precipitation during the incubation period. Moreover, the quality of the burrow influenced the success of the individual pairs as high-quality burrows were less likely to flood (Thompson and Furness 1991). These results contradict a previous study, which suggested that when flooding events occurred the majority of burrows and chicks were affected (Thompson and Furness 1991).

Wind and rain causing chilling is not only a short-term problem for chicks. The increase in metabolism may boost their immediate chances of survival; however, this can impact their growth rate and fledging mass (Cam et al. 2003; Kildaw 1999). Fledging mass and growth rate has been shown to influence the chances of seabird chicks returning to the colony in subsequent years to breed, therefore consistent years of bad weather and extreme events could affect recruitment of juveniles to the breeding population (Cam et al. 2003; Coulson and Porter 1985; Perrins et al. 1973).

\subsection{Storms}

Extreme events such as storms and hurricanes can have immediate and devastating effects on entire breeding colonies of seabirds (Aebischer 1993; Newell et al. 2015; Wolfaardt et al. 2012). In the UK a storm with gusts of over $60 \mathrm{~ms}^{-1}$ caused a significant increase in failure rate for exposed colonies of razorbills, guillemots, shags and kittiwakes (Newell et al. 2015). Gales also caused shag productivity to decline on the Isle of May in 1982 where westerly gales caused exposed colonies to yield a $31 \%$ lower productivity than sheltered colonies (Aebischer 1993). Fulmar, Fulmarus glacialis, reproductive success has also been found to be affected by weather, whereby periods of extreme weather were the most important factor influencing nesting success in the Canadian high arctic (Mallory et al. 2009). A devastating storm that passed through the Falkland Islands in December 2010 caused complete failure for some colonies of Black-browed Albatross (Thalassarche melanophris) and penguins (Wolfaardt et al. 2012). Waves inundated the low-lying areas of Beauchêne Island and washed away nests, eggs, chicks and adult birds as well as moving boulders that crushed some adults, a minimum of 251 adult albatrosses died and an estimated 27,666 nests were lost (Wolfaardt et al. 2012). On Christmas Island in the Indian Ocean a cyclone hit the Island and caused the 
loss of $61.3 \%$ of Red-billed Tropic Bird eggs (Phaethon aethereus) (Hennicke and Flachsbarth 2009).

\subsection{The effect of individual experience}

When considering the relationship between weather and reproductive success the effect of experience must be considered. Studies that have shown that experienced breeders have an increased likelihood of reproductive success and survival, whereas inexperienced birds are more vulnerable to the effects of climate change (Mauck et al. 2018; Nevoux et al. 2010; Oro et al. 2010). For Manx Shearwaters, the process of raising a chick requires huge investment from the parents and coordination is required to ensure the egg is continuously incubated and the chick sufficiently fed. Shearwaters with previous breeding experience improved the chances of the egg hatching, therefore increasing overall reproductive success (Brooke 1990). Pairs breeding together for consecutive years and pairs made up of two experienced individuals had a higher chance of reproductive success (Brooke 1990).

\subsection{Manx Shearwaters in the UK}

The Manx Shearwater is a pelagic, trans-Atlantic migratory seabird and part of the Procellariidae family. It is the only species to make the regular migration between South America and Europe, something only discovered in 1952 upon the recovery of a dead, ringed shearwater in Argentina which had been ringed on Skokholm Island (Brooke 1990). Manx Shearwaters are a medium sized seabird adapted to life at sea, where they can cover extensive distances in search of food and on migration. They are nocturnal, only returning to land at night, which is largely due to their physiology; their legs are located very far back on their bodies making them very ungainly on land and therefore very vulnerable to predation from diurnal, predatory birds such as large gulls (Brooke 1990).

Like many seabirds, shearwaters are long-lived and have delayed onset breeding of around five years old (Brooke 1990; Harris 1966). The oldest known Manx Shearwater was ringed as an adult, at least five years old, on Bardsey Island in 1953 and retrapped on the same island in 2003, making it at least 55 years old, at which time it was the oldest known age wild bird in Europe (Clark et al. 2004).

Shearwaters lay a single egg in a burrow, almost exclusively on off-shore islands 
that are free from land-based predators such as rats. They are very site faithful and return to their natal colony to breed. They typically arrive back to the colony in early spring, usually the beginning of March, to find or re-find a mate and claim a burrow for the breeding season which they will defend, excavate and maintain for around six weeks until the laying period begins in early May (Brooke 1990; Harris 1966). It is thought that pairs which have remained together for multiple years and/or are older, may have a better success rate in fledging a chick than pairs that are in the first year together (Brooke 1990; Wooller et al. 1992).

The single egg is incubated by both parents for around 51 days and once hatched will take about 10 weeks to fledge (Brooke 1990; Harris 1966). Shearwater eggs are able withstand periods of chilling of up to 7 days and remain viable (Matthews 1954). Foraging stints during the incubation period have been recorded to last between one and 26 days, although the average trip length is around a week and between stints individuals must build up enough body condition to enable them to perform the subsequent incubation period (Brooke 1990; Harris 1966).

From between eight and ten days old the chick is left alone as both parents forage, making trips that last between one and eleven days, sometimes travelling as far as the seas around Iceland (Brooke 1990; Shoji et al. 2015). There are two main foraging strategies that shearwaters on Skomer use, short and long trips (Shoji et al. 2015). It is thought that the long trips are for the purpose of adults feeding themselves and rebuilding body condition, and short trips are for chick provisioning (Shoji et al. 2015). During this period, it is important for birds to coordinate their foraging patterns so that the chick is fed regularly, and both adults also feed themselves. Chicks have a resilience to periods of starvation, but this may affect their growth rate and fledging weight which has been shown to affect their likelihood of survival (Brooke 1990; Perrins et al. 1973).

The chick is abandoned at around 50 days old and weighing up to a third more than its parents at around 600g (Brooke 1990). In the final days alone in the burrow, the young bird builds its strength and makes regular trips to the surface at night to exercise its wings. It will eventually fledge at an average weight of around $440 \mathrm{~g}$, heavy enough to buffer the impact of newly fledged birds potentially not feeding for up to 8 days post-fledging (Brooke 1990). 


\subsection{Manx Shearwater status and trends}

Manx Shearwaters are globally listed as Least Concern owing to their large range and current population size, although in the UK they have been assigned to the Amber list of conservation concern (Eaton et al. 2015; Birdlife International 2016). In the UK the biggest threat to shearwater populations is likely to be climate change and overfishing (Burthe et al. 2014). Skomer is thought to be the largest breeding colony of Manx Shearwaters in the world, and in addition to Skokholm and the Scottish island of Rum, comprise $82 \%$ of the total world population (Mitchell et al. 2004; Stubbings et al. 2016).

\subsection{Gap in existing research}

In recent years there has been a considerable amount of studies that have looked at the impact of climate change on seabirds in the UK, many of these studies have focussed on the North Sea colonies as this is where the effects of SST increase and climate change are being seen most clearly to date (Burthe et al. 2014; Frederiksen et al. 2004; Furness and Tasker 2000; Sandvik et al. 2005). However, the effects of climate and weather on more southerly populations is incredibly important and more long-term data and studies looking at climate change are vital for future conservation.

Compared with other breeding UK seabirds there has been relatively few studies which focus on the effect of climate change on Manx Shearwaters (Lauria et al. 2012; Riou et al. 2011). Manx Shearwaters are increasing on Skomer, and despite there only being three full island census' there is a vast amount of data available on their reproductive success and population changes (Stubbing et al. 2018). In addition, their foraging strategy suggests they may be less sensitive to changes in SST and fish stocks as they can travel great distances, pursue prey underwater and have a relatively plastic foraging strategy (Shoji et al. 2015).

Indirect effects of climate change, mediated though the food web, have been shown to negatively affect shearwaters on Skomer, therefore it is also likely that they could be affected by the direct effects, such as extreme weather, as shown on other islands (Riou et al. 2011; Thompson and Furness 1991). The fact that the shearwater population on Skomer, and neighbouring Skokholm, make up such a high percentage of the total world population of this species means that any threat 
to the shearwaters on these islands is a significant threat to the population as a whole. This is underlined in a study that concluded that Manx Shearwaters are of high concern with regards to vulnerability to climate change, and that in addition to the potential threats of pollution, bycatch and reduction in fisheries discards there is a very real threat to their populations in the UK (Burthe et al. 2014).

The last research on Skomer which looked at the inter-specific competition between shearwaters and puffins was undertaken in 1976 by Ruth Ashcroft, since this time the populations of both puffins and shearwaters have increased and therefore competition may now be a more important influence on reproductive success. Research on competition between species has been carried out on other islands and other species but other than this historic work Manx Shearwaters have not been studied in this way (Ashcroft 1976). Given that such a high proportion of the world population breeds on Skomer it is important to understand how this competition may be influencing population trends.

\subsection{Aims of this thesis}

The aim of this study is to identify if there is a relationship between weather conditions and the reproductive success of Manx Shearwaters on Skomer Island, with specific focus on extreme weather. This was carried out to answer two specific questions:

1. Is there a relationship between long-term colony-level reproductive success of Manx Shearwaters and weather over time?

2. Are extreme weather events during the breeding season linked to patterns in the short-term reproductive success of Manx Shearwaters?

It is expected that the relationships between weather and reproductive success will be more pronounced when using individual-level analysis due to the increased sample sizes and power of analytical methods. Informed by previous research I expect that the effect of rainfall will hold the most important, negative relationship with reproductive success due to the threat of burrow flooding (Price et al. 2020). I also expect to find a negative relationship between temperature and reproductive success.

This study also aims to discover whether inter-specific competition between two burrow-nesting species is affecting Manx Shearwaters on Skomer Island, both in 
terms of reproductive success and population growth.

1. Is there an association between the ongoing increase in Puffin numbers on Skomer Island and the reproductive success or population dynamics of Manx Shearwaters?

Previous research has shown that competition for burrow space does exist between Manx Shearwaters and Puffins, however this study was carried out 43 years ago and since then numbers of both species have increased (Ashcroft 1976). Given the scope of this study in terms of available data and time I do not expect to find any relationship between Puffin numbers and Manx Shearwater reproductive success, however it may be possible to provisionally rule this out.

\subsection{Thesis structure}

\section{Chapter 2 - Methods}

This chapter will outline the methods used to collect and analyse data, including field protocols and statistical approaches.

\section{Chapter 3 - part 1 Results}

This chapter section will focus on the effects of weather on Manx Shearwater reproductive success at a colony-level. Taking the colony as a whole the trends over time will be analysed and the effects of weather on different stages will be considered, overall reproductive success, fledging success and hatching success.

\section{Chapter 3 - part 2 Results}

This chapter section will take an individual-level approach, using only known individuals through ringing recovery data. Reproductive success of all known individuals in a given year will allow for more detailed analysis with greater statistical power. Pair identity and year will be considered alongside weather variables when analysing overall reproductive success, fledging success and hatching success.

\section{Chapter 4 - Competition on Skomer}

Anecdotal evidence and knowledge of the breeding biology of shearwaters and puffins has contributed to the suspicion that the increase of puffins on Skomer may lead to a decrease in reproductive success of shearwaters. This is a stand-alone chapter that will consider the effects of inter-specific competition including 
introduction, methods, results and discussion sections.

Chapter 5 - Overall Results

This final chapter will deal with the overall themes of the research and the takehome messages for future research. 


\section{Chapter 2 - Methods}

\subsection{Study location}

Skomer Island is situated off the Pembrokeshire coast, it is owned and managed by the Wildlife Trust for South and West Wales (WTSWW) and seabirds have been studied here for decades. Long term research has been carried out on shearwaters by Oxford University (1970-present), University of Gloucestershire (2014-present) and the Wildlife Trust. These long-term studies and others focussing on the other breeding seabirds on Skomer are supported by Joint Nature Conservation Committee (JNCC).

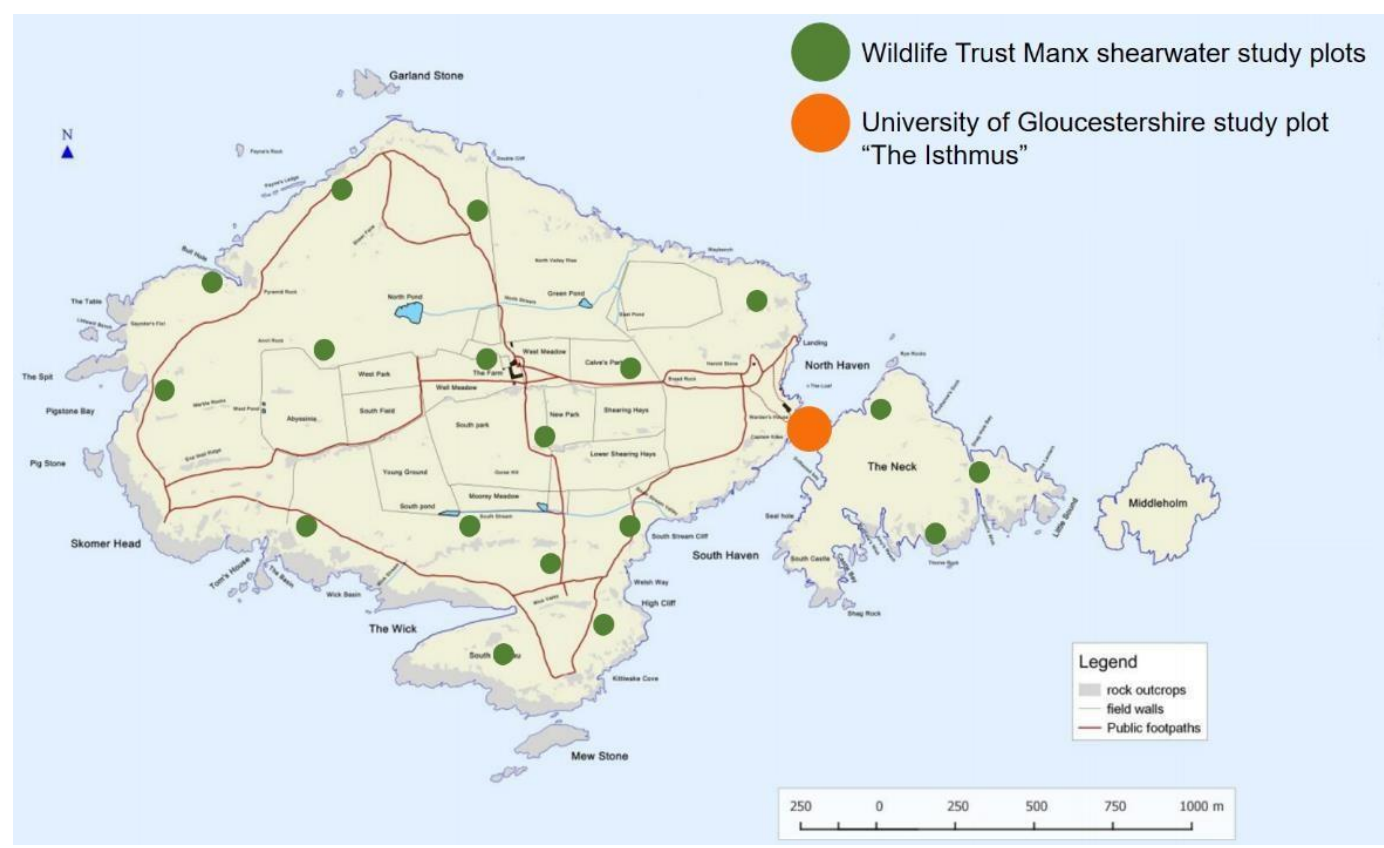

Figure 2. The study site, Skomer Island

Skomer Island located just off the coast of Pembrokeshire $\left(51.73611^{\circ} \mathrm{N} 5.29628^{\circ} \mathrm{W}\right)$, it is approximately 1.5 miles by 2 miles which includes The Neck which is connected by a narrows strip called The Isthmus (Fig. 2, orange circle). The Isthmus is the location of the study colony of shearwaters used to calculate annual reproductive success in this study, data are collected by a seasonal fieldworker and submitted to JNCC as part of their Seabird Monitoring Programme (SMP). Wildlife Trust staff conduct annual population estimates as 18 sites across the island, (Fig. 2 green circles). Monitoring methods detailed later in the chapter.

Due to the difficulty in carrying out a full island census only three have been undertaken on Skomer. The first in 1997/1998 estimated 102,000 breeding pairs but 
this was likely an underestimate as the next census using a different method in 2011 estimated 316,070 breeding pairs (Perrins et al. 2012; Smith et al. 2001). A 2018 whole island census estimated at 349,663 showed a further increase of over $10 \%$ in just seven years (Perrins et al. in development). This colony, and neighbouring island Skokholm, are therefore of both national and international importance.

\subsection{Shearwater monitoring techniques}

Manx Shearwaters and puffins have been monitored on Skomer Island for decades and so data are available on annual productivity from 1991 to 2019 , data were initially collected by Oxford University, 1991-2010, and from 2010 to the present day by the University of Gloucestershire. The level of detail within the dataset varies between years so the methods for analysis had to be selected carefully.

There were two measures of shearwater 'success' available for the project. The first is the Isthmus colony reproductive success which was used to investigate weather effects. The second measure is the total population estimates taken from the Wildlife Trust shearwater monitoring plots.

\subsubsection{Shearwater reproductive success}

Productivity monitoring on Skomer Island was carried out according to the Seabird monitoring handbook for Britain and Ireland (Walsh et al. 1995). This handbook provides a framework for seabird monitoring throughout the United Kingdom and therefore allows all data collection to be standardised.

The shearwater productivity protocol assessed burrow success by making a series of visits to burrows within a colony. At the beginning of the season, end of May/early June visits were made to identify occupied burrows. An occupied burrow was identified by either encountering a pair of birds within that burrow or an egg / incubating adult (burrows with 2 adults should checked until an egg was laid, or it was evident that no egg will be laid). Eggs were searched for by gently reaching beneath a sitting bird and feeling for presence or absence. Once an egg was found that burrow was left alone until chicks began to hatch later in the season, this ensured minimal disturbance to the incubating adult. These checks aimed to provide $100+$ burrows to be monitored throughout the season.

Checks were resumed to find hatched chicks at the end of June/early July, this was done in the same way as checks for eggs as recently hatched chicks will be brooded by the parent for several days. Checks were carried out every few days to minimise 
disturbance, exact hatch date is not required in this methodology. Once chicks were found the burrow were left alone. Checking for chicks continued until eggs are lost, discovered broken or were cold for a significant period. At the hatching stage burrows where there was no egg found originally were re-checked to ensure late lays were identified.

Towards the end of the season burrows where chicks were identified were visited to assess how many chicks survived to a size where fledging could be assumed, at this stage chicks were ringed (ringing was carried out by licensed individuals, licences issued by the British Trust for Ornithology).

Once burrow checks were completed eggs laid, hatching success and fledging success can be calculated as well as an overall productivity for that colony.

Another part of the monitoring was to assess adult survival. This was done by ringing adults and chicks throughout the breeding season to maintain a large sample of known individuals. Metal rings with a unique ring number inscribed on them were fitted under licence from the BTO by trained individuals (Fig 3), these rings were then entered into an online database as well as recorded by the fieldworkers. This allowed the fieldworker to record which individuals return to the colony each year, in which burrow and with which partner they breed and the success of each breeding attempt.
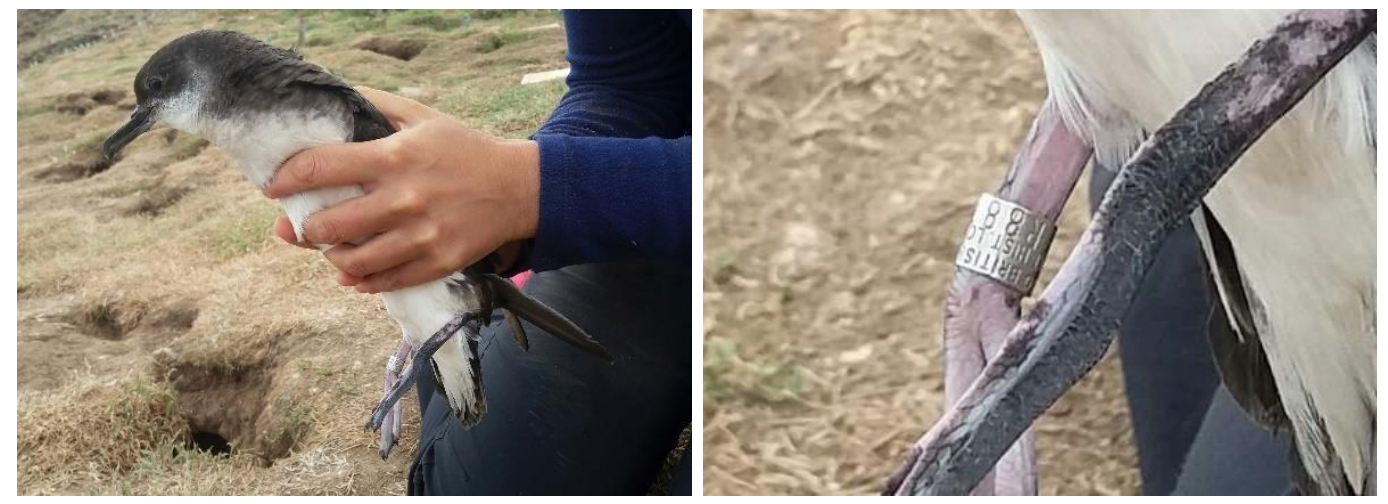

Figure 3 Manx Shearwater and BTO ring

\subsubsection{Components of reproductive success}

Manx Shearwater reproductive success data were provided dating back to 1991, however some of the earlier data were not as detailed as more recent data. Productivity data were broken down into three components from 1995 onwards and was always defined as a proportion. 
The first component is overall reproductive success. This is defined as the proportion of chicks that fledged per egg laid. This is calculated as number of chicks fledged divided by the total number of eggs laid.

The second is hatching success. This is defined as the proportion of eggs laid in a burrow that eventually hatched. Eggs that disappeared, were found damaged or did not hatch after a significant period were classed as failed.

The third component of productivity is fledging success. This is defined as the proportion of chicks that hatched that went on to fledge successfully. Any chicks that had hatched but subsequently disappeared or were found dead were classed as failed. For some years there was no reason for failure given, i.e. whether the chick was not found or if it was found dead. On occasion large chicks are known to move between burrows during the night, it is not known whether multiple checks were carried out for any burrows where chicks disappeared. If effort to try and find missing chicks was not consistent between years, it may lead to a reduced fledging success value for a given year.

\subsection{Weather data}

The focus of my research was to identify the relationships between seabird reproductive success, long-term population dynamics and weather variables, therefore the collation of accurate and relevant weather data was vital. Weather data were obtained from the Met Office weather station at Dale Fort which is a Field Studies Council residential education property located around $9 \mathrm{~km}$ south-east of Skomer $(51.702984,-5.150866)$. This was chosen as it had the most detailed weather data available for the period of study. The data were downloaded through the Centre for Environmental Analysis Archive (CEDA) (Met Office 2012).

The weather variables used were temperature (degrees Celsius), wind speed (knots), precipitation $(\mathrm{mm})$ and weather indices such as NAO (North Atlantic Oscillation) and SOI (Southern Oscillation Index). There are a variety of ways that the weather variables can be expressed:

- A monthly average

- A seasonal average

- Maximum or minimum daily value

- Number of days within a month without rain or wind

- 'Extreme' events 
NAO measures were informed by previous research and classified by season, winter or summer (Riou et al. 2011). Winter NAO was averaged across December and April, summer NAO was an average of May to August. Both values were also added into analysis as a lagged value, so for 2018 winter NAO for 2018 and 2017 were separately modelled.

Manx Shearwaters spend the winter in the Southern hemisphere so winter SOI and lagged winter SOI were calculated using the same method as NAO. NAO and SOI data were downloaded from the Climatic Research Unit, University of East Anglia at the following website (https://crudata.uea.ac.uk/cru/data/nao/nao.dat).

To allow for more specific analysis to be carried out weather variables were also categorised into three periods, this allows for weather variables to be matched specifically with stage of breeding they will most effect.

- Incubation - The months of May and June, all averages or totals are calculated across both months

- Fledging - The months of August and September, all averages or totals are calculated across both months

- Critical - This is the month of July, where chicks have recently hatched and are at their most vulnerable

\subsubsection{Extreme weather}

One of the first priorities of my research was to define the term 'extreme'. In general terms extreme weather can be defined as an event that is rare for the location where it occurs, for my research this is Skomer Island (Encyclopedia.com 2018).

Existing research into 'extreme' weather has provided examples of how it can be defined, McGregor et al. (2005) stated that a universal definition of 'extreme' would not be appropriate and therefore each study should apply their own measure. Pardo et al. 2017 defined events that occurred below the $5^{\text {th }}$ percentile or above the $95^{\text {th }}$ percentile to be 'extreme', other studies have included the $90^{\text {th }}, 95^{\text {th }}$ and $99^{\text {th }}$ percentile (McGregor et al. 2005). The Intergovernmental Panel on Climate Change classes events in the top or bottom 10\% as "rare" (Encyclopedia.com 2018; Jenouvrier 2013). My research shall be informed by previous studies and use $5^{\text {th }}$, $95^{\text {th }}, 10$ th, $90^{\text {th }}$ percentiles as well as 15 th and $85^{\text {th }}$ percentiles, and use variable selection to identify the most important percentiles for the study system.

To identify weather events that fall within these categories it was necessary to have 
a baseline for weather variables over a historic range. This was calculated for each weather variable and component of analysis by taking the average from the existing data set, in this case 1995-2019. Data was collated for analysis and presented as a frequency of occurrence, an integer representing the number of days in a period where the weather was 'extreme'.

Daily weather values for each variable were extracted for every day within the required period, in this example maximum temperature in July. Every available record of maximum temperature in July was collated between 1995 and 2019, then using $\mathrm{R}$ the $90^{\text {th }}$ percentile was calculated, all instances where the temperature matched or exceeded this temperature were identified.

For example, when looking at rain over the incubation period I gathered the total rainfall for every day during incubation for 25 years and then used percentiles to find the top $5 \%$ ( $95^{\text {th }}$ percentile). Then for each year I identified the number of days of 'extreme' rain during the incubation period. Therefore, the data carried forward for use in analysis was an integer representing the number of days where weather was defined as extreme e.g. 2003 - 5 days, 2004 - 10 days.

This was carried out for wind, temperature and rain variables during the breeding season between May and September The same was done for the two key periods of incubation (May and June) and the fledging period (August and September), weather variables were taken across both months and the same methodology applied.

Another weather variable for rain was included as informed by previous research on shearwaters and rain on Rum by Thompson and Furness (1991). "Twice daily rainfall" was calculated from the average rainfall per day across the period between 1995 and 2019, e.g. July, and then all days where rain matched or exceeded double this amount were identified.

Statistical Analyses - Chapter 3, part 1

All analyses were carried out using the statistical software $R$ (version 3.02.1, R Development Core Team 2014). All graphs were generated using the ggplot2 package in $\mathrm{R}$ (Wickham 2016). 
This table summarises the approaches taken in this research to model the relationships between weather and reproductive success. $\mathrm{n} / \mathrm{a}^{*}$, data-driven analysis was not carried out at the individuallevel as this did not prove important at the colony-level.

\begin{tabular}{|c|c|c|c|c|c|}
\hline \multirow[b]{2}{*}{$\begin{array}{l}\text { Level of } \\
\text { analysis }\end{array}$} & \multirow[b]{2}{*}{ Response } & \multicolumn{2}{|l|}{ Data-driven } & \multicolumn{2}{|c|}{ Hypothesis-driven } \\
\hline & & $\begin{array}{l}\text { Average } \\
\text { weather }\end{array}$ & $\begin{array}{l}\text { Extreme } \\
\text { weather }\end{array}$ & $\begin{array}{l}\text { Average } \\
\text { weather }\end{array}$ & $\begin{array}{l}\text { Extreme } \\
\text { weather }\end{array}$ \\
\hline \multirow[t]{5}{*}{$\begin{array}{l}\text { Colony } \\
\text { level }\end{array}$} & $\begin{array}{l}\text { Hatching } \\
\text { success }\end{array}$ & $\begin{array}{l}\text { GLM - variables } \\
\text { selected through }\end{array}$ & $\begin{array}{l}\text { GLM - variables } \\
\text { selected through }\end{array}$ & GLM & GLM \\
\hline & & PCA & PCA & & \\
\hline & $\begin{array}{l}\text { Fledging } \\
\text { success }\end{array}$ & $\begin{array}{l}\text { GLM - variables } \\
\text { selected through }\end{array}$ & $\begin{array}{l}\text { GLM - variables } \\
\text { selected through }\end{array}$ & GLM & GLM \\
\hline & & PCA & PCA & & \\
\hline & $\begin{array}{l}\text { Overall } \\
\text { reproductive } \\
\text { success }\end{array}$ & $\begin{array}{l}\text { GLM - variables } \\
\text { selected through } \\
\text { PCA }\end{array}$ & $\begin{array}{l}\text { GLM - variables } \\
\text { selected through } \\
\text { PCA }\end{array}$ & GLM & GLM \\
\hline \multirow[t]{3}{*}{$\begin{array}{l}\text { Individual } \\
\text { level }\end{array}$} & $\begin{array}{l}\text { Hatching } \\
\text { success }\end{array}$ & $n / a^{\star}$ & $\mathrm{n} / \mathrm{a}^{\star}$ & GLMM & GLMM \\
\hline & $\begin{array}{l}\text { Fledging } \\
\text { success }\end{array}$ & $n / a^{*}$ & $\mathrm{n} / \mathrm{a}^{*}$ & GLMM & GLMM \\
\hline & $\begin{array}{l}\text { Overall } \\
\text { reproductive } \\
\text { success }\end{array}$ & $n / a^{*}$ & $\mathrm{n} / \mathrm{a}^{\star}$ & GLMM & GLMM \\
\hline
\end{tabular}

\subsubsection{Colony-level weather analysis}

To analyse the overall trends in Manx Shearwater reproductive success General Linear Models were used with a binomial structure as the dependent variable was a proportion. Given that there were 82 'typical' and 42 extreme weather variables to be considered in this analysis a Principal Component Analysis (PCA) was used to try and summarise the greatest variation in just one or two Principal Components (PCs).

\subsubsection{Data-driven variable selection}

GLMs were run with the variables selected through PCA. PCA was used to try and summarise as much variance as possible from the 82 'typical' weather variables 
encompassing rain, wind, temperature and general weather indicators NAO and SOI. These included averages, maximum and minimum values and totals across the different time periods. Variables were categorised by month and by key stages of the breeding season, incubation, fledging and the 'critical' period after hatching. Variables were examined visually using a boxplot and then scaled as there were unequal variances between variables which would skew the PCA.

Visual inspection of a scree-plot enabled the optimum number of Principal Components, which explained the most variation within the data, to be selected. This is done by identifying where the 'kink' in the plot is which separates PCs which explain a high degree of variance from those with lower variance. These were then carried forward for use in a GLM.

Variable selection was carried out by examining the loading coefficients of each variable to PC1 and PC2. The loading coefficient is a relative measure of how much that variable contributes to the Principal Component, the variables with the highest loadings are those which provide the greatest contrast between observations on the PC axis.

The three weather variables that had the highest loading coefficients, and that were not measured over the same period (e.g. calm days during June is included within the measure of calm days during the incubation period), were carried forward for use in a GLM. Only three were selected as the number of variables available for modelling was restricted by the data on shearwater reproductive success.

This method was carried out for 'typical' weather conditions that encompassed average daily and monthly values for wind, rain and temperature, as well as maximum and minimum values of temperature, total monthly rainfall, maximum gust strength and the number of calm days during each period. Weather indicators, NAO and SOI were also included for summer and winter, both lagged and for the given year. The method was then repeated using extreme weather data that included temperature, rainfall and wind variables which ranged between the $5^{\text {th }}, 10^{\text {th }}, 15$ th, and 95 th, $90^{\text {th }}$ and $85^{\text {th }}$ percentiles.

Model selection was carried out using the 'dredge' function of the 'Multi-model Inference' package (MuMIn; Barton 2018). This method is based on Akaike's Information Criterion (AIC) and models were only reported if they were within 2 AIC units of the top ranked model. Given that the models were of a binomial structure it was not appropriate to use the standard measure of $R^{2}$, therefore pseudo- $R^{2}$ was 
calculated using the 'blorr' package (Hebbali 2019). Nagelkerke's $\mathrm{R}^{2}$ was chosen as this method allows for the use of the full scale of zero to one (Nagelkerke 1991).

\subsubsection{Hypothesis-driven variable selection}

Knowledge of the breeding biology of Manx Shearwaters led to the selection of variables that measure the effect of weather components which are likely to affect their reproductive success.

Average measures of temperature, wind and rainfall were used, and three models were run to account for hatching, fledging and overall reproductive success with weather variables specific to each period (incubation, fledging and critical respectively). Average weather variables were chosen to highlight the differences between average years where weather is not out of the ordinary and extreme years.

Extreme models were also run and as with the previous models three models were run, in this case with weather variables which fell in the $90^{\text {th }}$ percentile for temperature, rainfall and wind. The $90^{\text {th }}$ percentile was chosen as it was the middle value, it was more commonly used in previous research and during PCA events in the $90^{\text {th }}$ percentile often had the highest factor loadings.

Model selection was carried out as for data-driven analysis, and model validation was carried out for all models.

\subsection{Statistical analyses - Chapter 3, part 2}

\subsubsection{Individual-level weather analysis}

Manx Shearwaters have been monitored on the Isthmus since 1977, and in this time birds have been fitted with individually numbered metal rings that allow for individuals to be identified year on year, the database currently contains 1510 individuals. Given that so many birds are known this provides an extensive dataset on individual reproductive success which was used for this second part of analysis. For each year within the study all breeding attempts can be followed therefore the sample size is much higher when compared to using colony-level data.

This different level of analysis measures something very different to colony-level analysis as it only includes birds which are known. This is important as the majority of the birds in the study are returning birds that either hatched in this colony or have bred here for many years. Given the biology of these birds the older they are and the longer they stay with a partner the more successful they are, therefore, this level of 
analysis is inherently more focussed on experienced breeders.

To investigate the effects of weather on individual success within the colony the success or failure of each pair was analysed using a Generalised Linear Mixed Model (Ime4) with a binomial structure. Reproductive success (hatching, fledging or overall) was set as the response variable with pair identity as a random factor and weather variables as explanatory variables.

Model selection was carried out as above using the 'dredge' function based on AIC, models within 2 AIC points of the top model are reported. Models were also compared with respect to $\mathrm{R}^{2}$ values to examine the proportion of variance explained by the fixed effects (marginal $R^{2}$ ) and fixed and random effects combined (conditional $\mathrm{R}^{2}$ ) (Nakagawa and Schielzeth 2013).

Model validation was carried out and overdispersion calculated for all models.

\subsubsection{Hypothesis-driven weather variables for a mixed model}

Colony-level analysis showed that variables selected through PCA did not explain more variation than variables selected based on a priori considerations. Therefore, mixed modelling variable selection was hypothesis-driven, and the same variables were selected as for the GLMs. Given the more extensive dataset available for these models the two-way interactions between these variables were included as it is possible that the effects of different components of weather may be additive and so may have an important effect on reproductive success. For each stage, hatching, fledging and overall reproductive success two models were constructed, the first with average weather variables and the second with extreme weather variables (as shown in part 1).

\subsubsection{Random Factors}

The identity of the adults is of interest to this study as research has shown that parent age, choice of partner and the longevity of the pair influences reproductive success, it was therefore important to control for this (Brooke 1978; Mauck et al. 2018).

With respect to the shearwaters two random factors were available, individual ID and pair ID. Both are based on ringing data as discussed above (Shearwater productivity monitoring 2.4 .1 ).

The sex of individual shearwaters was not known and therefore it was not possible 
to explain the importance of one sex over the other. The pair bond between individuals is very stable and 'divorce' in uncommon as shearwaters are more successful when they maintain the same partner over several years (Brooke 1990). When exploratory models were constructed pair identity explained more variation and biologically speaking was of greater interest and therefore individual ID was dropped from the models.

Pair identity was created and assigned to each pair. When a pair was identified using individual ring numbers the pair was assigned a 'pair ID' number. This was then assigned to this pair for each year that they bred together, the same code was applied for each year the same pair bred together. See Table 2 as an example. Data were entered from spreadsheets formed each year by the fieldworker, the individual found first was entered into this database as individual 1, and any duplications were removed.

\section{Table 3. Pair identity example table}

Example data showing the identity of individual shearwaters by ring number, the year in which they were recovered at the colony, the ring number of their partner, and PairlD, the identity assigned to that pair.

\begin{tabular}{|l|l|l|l|}
\hline ID & YEAR & partner & PairID \\
\hline EJ47769 & 2009 & EJ47789 & 1 \\
\hline EJ47769 & 2010 & EJ47789 & 1 \\
\hline EJ47789 & 2011 & EJ47769 & 1 \\
\hline EJ47789 & 2012 & EJ47769 & 1 \\
\hline FR88706 & 2009 & EJ47770 & 2 \\
\hline EJ47770 & 2010 & FR88706 & 2 \\
\hline EJ47770 & 2011 & FR88706 & 2 \\
\hline
\end{tabular}

Table 3 shows that individual 1, EJ47769 was paired with individual 2, EJ47789 between 2009-2012, this pair was assigned pair ID 1, and therefore any year in which there individuals breed together will be assigned the same PairID and it is possible to track the success of these pairings between years. It is therefore possible to use Pair ID as a random effect in a GLMM and identify whether the identity of the parents is important in determining the outcome of a breeding attempt.

Year could be included to account for variation in each year that is unexplained by the fixed factors. Explanatory models showed that although in some models year slightly improved the model, generally the models showed less significant 
relationships with weather and year contributed very little explanatory power. Given that demography has such well-studied effects on reproductive success it was thought to be more important to focus on the effects that pair identity, especially experienced breeders had on reproductive success. There are many different factors not included in this model that may affect reproductive success; indirect climate effects, burrow quality and individual parent ID. The effects of these other factors will be explored in the discussion. 


\section{Chapter 3 - Results}

\subsection{Colony-level analysis}

The aim of this part one of the chapter is to give a colony-level overview of the ongoing trends in Manx Shearwater productivity at the Isthmus colony, in terms of hatching success, fledging success and overall reproductive success. The trends were calculated over time and in relation to environmental variables.

When analysing overall colony-level reproductive success, the number of variables that can be tested is restricted by the sample size of the dependent variable, in this case 1995-2019, 25 data points. General practice suggests that the number of independent variables included in a model should be anywhere between $\mathrm{n} / 5$ and $\mathrm{n} / 25$, where $\mathrm{n}$ is the number of rows in the data frame (Thomas et al. 2017a). For this level of analysis three weather variables and year were used in each model to ensure the models were statistically viable, this corresponds to $4 / 25$ which falls within the top end of the recommended range. Considering this decision and given that there is a high degree of correlation between the weather variables, it was decided to use Principal Component Analysis

Weather variables were selected in two ways. Knowledge of previous research and the breeding biology of the birds led to hypothesis-driven variable selection. Principal Component Analysis allowed the selection of a smaller number of variables from the original extensive numbers, to carry forward for analysis. General Linear models were then constructed with these variables using components of reproductive success as responses. 


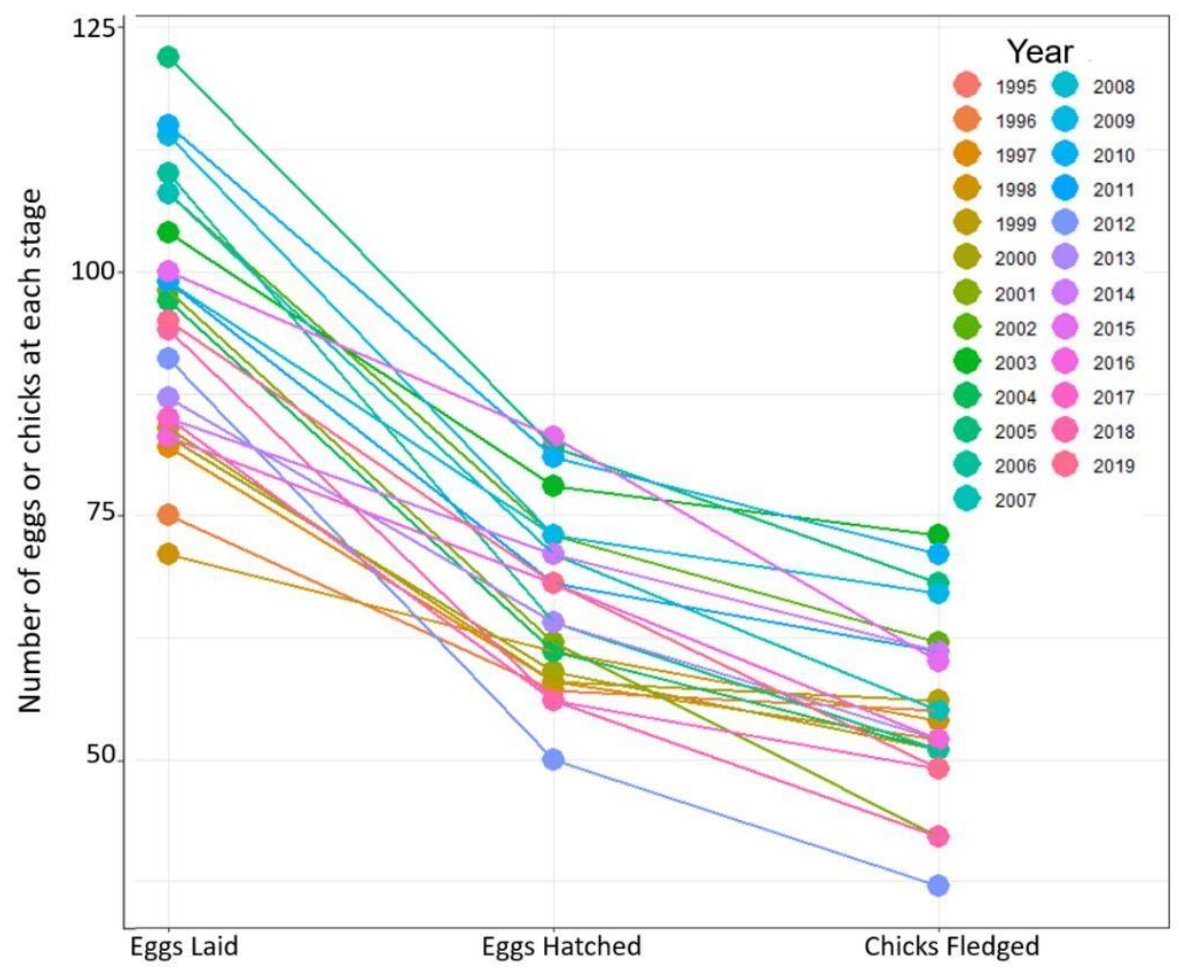

Figure 4 Manx Shearwater reproductive success 1995-2019

Manx Shearwater reproductive success at the Isthmus colony, Skomer Island, as shown by the number of eggs laid, number of chicks hatched and total number of chicks fledged per year since 1995.

\subsubsection{Trends in Manx Shearwater reproductive success}

Reproductive success can be broken down into three main components, hatching success, fledging success and overall reproductive success. Figure 4 shows Manx Shearwater breeding attempts between 1995 and 2019, reproductive success is calculated from number of eggs laid, number of eggs hatched and number of chicks going on to fledge. This figure demonstrates that the number of failures at egg stage is higher than the failures at chick stage. Shearwaters provide a high level of parental care, and once a chick has hatched there is a high chance they will go on to successfully fledge: more breeding failures occur during incubation than during the chick stage. The number of breeding attempts, occupied burrows found with an egg, varies between years from 71 in 1998 to 122 in 2005.

Figure 5, below, shows the trend in each component of reproductive success over time. All components have a shown a decreasing trend between 1995 and 2019, although the only significant trend is in fledging success. Table 4 summarises the 
results of a GLM constructed from reproductive success and year, highlighting the trends over time.

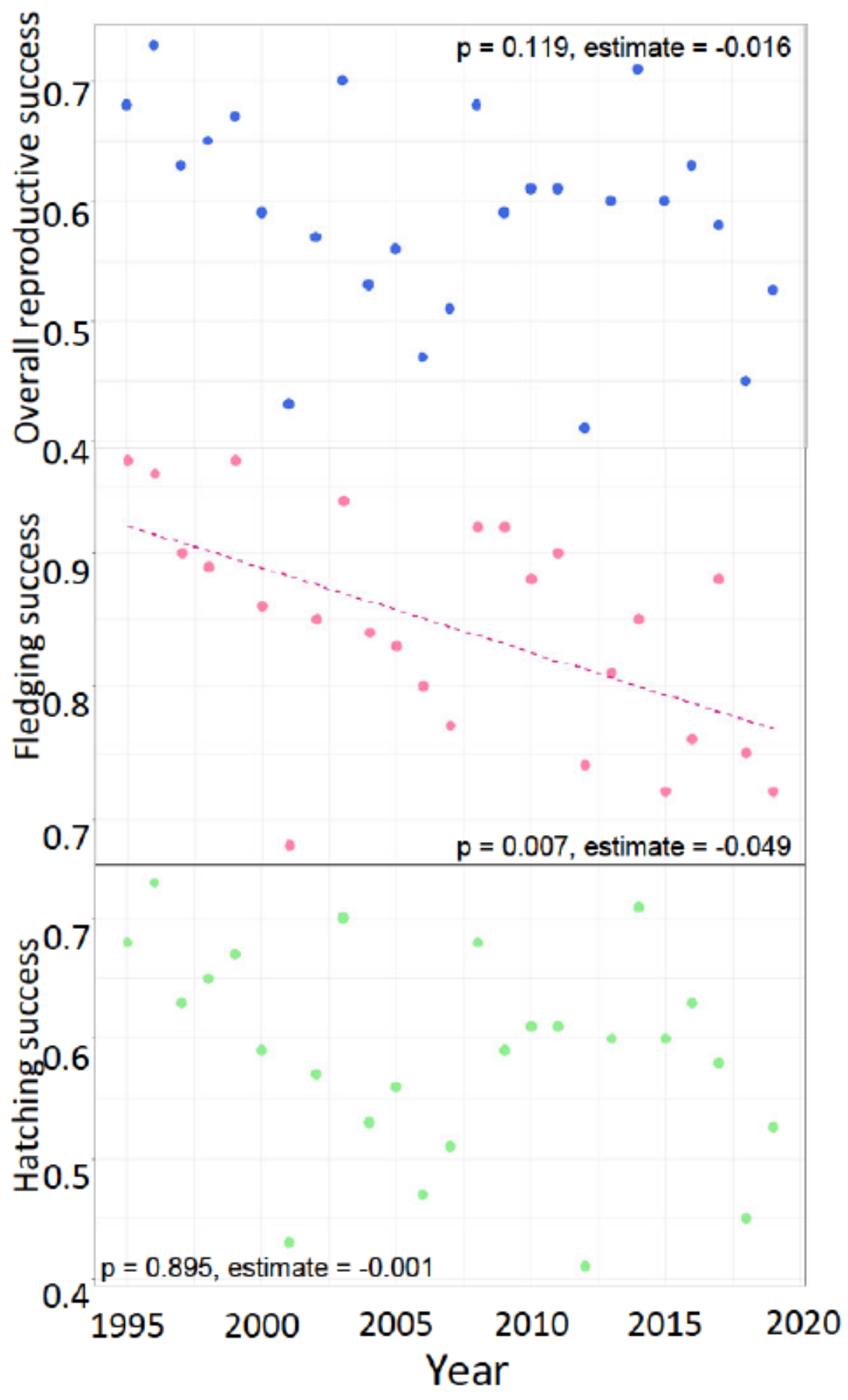

Figure 5 Colony-level reproductive success of Manx Sheanwaters 1991-2019

Manx Sheanwater reproductive success between 1991 and 2019. Overall reproductive success and hatching success do not show significant trends over time, whereas fledging success is showing a significant downward trend. 
Table 4 Manx Shearwater reproductive success GLM

\begin{tabular}{llllll}
\hline Response & Range & Mean & $\begin{array}{l}\text { Parameter } \\
\text { estimate }\end{array}$ & P-value & Pseudo- $\mathbf{R}^{2}$ \\
$\begin{array}{l}\text { Overall reproductive } \\
\text { success }\end{array}$ & 0.32 & 0.59 & -0.016 & 0.119 & -0.037 \\
Hatching success & 0.31 & 0.70 & -0.001 & 0.895 & -0.043 \\
Fledging success & 0.29 & 0.84 & -0.049 & $0.007^{\star \star}$ & -0.036
\end{tabular}

Table 4 shows a summary of each component of reproductive success and the results of a GLM where year was the independent variable in each case.

\subsubsection{Weather and colony-level productivity}

Two approached were taken during this analysis. The first was data-driven, the variables were selected using PCA to identify the variables within the large sample that explained the most variation.

The second approach was hypothesis-driven, informed by previous research and knowledge of the breeding biology of Manx Shearwaters. Variables were selected give an overview of the weather experienced by shearwaters during the breeding season.

\subsubsection{Data-driven weather analysis}

PCA was used to try and summarise as much variance as possible from the 82 original weather variables encompassing rain, wind, temperature and general weather indicators NAO (North Atlantic Oscillation) and SOI (Southern Oscillation Index). Variables were also categorised by month and by key stages of the breeding season, incubation, fledging and the 'critical' period after hatching. Variables were examined visually using a boxplot and then scaled to minimise unequal variances between variables which would skew the PCA. 


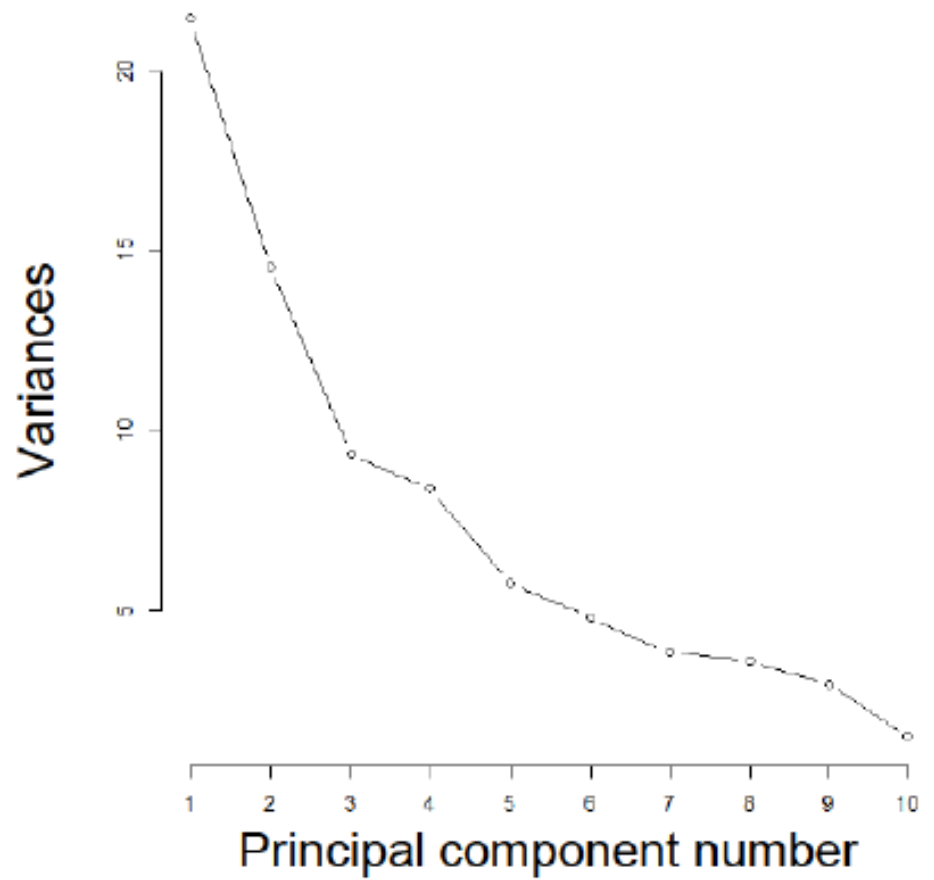

Figure 6 Scree-plot of typical' weather PCA

Scree-plot showing the cumulative variance of each principal component summarising typical weather variables, there is a distinct kink after the second PC.

The first PC explained $28 \%$ of the variation within the variables and the second $19 \%$, Fig 6. A GLM including PC1, PC2 and Year showed no significant relationship between either PC on hatching success, fledging success or overall reproductive success.

\subsubsection{Variable selection using PCA - average and 'typical weather}

Variable selection was carried out by examining the loading coefficients of each variable, variables were selected based on PC1 as this explained the most variation. The loading coefficient is a relative measure, the variables with the highest loadings are those which provide the greatest contrast between observations on the PC1 axis. This method allows the most important variables to be filtered out.

The three weather variables that had the highest loading coefficients, and that were not measured over the same period (e.g. calm days during June is included within the measure of calm days during the incubation period), were carried forward for 
use in a GLM with year. The threshold for selection of variables was determined by the restrictive number of years available for analysis, as discussed previously.

The top three variables were the number of calm days in June (wind below 3 knots), the number of calm days during the fledging period (August and September) and the average temperature in June. A model was constructed using these variables and year, the top models were selected using the 'dredge' function and were ranked by AIC, Table 4 .

\section{Table 5 GLM: data-driven typical' weather}

Results from a General Linear Model using weather as predictors of overall reproductive success in Manx shearwaters. Variables generated using PCA were the number of calm days in June, number of calm days during the fledging period, average temperature in June and year. Models were ranked by AIC and the three top models were within two AIC points.

\begin{tabular}{lllllllllll}
\hline $\begin{array}{l}\text { Model } \\
\text { rank }\end{array}$ & Parameter & Estimate & +-SE & F-stat & d.F & $\begin{array}{l}\text { P- } \\
\text { value }\end{array}$ & $\begin{array}{l}\text { Pseudo- } \\
R^{2}\end{array}$ & AIC & $\Delta$ AIC \\
\hline 1 & Year & -0.003 & 0.003 & 1.148 & 1,19 & 0.297 & 0.013 & -38.36 \\
\hline 2 & $\begin{array}{l}\text { Calm days } \\
\text { during June }\end{array}$ & -0.003 & 0.003 & 0.824 & 1.19 & 0.375 & 0.236 & -38.02 & 0.34 \\
3 & $\begin{array}{l}\text { Calm days } \\
\text { during the } \\
\text { fledging } \\
\text { period }\end{array}$ & -0.002 & 0.002 & 0.700 & 1,19 & 0.413 & 0.223 & -37.89 & 0.47 \\
\hline
\end{tabular}

Table 5 shows that no associations were found between overall reproductive success and weather variables, and that the best model only included year, suggesting that year is a more important predictor of reproductive success than any of the selected weather variables. That being said, weather variables explained more variation in success than year.

\subsubsection{Variable selection using PCA - extreme weather}

Initially there were 48 different extreme weather variables encompassing wind, rain and temperature that considered the number of extreme events within the top and bottom $10 \%$ of events across a 25 -year period. This was calculated for eachmonth within the breeding season and for three key periods, the incubation, fledging and 'critical' post-hatching period. General weather indicators, NAO and SOI, were also included. 


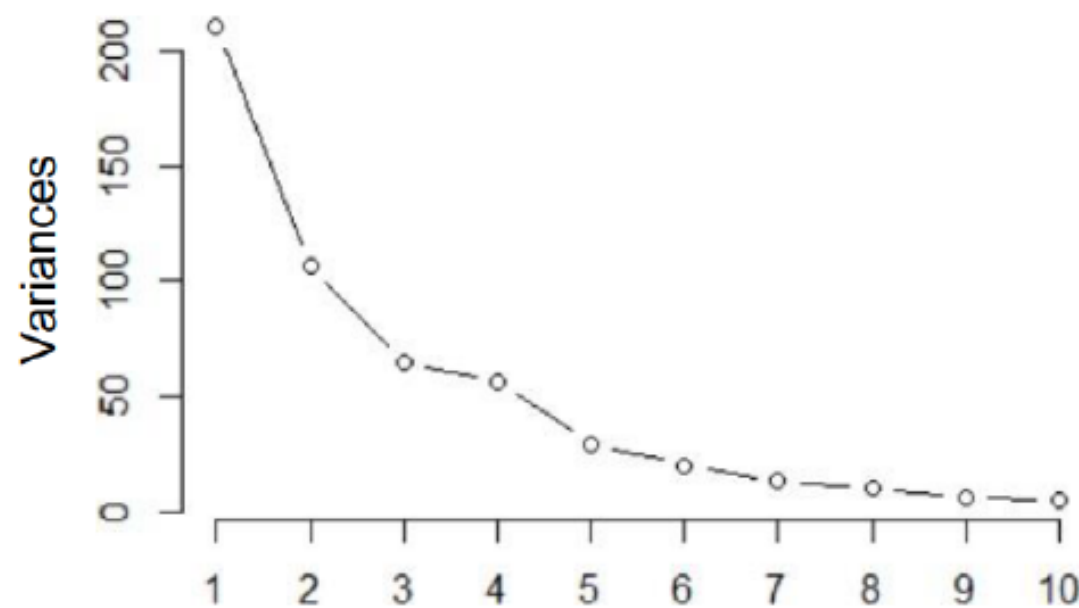

\section{Principal component number}

Figure 7 Scree-plot of extreme weather PCA

Scree-plot showing the cumulative variance of each principal component summarising extreme weather variables, there is a distinct kink after the second PC.

The first PC explained $40 \%$ of the variation within the variables and $2^{\text {nd }} \mathrm{PC} 20 \%$, Fig 7. Both PCs were included with year in a GLM but none of the variables proved to be significant to overall productivity, hatching or fledging success.

Variable selection was carried out in the same method as for typical weather. The three variables that contributed most to PC1 were the number of dry days during the incubation and fledging period and extreme temperature events during the fledging period. A model was constructed using these variables and year, the top models were selected using the 'dredge' function and were ranked by AIC, Table

6.

Table 6 GLM: data-driven extreme weather

Results from a General Linear Model using weather as predictors of overall reproductive success in Manx Shearwaters. Variables generated using PCA were the number of dry days during the fledging period, dry days during the incubation period and extreme temperature in June. Models were ranked by AIC and the two top models were within two AIC points. The best model included only dry days during the fledging period, this relationship is significant but had less explanatory power than Year, Fig 8.

\begin{tabular}{llllllllll}
\hline $\begin{array}{l}\text { Model } \\
\text { rank }\end{array}$ & Parameter & Estimate & \pm SE & F-stat & d.F & P-value & $\begin{array}{l}\text { Pseudo } \\
-R^{2}\end{array}$ & AIC & $\Delta$ AIC \\
\hline 1 & $\begin{array}{l}\text { Fledging } \\
\text { dry days }\end{array}$ & 0.006 & 0.003 & 5.632 & 1,15 & $0.031^{*}$ & 0.163 & -31.66 & \\
\hline & Year & -0.007 & 0.003 & 4.213 & 1.15 & 0.058 & 0.223 & -30.45 & 1.21 \\
\hline
\end{tabular}




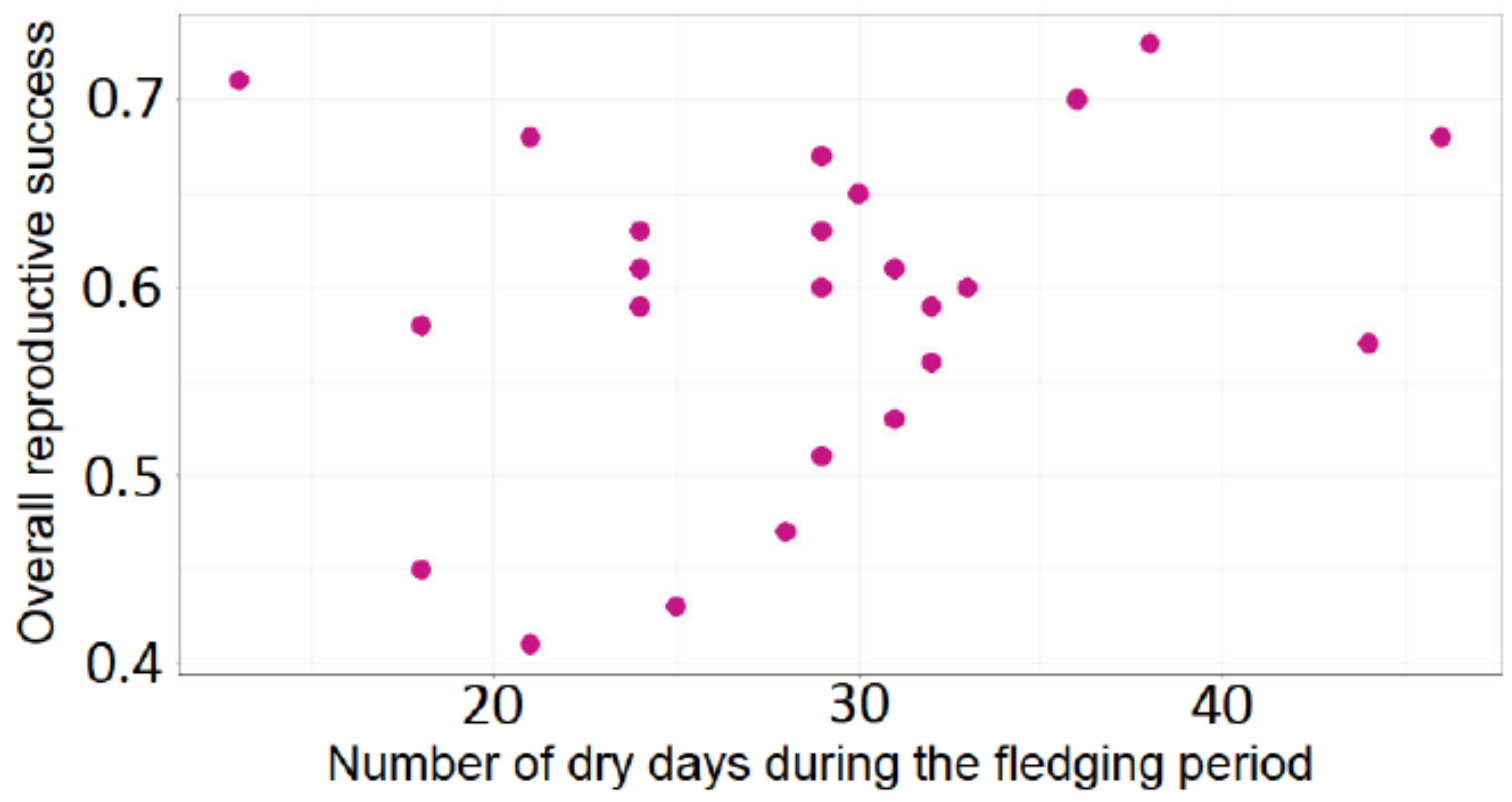

Figure 8 Relationship between Manx Shearwater overall reproductive success and the number of dry days during the fledging period.

As the number of dry days during the fledging period increased overall reproductive success improved, suggesting drier weather during the fledging period is important to reproductive success, or it may be that wet weather has a negative impact on reproductive success

\subsubsection{Hypothesis-driven weather analysis}

\section{Average weather}

Data-driven variable selection through PCA provided weather variables that showed little explanatory power and very few significant relationships between reproductive success and weather.

Hypothesis-driven variable selection was carried out to assess the relationships between average weather conditions and overall reproductive success, hatching success and fledging success. To do this, three variables summarising the average temperature, gust strength and rainfall across each of the three key periods were selected and models constructed, all models included year. A model was constructed using these variables and year, the top models were selected using the 'dredge' function and were ranked by AIC.

Models concerning hatching success and overall reproductive success did not show any associations between success and weather variables or year. The top ranked model regarding fledging success only included year which suggests that at a colony-level Year was a better predictor of fledging success than any of the average weather variables. 


\section{Extreme weather}

Variables summarising the number of extreme temperature, wind and rainfall events over the three key periods were selected and models constructed, all models included year, Table 7. For each weather component events that occurred in the top $10 \%$ of all weather across the 25 -year period of study were chosen.

As with the models concerning average weather hatching success and overall reproductive success showed no association with extreme weather variables. The top ranked model detailing fledging success included extreme wind, temperature and year. Only year was retained in all three models and in all cases had a significant negative relationship with fledging success.

\section{Table 7 GLM: Hypothesis-driven extreme weather}

Results from a General Linear Model using extreme weather as predictors of overall reproductive success in Manx Shearwaters. Variables selected were extreme events of temperature, wind and rainfall across the fledging period of August and September. Models were ranked by AIC and the two top models were within two AIC points.

\begin{tabular}{|c|c|c|c|c|c|c|c|c|c|}
\hline $\begin{array}{l}\text { Model } \\
\text { rank }\end{array}$ & Parameter & Estimate & $\pm \mathrm{SE}$ & F-stat & d.F & $P$ - value & $\begin{array}{l}\text { Pseudo- } \\
\mathrm{R}^{2}\end{array}$ & $\mathrm{AIC}$ & $\Delta \mathrm{AIC}$ \\
\hline \multirow[t]{3}{*}{1} & $\begin{array}{l}\text { Fledging } \\
\text { Extreme Wind }\end{array}$ & -0.011 & 0.006 & 3.80 & 3,13 & 0.076 & 0.436 & -36.63 & \\
\hline & $\begin{array}{l}\text { Fledging } \\
\text { Extreme }\end{array}$ & 0.005 & 0.003 & & & 0.183 & & & \\
\hline & $\begin{array}{l}\text { Temperature } \\
\text { Year }\end{array}$ & -0.008 & 0.003 & & & $0.033^{*}$ & & & \\
\hline \multirow[t]{2}{*}{2} & $\begin{array}{l}\text { Fledging } \\
\text { Extreme Wind }\end{array}$ & -0.010 & 0.006 & 4.4 & 2,14 & 0.10 & 0.231 & -36.22 & 0.41 \\
\hline & Year & -0.010 & 0.003 & & & $0.01^{*}$ & & & \\
\hline 3 & Year & -0.006 & 0.003 & 4.90 & 1,15 & $0.043^{*}$ & 0.223 & -34.74 & 1.89 \\
\hline
\end{tabular}

\subsubsection{Summary: Chapter 3, part 1}

Overall colony trends show a significant decrease in fledging success, a decreasing trend in overall reproductive success and no trend in hatching success.

Data-driven analysis showed very limited results. Variables selected using Principal Component Analysis of 'typical' weather showed no significant results and relatively little explanatory power. PCA of extreme weather did produce a model with a significant relationship between overall reproductive success and dry days during the fledging period, however, explanatory power was low, and year explained more variation. 
Hypothesis-driven analysis using weather averages showed no significant relationships between weather and hatching, fledging or overall reproductive success. Extreme weather analysis reported no relationship between hatching and overall reproductive success and extreme weather. Extreme weather did not have a significant relationship with fledging success, but the top model does explain nearly $44 \%$ of variation in fledging success.

Using both methods the only significant relationships observed were between overall reproductive success, Year and Fledging dry days, which suggests that at the colony-level absence of rainfall and Year are the best predictors of reproductive success.

\subsection{Chapter 3 - Individual-level analysis}

\section{Part 2.}

The aim of the second part of the chapter was to look at relationships between reproductive success and weather variables in more detail. Individual-level data were available for the Isthmus colony which provided a far bigger data set with many hundreds of data points per year, including individual and pair identities. At each stage of the breeding process each pair was coded with a binary response to document success or failure. This allowed for General Linear Mixed Models (GLMMs) to be used with random factors to further enhance the ability to disentangle the relationships between reproductive success and weather, as well as account for year, individual and pair identity.

\subsubsection{Trends}

Reproductive success at each level was plotted against year and a GLM was constructed with Year as the independent variable, in this instance using the binomial response of success or failure with respect to each stage of the breeding process. The trends are shown and summarised in Fig. 9 and Table 8. 
Mean values of reproductive success and GLM results using Year as a predictor, similar mean values for individual-level and colony-level reproductive success. The trends are also similar although no significant trends shown, fledging success is significantly declining at the colony-level.

\begin{tabular}{lllll}
\hline Response & Mean & $\begin{array}{l}\text { Parameter } \\
\text { estimate }\end{array}$ & P-value & $\begin{array}{l}\text { Pseudo- } \\
\mathbf{R}^{2}\end{array}$ \\
$\begin{array}{l}\text { Overall reproductive } \\
\text { success }\end{array}$ & 0.54 & -0.002 & 0.808 & 0.0002 \\
$\begin{array}{l}\text { Hatching success } \\
\text { Fledging success }\end{array}$ & 0.70 & -0.002 & 0.803 & 0.0004 \\
\hline
\end{tabular}




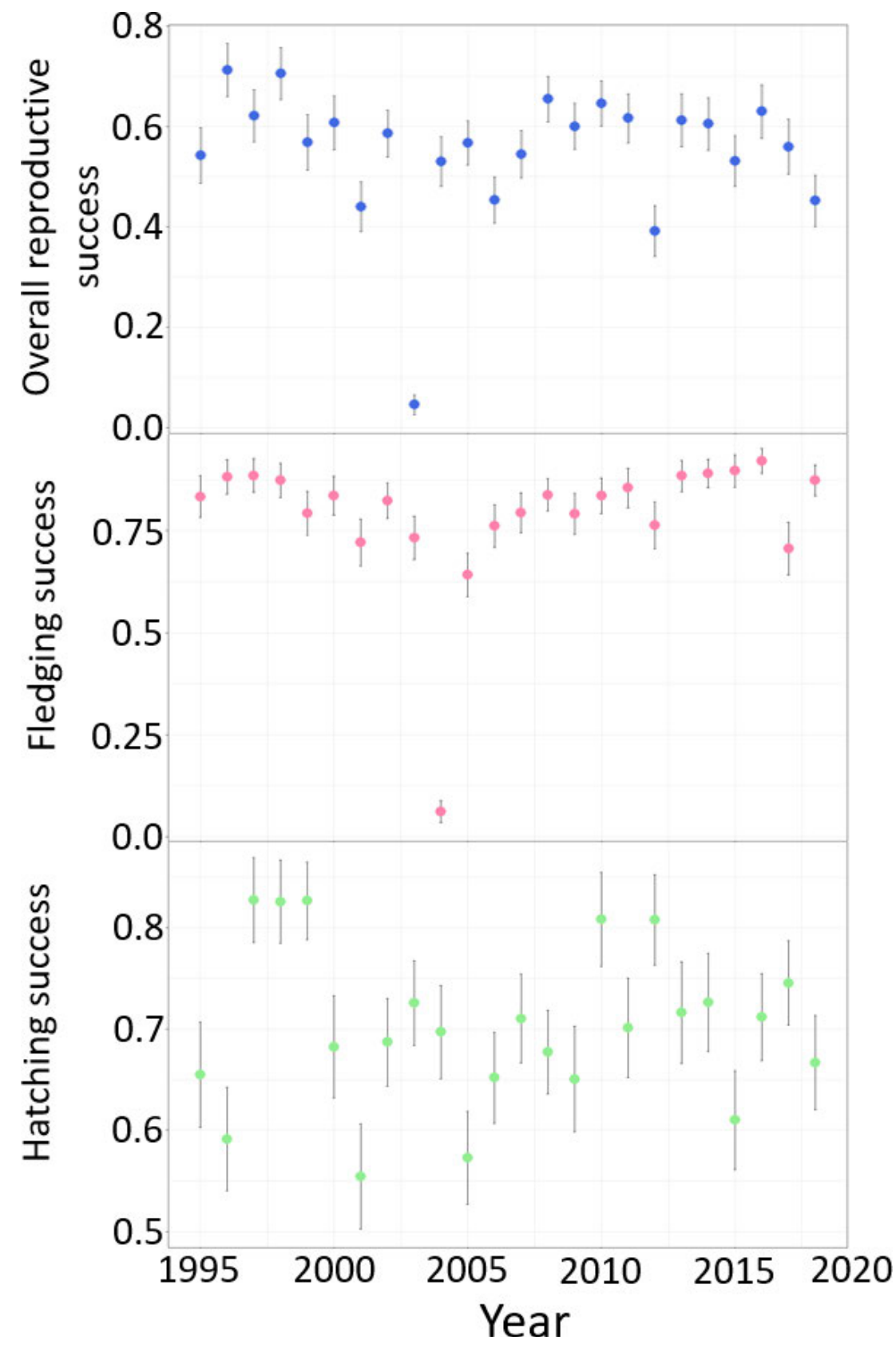

Figure 9 Individual-level reproductive success of Manx Shearwaters 1995-2019

Manx Shearwater reproductive success between 1995 and 2019 expressed as a proportion. Reproductive success as the number of chicks fledged per eggs laid, fledging success as the number of chicks hatched which went on to fledge and hatching success the proportion of eggs laid which went on to successfully hatch. Fledging and hatching success show no significant trend over time, overall productivity shows a marginally significant increase over the time period.

\subsection{Individual-level average weather analysis}

In all cases two models were run, one with three weather variables and the corresponding two-way interactions, and a second with six weather variables and no interactions. Three variables were chosen so as not to construct an overly 
complicated model that could be easily interpreted, each variable represents the average of a weather component that may affect shearwater reproductive success. PairlD was included as a random factor.

\subsubsection{Average weather analysis}

\section{Hatching success}

The optimal model had all three single variables plus the interactions between temperature/gust strength and temperature/rainfall, Table 9. This model explained $11 \%$ of the variation in hatching success. In all models the random effect of PairID explained more variation than the fixed effects, suggesting the pair ID is a more important factor for successfully hatching a chick in average weather conditions.

The most frequently retained variable throughout the top models was average rainfall, which was in every model, although this was not statistically significant. There was always a negative relationship between average rainfall and hatching success. 
Table 9 GLMM: Average weather and hatching success

\begin{tabular}{|c|c|c|c|c|c|c|c|c|c|}
\hline Rank & Fixed effects & Random effects & Est. & $\pm \mathrm{SE}$ & P-Value & Marg. $\mathrm{R}^{2}$ & Cond. $\mathbf{R}^{2}$ & AIC & $\triangle \mathrm{AIC}$ \\
\hline \multirow[t]{5}{*}{1} & Average Gust Strength & Pair ID & 0.013 & 0.025 & 0.596 & 0.010 & 0.107 & 2498.76 & \\
\hline & Average Temp & & -0.004 & 0.042 & 0.928 & & & & \\
\hline & Average Rainfall & & -0.016 & 0.025 & 0.528 & & & & \\
\hline & Average Temp: Average Rainfall & & 0.003 & 0.002 & 0.113 & & & & \\
\hline & Average Temp: Average Gust Strength & & -0.002 & 0.002 & 0.197 & & & & \\
\hline \multirow[t]{4}{*}{2} & Average Gust Strength & Pair ID & -0.015 & 0.009 & 0.072 & 0.008 & 0.103 & 2499.39 & 0.63 \\
\hline & Average Temp & & -0.043 & 0.018 & $0.015^{\star}$ & & & & \\
\hline & Average Rainfall & & -0.031 & 0.017 & 0.069 & & & & \\
\hline & Average Temp: Average Rainfall & & 0.003 & 0.001 & $0.006^{\star *}$ & & & & \\
\hline \multirow[t]{5}{*}{3} & Average Gust Strength & Pair ID & -0.037 & 0.021 & 0.073 & 0.009 & 0.105 & 2500.10 & 1.34 \\
\hline & Average Temp & & -0.038 & 0.018 & $0.032^{*}$ & & & & \\
\hline & Average Rainfall & & -0.044 & 0.024 & 0.061 & & & & \\
\hline & Average Rainfall: Average Gust Strength & & 0.002 & 0.001 & 0.225 & & & & \\
\hline & Average Temp: Average Rainfall & & 0.003 & 0.001 & $0.027^{*}$ & & & & \\
\hline \multirow[t]{6}{*}{4} & Average Gust Strength & Pair ID & -0.001 & 0.034 & 0.976 & 0.010 & 0.12 & 2500.49 & 1.73 \\
\hline & Average Temp & & -0.006 & 0.030 & 0.844 & & & & \\
\hline & Average Rainfall & & -0.024 & 0.025 & 0.340 & & & & \\
\hline & Average Rainfall: Average Gust Strength & & 0.001 & 0.002 & 0.613 & & & & \\
\hline & Average Temp: Average Rainfall & & 0.002 & 0.001 & 0.088 & & & & \\
\hline & Average Temp: Average Gust Strength & & -0.002 & 0.001 & 0.179 & & & & \\
\hline \multirow[t]{3}{*}{5} & Average Temp & Pair ID & -0.037 & 0.018 & $0.035^{*}$ & 0.006 & 0.10 & 2500.61 & 1.85 \\
\hline & Average Rainfall & & -0.021 & 0.016 & 0.196 & & & & \\
\hline & Average Temperature: Average Rainfall & & 0.003 & 0.001 & $0.021^{*}$ & & & & \\
\hline \multirow[t]{3}{*}{6} & Average Gust Strength & Pair ID & -0.047 & 0.020 & $0.021^{*}$ & 0.006 & 0.104 & 2500.68 & 1.92 \\
\hline & Average Rainfall & & -0.024 & 0.018 & 0.194 & & & & \\
\hline & Average Rainfall: Average Gust Strength & & 0.003 & 0.001 & $0.037^{\star}$ & & & & \\
\hline
\end{tabular}




\section{Fledging success}

\section{Average weather}

All models explained a high degree of the variation in fledging success, $21.8 \%$ $21.9 \%$ (Table 10). The optimal model had all three single variables plus the interaction between average temperature/average rainfall, all of which were highly significant. Both average rainfall and average temperature had negative relationships with fledging success.

The top three models were highly consistent, all containing the single variables and the interaction between temperature/rainfall, which was always positive. Average temperature was always highly significant and had a negative relationship with fledging success. Burrows usually provide a stable environment where fluctuations in temperature are less pronounced, increasing temperature may be directly causing the chick to overheat or the effect may be indirect.

In comparison with the hatching success models the fixed effects in the fledging success models explained a much larger amount of variation, and the split in variation was much more even in the fledging success models than for hatching success. This suggests that pair ID plays a more important role in hatching success compared to fledging success. 
Table 10 GLMM: Average weather and fledging success

\begin{tabular}{|c|c|c|c|c|c|c|c|c|c|}
\hline $\begin{array}{l}\text { Model } \\
\text { rank }\end{array}$ & Fixed effects & $\begin{array}{l}\text { Random } \\
\text { effects }\end{array}$ & Estimate & $\pm S E$ & $\begin{array}{l}\text { P- } \\
\text { Value }\end{array}$ & $\begin{array}{l}\text { Marg. } \\
\mathrm{R}^{2}\end{array}$ & $\begin{array}{l}\text { Cond. } \\
\mathrm{R}^{2}\end{array}$ & $\mathrm{AIC}$ & $\triangle \mathrm{AIC}$ \\
\hline \multirow[t]{4}{*}{1} & Average Gust Strength & Pair ID & 0.063 & 0.011 & $<0.001^{\star \star \star}$ & 0.162 & 0.218 & 1478.16 & \\
\hline & Average Temperature & & -0.264 & 0.035 & $<0.001^{\star \star \star}$ & & & & \\
\hline & Average Rainfall & & -0.725 & 0.204 & $<0.001^{\star \star \star}$ & & & & \\
\hline & Average Temperature: Average Rainfall & & 0.094 & 0.094 & $<0.001^{\star \star \star}$ & & & & \\
\hline \multirow[t]{5}{*}{2} & Average Gust Strength & Pair ID & 0.043 & 0.024 & 0.075 & 0.160 & 0.217 & 1478.61 & 0.45 \\
\hline & Average Temperature & & -0.276 & 0.040 & $<0.001^{\star \star \star}$ & & & & \\
\hline & Average Rainfall & & -0.711 & 0.204 & $<0.001^{\star \star \star}$ & & & & \\
\hline & Average Temperature: Average Rainfall & & 0.091 & 0.015 & $<0.001^{\star \star \star}$ & & & & \\
\hline & Average Temperature: Average Gust Strength & & 0.002 & 0.002 & 0.356 & & & & \\
\hline \multirow[t]{5}{*}{3} & Average Gust Strength & Pair ID & 0.089 & 0.034 & $0.010^{\star *}$ & 0.160 & 0.219 & 1479.66 & 1.5 \\
\hline & Average Temperature & & -0.250 & 0.038 & $<0.001^{\star \star \star}$ & & & & \\
\hline & Average Rainfall & & -0.539 & 0.298 & 0.07 & & & & \\
\hline & Average Rainfall: Average Gust Strength & & -0.012 & 0.015 & 0.436 & & & & \\
\hline & Average Temperature: Average Rainfall & & 0.089 & 0.015 & $<0.001^{\star \star \star}$ & & & & \\
\hline
\end{tabular}




\section{Overall reproductive success}

\section{Average weather}

Two models were ranked as significantly better than all others, see Table 11. Both models explained around $11 \%$ of the variation in overall reproductive success and four times more variation was explained by the random factors. This suggests that in years where weather is 'average', pair ID is more important at explaining variation in overall reproductive success, although there is still a large amount of variation which is unexplained by either random or fixed factors.

The only difference between the models is the inclusion of the interaction between wind and rain in the second model. In both models average wind, and the interactions between average temperature/wind and rain/temperature were all significant. Average wind and the interaction between temperature and rain had negative relationships with overall reproductive success.

In comparison with the hatching and fledging success models, models of overall reproductive success showed similar $\mathrm{R}^{2}$ values to hatching success models. This suggests that pair ID plays more of a role in hatching and overall reproductive success than fledging success, in fact weather had very little effect on hatching and overall reproductive success. 
Table 11 GLMM: Average weather and overall reproductive success

\begin{tabular}{|c|c|c|c|c|c|c|c|c|c|}
\hline $\begin{array}{l}\text { Model } \\
\text { rank }\end{array}$ & Fixed effects & $\begin{array}{l}\text { Random } \\
\text { effects }\end{array}$ & Estimate & +-SE & $\begin{array}{l}\text { P- } \\
\text { Value }\end{array}$ & $\begin{array}{l}\text { Marg. } \\
\mathrm{R}^{2}\end{array}$ & $\begin{array}{l}\text { Cond. } \\
\mathrm{R}^{2}\end{array}$ & $\mathrm{AlC}$ & $\triangle \mathrm{AIC}$ \\
\hline \multirow[t]{5}{*}{1} & Average Gust Strength & Pair ID & -0.036 & 0.016 & $0.027^{\star}$ & 0.021 & 0.110 & 2899.63 & \\
\hline & Average Temp. & & -0.028 & 0.022 & 0.181 & & & & \\
\hline & Average Rainfall & & 0.119 & 0.088 & 0.177 & & & & \\
\hline & Average Temp: Average Gust Strength & & 0.003 & 0.001 & $0.002^{\star \star}$ & & & & \\
\hline & Average Temp: Average Rainfall & & -0.023 & 0.008 & $0.003^{\star \star}$ & & & & \\
\hline \multirow[t]{5}{*}{2} & Average Gust Strength & PairlD & -0.060 & 0.025 & $0.015^{\star}$ & 0.022 & 0.111 & 2899.98 & 0.35 \\
\hline & Average Temp & & -0.027 & 0.022 & 0.216 & & & & \\
\hline & Average Rainfall & & -0.010 & 0.134 & 0.938 & & & & \\
\hline & Average Rainfall: Average Gust Strength & & 0.013 & 0.010 & 0.199 & & & & \\
\hline & Average Temp: Average Rainfall & & -0.025 & 0.008 & $0.002^{\star \star}$ & & & & \\
\hline
\end{tabular}




\subsubsection{Individual-level extreme weather analysis}

The GLMMs looked at success between years and used weather variables across the relevant period as predictor variables, which covered temperature, rainfall and wind, more variables could be used in this method owing to the considerably larger sample size. Initially the model was run with both random factors of year and pair identity (pair ID). Year was subsequently dropped from analysis as models with only Pair ID explained the same amount of variation.

\section{Hatching success}

The optimal model had all three single variables plus the interactions between temperature/rain and rain/wind, this model explained $13 \%$ of the variation in hatching success, almost all of which was attributed to the explanatory power of the random effect, Table 12.

The most common variables in the models were extreme rain, wind, temperature and the interaction between rain and temperature which were in all four models. All single variables had negative relationships with hatching success whereas the interaction between extreme rain and temperature had a positive relationship with hatching success. In all models rain, temperature and the interaction between extreme rain and temperature were highly significant.

In comparison with the average weather model, a slightly higher proportion of variance was explained by the fixed effects than the random effects, on average $3 \%$ (extreme weather) compared to an average of $0.8 \%$ (general weather). This suggests that in years where weather is extreme, weather explains a slightly higher proportion of hatching success than when the weather is average, but this is not enough of a difference to draw conclusions from. 
Table 12 GLMM: Extreme weather and hatching success

\begin{tabular}{|c|c|c|c|c|c|c|c|c|c|}
\hline \multirow[t]{6}{*}{ Model rank } & Fixed effects & Random effects & Estimate & +-SE & P. Value & Marg. $\mathbf{R}^{2}$ & Cond. $\mathbf{R}^{2}$ & AIC & $\triangle \mathrm{AIC}$ \\
\hline & Extreme Rain & Pair ID & -0.484 & 0.102 & $<0.001^{\star \star \star *}$ & 0.03 & 0.13 & 1756.13 & \\
\hline & Extreme Wind & & 0.003 & 0.042 & 0.938 & & & & \\
\hline & Extreme Temp & & -0.175 & 0.043 & $<0.001^{\star \star \star *}$ & & & & \\
\hline & Extreme Rain: Extreme Wind & & 0.021 & 0.012 & 0.068 & & & & \\
\hline & Extreme Rain: Extreme Temp & & 0.054 & 0.014 & $<0.001^{* * *}$ & & & & \\
\hline \multirow[t]{4}{*}{2} & Extreme Rain & Pair ID & -0.366 & 0.079 & $<0.001^{\star \star *}$ & 0.027 & 0.130 & 1757.48 & 1.35 \\
\hline & Extreme Wind & & 0.069 & 0.022 & $0.001^{\star *}$ & & & & \\
\hline & Extreme Temp & & -0.171 & 0.043 & $<0.001^{* * *}$ & & & & \\
\hline & Extreme Rain: Extreme Temp & & 0.051 & 0.014 & $<0.001^{\star \star \star *}$ & & & & \\
\hline \multirow[t]{6}{*}{3} & Extreme Rain & Pair ID & -0.484 & 0.102 & $<0.001^{* * *}$ & 0.031 & 0.132 & 1757.60 & 1.47 \\
\hline & Extreme Wind & & 0.052 & 0.079 & 0.511 & & & & \\
\hline & Extreme Temp & & -0.155 & 0.052 & $0.003^{\star \star}$ & & & & \\
\hline & Extreme Rain: Extreme Wind & & 0.019 & 0.012 & 0.126 & & & & \\
\hline & Extreme Rain: Extreme Temp & & 0.055 & 0.015 & $<0.001^{* * *}$ & & & & \\
\hline & Extreme Temp: Extreme Wind & & -0.006 & 0.009 & 0.465 & & & & \\
\hline \multirow[t]{5}{*}{4} & Extreme Rain & Pair ID & -0.392 & 0.082 & $<0.001^{* \star *}$ & 0.030 & 0.131 & 1757.94 & 1.81 \\
\hline & Extreme Wind & & 0.135 & 0.057 & $0.019^{*}$ & & & & \\
\hline & Extreme Temp & & -0.139 & 0.050 & $0.006^{* *}$ & & & & \\
\hline & Extreme Rain: Extreme Temp & & 0.054 & 0.014 & $<0.001^{* * *}$ & & & & \\
\hline & Extreme Temp: Extreme Wind & & -0.011 & 0.008 & 0.214 & & & & \\
\hline
\end{tabular}




\section{Fledging success}

Models were ranked by $\mathrm{AIC}$ and models within two AIC points were ranked as the top models, two models were within the two-point range, see Table 13.

The best model had all three single variables plus the interactions between extreme rain/wind and wind/temperature, this model explained $27 \%$ of the variation in fledging success. Extreme wind, temperature and the interaction between rain and temperature were all highly significant, the interaction between wind and temperature was also significant.

The most common variables in the models were extreme rain, wind, temperature and the interactions between rain/wind and wind/temperature which were all in both models. In both models wind, temperature and the interaction between wind/temperature were highly significant, all single variables were negatively associated with fledging success.

Both models had high explanatory power, $27 \%$, and almost all the variance was explained by the fixed factors, the random factors contributed very little. In comparison with the general weather model, a higher proportion of variance was explained by the fixed effects than the random effect, 97\% (extreme weather) compared to $74 \%$ (general weather). This suggests that in years where weather is extreme, weather plays a more important role in determining fledging success. 
Table 13 GLMM: Extreme weather and fledging success

\begin{tabular}{|c|c|c|c|c|c|c|c|c|c|}
\hline $\begin{array}{l}\text { Model } \\
\text { rank }\end{array}$ & Fixed effects & $\begin{array}{l}\text { Random } \\
\text { effects }\end{array}$ & Estimate & +-SE & P. Value & Marg. $\mathbf{R}^{2}$ & Cond. $\mathbf{R}^{2}$ & AIC & $\triangle \mathrm{AIC}$ \\
\hline \multirow[t]{5}{*}{1} & Extreme Rain & Pair ID & -0.154 & 0.079 & 0.052 & 0.26 & 0.269 & 1025.43 & \\
\hline & Extreme Wind & & -0.247 & 0.057 & $<0.001^{\star \star \star}$ & & & & \\
\hline & Extreme Temperature & & -0.351 & 0.040 & $<0.001^{\star \star \star}$ & & & & \\
\hline & Extreme Rain: Extreme Wind & & 0.043 & 0.014 & $0.002^{\star \star}$ & & & & \\
\hline & Extreme Wind: Extreme Temperature & & 0.037 & 0.005 & $<0.001^{\star \star \star}$ & & & & \\
\hline \multirow[t]{6}{*}{2} & Extreme Rain & Pair ID & -0.156 & 0.080 & 0.052 & 0.26 & 0.270 & 1027.40 & 1.97 \\
\hline & Extreme Wind & & -0.243 & 0.061 & $<0.001^{\star \star \star}$ & & & & \\
\hline & Extreme Temperature & & -0.353 & 0.042 & $<0.001^{\star \star \star}$ & & & & \\
\hline & Extreme Rain: Extreme Wind & & 0.041 & 0.017 & $0.014^{\star}$ & & & & \\
\hline & Extreme Wind: Extreme Temperature & & 0.037 & 0.006 & $<0.001^{\star \star \star}$ & & & & \\
\hline & Extreme Rain: Extreme Temperature & & 0.003 & 0.018 & 0.868 & & & & \\
\hline
\end{tabular}




\section{Overall reproductive success}

A mixed model was run using three extreme weather variables across the critical period post-hatching in July and the corresponding two-way interactions, pair ID was included as a random factor. The models were ranked by AIC and three models were significantly better than all others, Table 14 .

The 'best' model included extreme rain, wind, and the interaction between them. This model explained $9 \%$ of the variation in reproductive success, and most of the explanatory power came from the random factor, Pair ID. When compared with the general weather model both 'top' models yielded similar results. Total variation explained was on average 11\% (general weather) and 9.3\% (extreme weather) and the fixed effects explained $11 \%$ and $10 \%$ of variation respectively.

This suggests that all weather conditions have a similar impact on overall reproductive success, but that Pair ID is always a more important predictor of success than weather.

The only significant fixed effect was the interaction between extreme wind/rain, which always had a negative relationship with success, this result is logical as wind and rain could have both direct and indirect effects on chicks. 


\begin{tabular}{|c|c|c|c|c|c|c|c|c|c|}
\hline $\begin{array}{l}\text { Model } \\
\text { rank }\end{array}$ & Fixed effects & $\begin{array}{l}\text { Random } \\
\text { effects }\end{array}$ & Estimate & +-SE & P. Value & $\begin{array}{l}\text { Marginal } \\
\mathbf{R}^{2}\end{array}$ & $\begin{array}{l}\text { Conditional } \\
\mathbf{R}^{2}\end{array}$ & AIC & $\triangle \mathrm{AIC}$ \\
\hline \multirow[t]{3}{*}{1} & Extreme Rain & Pair ID & 0.070 & 0.049 & 0.149 & 0.012 & 0.091 & 2266.30 & \\
\hline & Extreme Wind & & 0.029 & 0.031 & 0.362 & & & & \\
\hline & Extreme Rain: Extreme Wind & & -0.065 & 0.019 & $<0.001^{\star \star \star}$ & & & & \\
\hline \multirow[t]{4}{*}{2} & Extreme Rain & Pair ID & 0.066 & 0.049 & 0.178 & 0.014 & 0.094 & 2266.60 & 0.30 \\
\hline & Extreme Wind & & 0.030 & 0.031 & 0.339 & & & & \\
\hline & Extreme Temperature & & -0.023 & 0.016 & 0.157 & & & & \\
\hline & Extreme Rain: Extreme Wind & & -0.069 & 0.019 & $<0.001^{\star \star \star}$ & & & & \\
\hline \multirow[t]{5}{*}{3} & Extreme Rain & Pair ID & 0.080 & 0.052 & 0.127 & 0.014 & 0.095 & 2268.03 & 1.73 \\
\hline & Extreme Wind & & 0.083 & 0.076 & 0.278 & & & & \\
\hline & Extreme Temperature & & -0.015 & 0.019 & 0.406 & & & & \\
\hline & Extreme Rain: Extreme Wind & & -0.083 & 0.027 & $0.002^{\star \star}$ & & & & \\
\hline & Extreme Wind: Extreme Temperature & & -0.011 & 0.014 & 0.449 & & & & \\
\hline
\end{tabular}




\subsubsection{Summary: Chapter 3, part 2}

Individual-level trends were different to trends at a colony-level. At the individuallevel all components of productivity showed a very small decreasing trend over, none of these trends were significant.

Analysis using average weather variables showed little effect of weather on hatching success with very little explanatory power. Pair identity explained nearly $10 \%$ of variation in hatching success compared with just $1 \%$ which was explained by weather. Extreme weather variables, especially rain and temperature, had highly significant relationships with hatching success, but as with average weather pair identity still explained more variation.

Models constructed to explore fledging success had the highest R-squared values compared with models exploring hatching or overall reproductive success. Fledging success was also the only measure of success where weather variables explained more variation than Pair ID, under both normal and extreme conditions.

There was very little difference between models exploring overall reproductive success under normal and extreme weather conditions.

These results, along with the trends over time, show that although there are significant relationships between weather and reproductive success there is no trend in success over time as was shown at the colony-level. It may be that pair identity, as a proxy for experience, is the reason for this. 


\subsection{Discussion}

This study found key differences between reproductive success at the colony- and individual-level. Overall reproductive success shows a slight, yet insignificant decline over the study period, between 1995 and 2019, at both levels. The most interesting difference is the trend in fledging success, which is significantly declining at the colony-level but not at the individual-level, the possible reasons for this are discussed below.

At the colony-level, models did not show a significant relationship between fledging and hatching success and weather variables, average or extreme. The only model that showed a significant result was the relationship between overall reproductive success and the number of dry days during the fledging period. This was a positive result which suggests that reproductive success decreased when rainy days were more frequent. Given that this was the only significant relationship with any weather variable at this level of analysis, the effect of rain must be strong to be detected at this coarse-level.

At the individual-level, where models had considerably higher power, in general, the relationships between extreme weather and reproductive success were of greater significance and showed more explanatory power, compared with average weather models. This was particularly evident when considering fledging success. Both aspects of weather, average and extreme, showed significant relationships with reproductive success. Rainfall was the only variable that was retained within all extreme and general models at all levels of reproductive success, suggesting that this is the most important weather variable when considering the effects of weather on reproductive success.

Recent research has shown that climate change and extreme weather is and will continue to be one of the most significant threats to seabirds around the world (Dias et al. 2019; Croxall et al. 2012). This study shows that reproductive success of Manx shearwaters has significant relationships with weather, particularly extreme weather. However, overall this does not seem to be having a significant effect on the trends in reproductive success over time. It may be that the indirect effects of climate change are more influential on reproductive success than direct effects. 
What is becoming increasingly apparent is that seabirds are often experiencing multiple threats simultaneously, $89 \%$ of species affected by climate change (e.g. extreme weather) also face other threats (Dias et al. 2019). Mitigating for the effects of climate change and extreme weather will be incredibly difficult, therefore it is vital that in the future any other potential threats to shearwaters are minimised (Dias et al. 2019). It is critical that Skomer is keep free of non-native, invasive species such as rats.

\subsubsection{Demographic effects on reproductive success}

One of the key findings of this research is the distinction between the levels of analysis and how this reflects upon the population dynamics of shearwaters on

Skomer Island. Given the coarse level of analysis at the colony-level it may be expected that the results will not be as informative as more detailed analysis. However, it was important that analysis at this level was comprehensive in order to provide a base going forward for more detailed analysis and demonstrate the importance of long-term data sets with demographic information. At the colony-level there is a significant reduction in fledging success between 1995 and 2019 but at the level of the individual there is no significant trend.

The main difference between the colony level and individual-level samples is the demographic of individuals within the sample. At the colony-level all birds were incorporated, including unknown individuals that are new to the population, possibly first-time breeders, or individuals which have not been encountered before. These individuals, whose pair identity cannot be assigned, were not included in the individual-level analysis.

Climatic conditions have a greater impact on inexperienced breeders (Mauck et al. 2018; Nevoux et al. 2010). This could explain why fledging success is declining at the colony-level but not at the individual-level, based on the assumption that the birds included in the individual based analysis are more experienced breeders (Boersma and Rebstock 2014; Mauck et al. 2018; Oro et al. 2010; Riou et al. 2011).

Experienced breeders have an increased likelihood of reproductive success, this may be because experienced birds are more efficient and effective foragers (Mauck et al 2018). This in part explains why the difference in trends is apparent during chick provisioning when adults must feed themselves and the chick (Mauck et al. 2018). 
This increased efficiency may not show much of an effect in good years, where there is a high abundance of prey, but in poor years where conditions are variable, and prey is scarce or of poorer quality this may make a significant difference.

On Skomer, links have already been shown between prey abundance and experience (Riou et al. 2011). Riou et al. (2011) showed that although there was a negative relationship between chick weight and increased sea surface temperature, this was not the case for all individuals. $20 \%$ of chicks reached a peak fledging mass of $450 \mathrm{~g}$, therefore some adults must have been able to forage effectively, and previous research suggests these adults are likely to have been more experienced breeders (Riou et al. 2011; Mauck et al. 2018).

What was not clear in this study was the positive effect of experience on hatching success, which was shown in previous research (Brooke 1990). Brooke (1990) found that experienced pairs improved their overall reproductive success by having an increased likelihood of successfully hatching an egg. This study did not find any difference between hatching success at the colony or individual-level (means of 0.7 and 0.69 respectively). However, individual-level analysis showed that pair ID explained considerably more variance in hatching success than weather, suggesting that weather was not as influential, so the overall impact of experience is unclear.

\subsubsection{Trends in fledging success}

Although there was no significant trend in fledging success at the individual-levelof analysis the models explained a high proportion of variation ( $r$-squared $=22 \%$ and $27 \%$, Tables 10 and 13). Models based on average and extreme weather showed the highest total variation explained by any of the individual-level models and fledging success was the only component of reproductive success where weather explained a greater amount of variation than pair identity.

This is particularly evident in the extreme weather models where $97 \%$ of the variation explained by the fixed and random factors came from the fixed factors, weather. This is in contrast to the results of hatching and overall reproductive success where in all models (average and extreme), the random factor of pair identity explained more variation. This suggests that when weather is extreme, pair identify, and therefore parental experience does not improve the chances of fledging success. Extreme weather significantly reduces fledging success no matter how 
experienced the parents.

Extreme weather was shown to have a highly significant effect at the individuallevel. However, the highest proportion of variation in success explained by extreme weather was $26 \%$, and the lowest was just $1.2 \%$. Even when taking pair identity into account, these figures leave a lot of variation unexplained, therefore, there must be other factors which have a more important effect on reproductive success than extreme weather.

These results suggest that the indirect effects of climate change, such as increased SST may be more important than the direct effects of weather. It would be interesting if future modelling could include both weather variables and SST to identify any interactions between the indirect and direct effects of climate change.

\subsubsection{Effects of rain}

Research has shown that most failures in seabird, and shearwater, reproductive success usually occur during the incubation period, potentially due to poor coordination between parents, but also as a consequence of weather conditions (Brooke 1990; Cuthbert 2005; Thomson and Furness 1992).

Burrow flooding has been proven as a cause of egg failure in many seabird species, including Manx Shearwaters (Fagundes et al 2016; Huntington et al. 1996; Thompson and Furness 1991). Hatching success on Skomer is highly variable between years, yet at the colony-level there was no significant relationship between hatching success and rainfall, even at the extreme level.

Previous research has found that when it comes to rainfall the most important factor is the intensity of rainfall rather than the total amount. This was reflected in Thompson and Furness' (1991) research as they found that that most significant relationship was between hatching success and the number of days during incubation where rainfall was twice the daily average, i.e. very heavy rain over a short period. This was also shown by Kaiser and Forbes (1992) who found that the intensity of rainfall was of much greater importance to burrow nesting species than the total rainfall over a monthly period.

These results match what was shown on Skomer at the individual-level of hatching success, the effect of average levels of rain was not significantly associated with hatching success whereas extreme rain was (tables 9 and 12). Extreme rain was 
retained in all models after model selection was carried out, and in all cases had a highly significant negative relationship with hatching success. However, the explanatory power of weather variables included in this model is very low just $3 \%$, whereas pair identity explained $10 \%$ of the variation in hatching success. This result implies that even under extreme weather conditions the experience of the parents is more important in determining hatching success. This is corroborated by Brooke's experiments which showed that the increase in reproductive success shown by experienced pairs was driven by increased hatching success (1990).

\subsubsection{Effects of temperature}

\subsubsection{Hatching success}

Temperature shows a similar pattern to that of rainfall. Although average temperature had significant relationship with hatching success in half of the selected 'top models', extreme temperature and hatching success were significantly negatively associated in all 'top models' (table 12).

One of the advantages of burrow nesting is the stability of the environment, particularly when it comes to temperature (Bancroft et al. 2005). Any changes in the burrow environment can have cumulative physiological effects on an incubating bird as they can be in the burrow for up to 12 days and increases in temperature can have similar thermoregulatory costs to cooler temperatures (Mauck et al. 2018).

This is not reflected in these results, which suggest that hatching success decreases as both average temperature and the number of extreme temperature events increases. Under extreme high temperatures there may very high physiological costs incurred to try and keep cool, as over-heating has been shown to affect mortality, although given that shearwaters nest in burrows and in such a temperate climate this seems unlikely (Sydeman et al. 2012). Where temperature is linked to mortality it may be a direct effect of heat stress but in many cases increased temperatures have indirect effects such as decreased parental attendance at the nest which may increase predation risk and increase levels of parasitism (Gaston et al. 2002; Oswald et al. 2008).

Results showed negative relationships between hatching success and extreme rain and temperature in isolation. In addition, the interaction between rain and temperature was retained in all 'top' models for extreme weather and all models bar 
one for average weather. In contrast to the single variables, the interaction term had a positive relationship with hatching success under average and extreme weather conditions.

\subsubsection{Fledging success}

Temperature also showed highly significant, negative relationship with fledging success, both under average and extreme conditions (tables 10 and 13). As shown above an increase in temperature in the burrow is usually associated with a decreased metabolic rate, and this has been shown to increase growth rate in seabird chicks (Kulaszewicz and Jakubas 2018). The underlying cause of this negative relationship is not clear but may be linked to increased SST which is known to affect the availability of vital food resources for shearwaters (Riou et al. 2011).

As with hatching success the interaction between rainfall and temperature was positive, but regarding fledging success, was only significant under average weather conditions, not extreme.

\subsection{Effects of wind}

Under average weather conditions gust strength had significant, negative relationships with fledging success and overall reproductive success (tables 10 and 11). Under extreme conditions wind had a significant, negative relationship with fledging success, but of the hatching success extreme wind was only significant in half of the 'top' models and the relationship was positive (tables 13 and 14). These findings are somewhat logical as during incubation the incubating adult protects the egg from any draughts and keep the egg warm. When the chick is alone in the burrow they do not have this protection and are therefore at greater risk of chilling.

It is likely that wind exacerbates the effects of temperature and rainfall, as wind can drive rain into a burrow or intensify the effects of cold weather. This effect was shown as the interaction between extreme rain and wind had a significant, negative relationship with overall reproductive success. However, this is not reflected in fledging success as the same interaction had a positive relationship with fledging success.

Research has shown that some seabirds show a preference for burrows that are orientated away from the prevailing wind direction (Fagundes et al. 2016; Fricke et al. 2015). This study did not take burrow orientation into account, but it is likely that 
Manx Shearwaters also favour burrows face away from prevailing wind to reduce the effect of wind chill and rainfall. 


\section{Chapter 4 - Competition and Puffins on Skomer}

\subsection{Competition}

There may be another factor that may be of greater importance to shearwater reproductive success, competition with Atlantic Puffins.

Evidence from previous research has suggested that the shearwater populations on Rum and Skomer may be limited by the number of highquality burrows available (Ashcroft 1976; Thompson and Furness 1991). On Rum, competition is intra-specific (within the same species), however on Skomer Island a potential limiting factor for Manx Shearwaters may be interspecific (with another species), with Atlantic Puffins (Ashcroft 1976; Thompson and Furness 1991).

Puffin numbers on Skomer have increased rapidly in the last 15 years, this change has been particularly noticeable in recent years as puffins have doubled since 2012 and are beginning to expand their range across the island (Stubbings et al. 2018). This population increase has culminated in the highest recorded count since 1988 of 30,895 individuals (Stubbings et al. 2018). The reasons behind this increase are not completely understood but could be linked to the fact that the effects of climate change are currently not as severe as in other regions, see section 1.5.2 (Lauria et al. 2013).

\subsubsection{Habitat selection}

Ruth Ashcroft studied Skomer's puffins in the 1970s, with a chapter dedicated to competition between puffins and shearwaters and this has been a key reference point for this section (Ashcroft 1976). She showed that despite having significantly different habitat preferences there was overlap in burrow selection between shearwaters and puffins (1976). All puffin colonies were shown to have shearwaters present but only a small proportion of shearwater colonies had puffins present.

Puffins show a preference for nesting in burrows on sloping ground near to the coast, as these areas allow for easier take-off and landing and reduces the risk of predation by Great Black-backed Gulls (Larus marinus) (Grant and Nettleship 1971; Nettleship 1972). Proximity to the coast is also of benefit as it reduces the risk of kleptoparasitism, in the form of fish being stolen from 
puffins by gulls, as they return to the burrow (Nettleship 1972). A contributing factor to the higher productivity in coastal, sloping areas is the high quality of individuals associated with them, older more experienced birds, (similarly to shearwaters) will be better at provisioning their chicks and are more likely to cope with unfavourable conditions (Hatch 1990; Murphy et al. 1992; Rodway et al. 1998; Sydeman et al. 1991).

Ashcroft (1976) also found that main cause for competition is the lack of burrows, with observations of colour-ringed puffins showed that between $10-30 \%$ of adults did not have a burrow in which to nest. Exclusion experiments on shearwaters showed that if one pair was removed from a burrow, new pairs readily took over this burrow, and if further exclusion happened a third pair would take up residence (Ashcroft 1976). These results showed that there are adult birds of both species unable to find an unoccupied burrow to breed in (Ashcroft 1976).

When artificial burrows were instated, shearwaters occupied all inland and mid- colony burrows, whereas all cliff edge burrows were either regularly visited or occupied by puffins (Ashcroft 1976). As all burrows were used it suggests that were the other species not occupying the other sites either species may take up all available burrows, suggesting that there is a competitive advantage for each species in each site (Ashcroft 1976).

\subsubsection{Inter-specific competition}

Studies of other shearwaters have shown that the availability of appropriate nest sites are the limiting factor in terms of the breeding population, and this is caused by both inter and intraspecific competition (Ramos et al. 1997). In addition to interspecific competition shearwaters may also face intraspecific competition from other Manx Shearwaters. Ashcroft (1976) showed that adult shearwaters were without burrows during her study on Skomer. Given that shearwaters nest in high numbers both on the coast and inland it seems that shearwaters are less specific than puffins when it comes to burrow choice, and therefore may be less affected by competition than puffins.

\subsection{Chapter aim}


Shearwaters.

Reproductive success data and population estimates of Manx Shearwaters as well as the population estimates of Puffins on Skomer will be used to explore the population trends of both species and answer the question:

1. Is there a relationship between the ongoing increase in Puffin numbers on Skomer Island and the reproductive success or population dynamics of Manx Shearwaters?

\subsection{Methods}

\subsubsection{Manx Shearwater population estimates}

To estimate the population of Manx Shearwaters on Skomer Island, the Seabird Monitoring Handbook method of tap playbacks within sample study plots is used and carried out by Wildlife Trust for South and West Wales (WTSWW) staff each year (Walsh et al. 1995). It is very difficult to count occupied shearwater nests as they are in burrows and the birds are nocturnal (Walsh et al. 1995). However, a successful way of determining occupancy is to play a sound recording of a male shearwater down a burrow during the day within the incubation period and wait for a response call. This method surveys 18 plots across Skomer, which are around $1000 \mathrm{~m}^{2}$ circles rather than the 20 to $30 \mathrm{~m}^{2}$ circles suggested in the handbook. Burrow occupancy is measured as:

"the number of burrows from which there is a response to a recording of male calls played at natural volume from within $0.3 \mathrm{~m}$ of the burrow entrance for a maximum of 15 seconds" (Walsh et al. 1995).

A correction factor is then applied to account for individuals that are present within the burrows but do not respond to the tape. This is necessary because females very rarely respond to the tape, but males often do (Perkins et al. 2017; Walsh et al. 1995). The correction factor is calculated by taking a sample of burrows where occupancy is confirmed by manually checking the burrow, then the tape is played to these burrows and the number of responses recorded. This is repeated several times throughout the incubation period and a correction factor is calculated, this was originally calculated by Brooke in 1978 as 1.98 .

Since this method of monitoring was started in 1998 the same method of 
using Dictaphone playback had been used, including during the whole island census in 2011 (Perrins et al. 2012). The original tape was of a single male shearwater but in 2018 a new method was introduced that used a duet of both male and female birds as this was shown to elicit a greater response rate than male call alone (Perkins et al. 2017). Females very rarely responded to the male only call but often responded to the duet, thus using the duet improved precision by up to $50 \%$ (Perkins et al. 2017). The new method may have increased the total number of responses to tape; however, a new calibration factor was calculated to ensure that the results are comparable between 1998-2017 and 2018-2019.

I will use the total number of responses across the plots as a proxy for the Manx Shearwater population on Skomer Island so that year-on-year population changes can be analysed, and trends identified. The 18 plots monitored spanned different habitats across the island, and I will use both the overall number of responses across the entire island as well as break down the responses into inland and coastal sites.

\subsubsection{Manx Shearwater whole island census}

In 1998 the breeding population was estimated at 101,800 pairs and was therefore thought to be the largest colony in the world (Smith et al. 2001). However, when the second census was carried out in 2011 the estimate was far higher at 316,070 apparently occupied sites (Perrins et al. 2012). This difference may be down to several factors including a population increase, reduced age of first breeding, high levels of immigration from other colonies or due to a difference in methods (Perrins et al. 2012). The most recent census in 2018, using a similar method to 2011 , returned a figure of 349,663 pairs and used very similar methods (Perrins et al. in preparation).

In 2011 and 2018 the island was divided into 334 one-hectare squares, not all squares were viable for nesting shearwaters, they may be rocky, boggy or partly sea. A point within the square was pre-selected and the observer place a cane at this point and used two $10 \mathrm{~m}$ long ropes to produce a sector. Every burrow within that sector was checked to determine whether it was a suitable burrow (length $>0.7 \mathrm{~m}$ ), all potentially suitable burrows then had tape played down them and responses were logged, this was then repeated until the entire circle around the cane was completed. The result was then extrapolated for 
each square and all squares added to give an all island estimate. For more detailed methodology see Perrins et al. (2012).

\subsection{Puffin monitoring techniques - spring counts}

Puffin counts were taken from Skomer Seabird reports $(2018,2010,2003$, and 1997) and represent the maximum number of puffins seen on one evening in spring, April/May.

Total island puffin counts are carried out annually on Skomer on spring evenings when puffins come in in large numbers. This method is not able to provide an accurate number of individuals on the island, but it allows for an estimate to be made of population size and when carried out over successive years following the same method can give a good idea of population trends. On Skomer the puffin count takes place during the prelaying period in mid to late April over five nights where there are large numbers of puffins on land and near the island. The island is divided into seven sections and at least two people are assigned to each section. All counters set off at the same time and have a set time limit within which to complete the count. Puffins are counted on land, in the air and on the sea separately. Counts are repeated until both counters produce a figure within $10 \%$ of the other. The highest figure over the different evening counts is used as the population estimate for that year. Count data were available between 1989 and 2019 although only the total island count was detailed in the seabird reports and in several years the breakdown of counts around the island was lost and could not therefore be used.

\subsection{Statistical analysis}

This chapter will use statistical analysis to attempt to uncover evidence of inter-specific competition between puffins and Manx Shearwaters. Linear regression and a t-test were used to examine the trends in shearwater reproductive success for Skomer and Skokholm islands, one island with competition and one without. Data for Skokholm Island was taken from the Skokholm Seabird Reports (Brown and Eagle 2013; 2014; 2015; 2016; 2017; 2018), 2019 data by personal communication (Brown 2019). In addition to assessing overall colony success, a binomial GLM (Bernoulli 
structure) was used to investigate whether Puffin numbers were affecting Manx Shearwater reproductive success at an individual level, all breeding attempts at the Isthmus were included for each year and coded as one or zero, success or failure (as was used for weather analysis see section 2.5.1).

Total population estimates for puffins and shearwaters on Skomer will be compared. The 18 study plots for shearwater populations will then be categorised as coastal or inland, trends of coastal vs inland plots will be compared as inter-specific competition will only occur at coastal plots. Each of the 18 plots will also be investigated individually to identify plot-specific trends.

\subsection{Results}

\subsubsection{Comparison with another colony}

The Isthmus colony is the only colony on Skomer to be monitored for reproductive success, so it is not possible to draw comparisons between colonies within the island. The nearest comparable colony is on Skokholm Island. Figure 10 shows a difference in trends between productivity at these colonies. A five-year running mean was applied to the Skomer data which has smoothed the inter-annual variation and gives a clearer trend over time. 


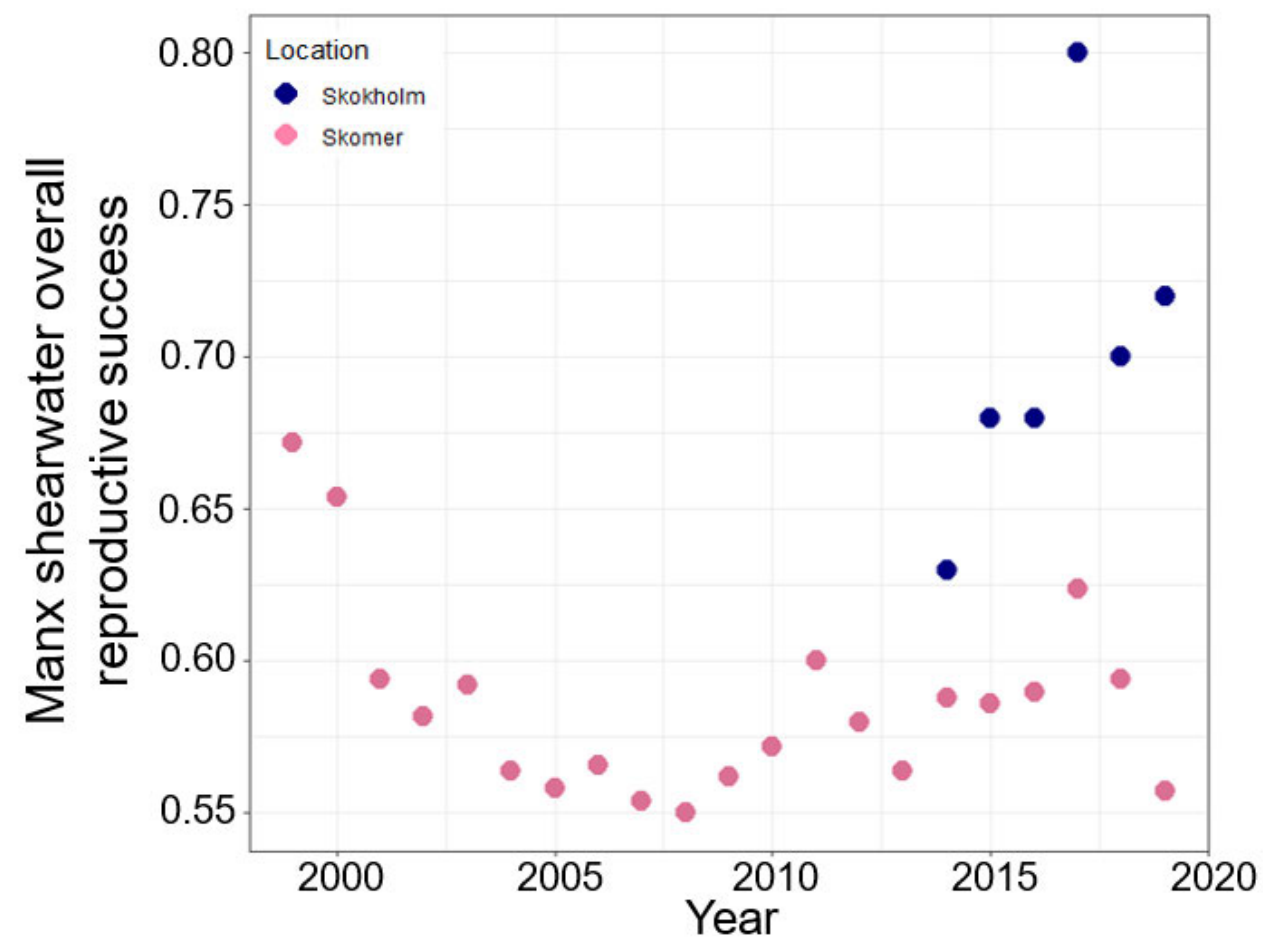

Figure 10 Comparison of reproductive success between two islands, Skomer and Skokholm.

Skokholm Manx Shearwater monitoring started in 2014 and is calculated across three separate colonies, all without the presence of puffins. When comparing the data over this time period the trends are clearly very different (t-test ${ }_{(8.5)}=2.76, \mathrm{~d}_{\mathrm{f}} \mathrm{f}=$ $0.21, p=0.023)$. A simple linear regression for each location showed that between 2014 and 2019 there was no significant trend on Skokholm (F-Stat $=2.78_{(1,4)}, p=$ 0.21 , adj- $\left.R^{2}=0.19\right)$ but that there was a significant downward trend on Skomer $(F-$ Stat $=10.7(1,4), p=0.031$, adj- $\left.R^{2}=0.66\right)$. The difference in trends is interesting as one of the main disparities between the colonies is the lack of puffins within the Skokholm study colonies, however drawing conclusions from analysis based on such a small sample size, six years, should be undertaken with caution.

Data gathered using individual Manx Shearwater breeding attempts provided a more detailed method of analysis. To investigate the relationship between reproductive success and Puffin population increases a binomial GLM was used. As with overall colony level success, no significant relationships were apparent $(F-$ stat $=0.22(1$, 2473), $p=0.64$, adj $-R^{2}=-0.0003$ ). 


\subsubsection{Shearwater and puffin population trends on Skomer Island}

Productivity is not the only measure of shearwater success on Skomer, every year a tape playback census is carried out across 18 study plots by WTSWW staff. This allows for an estimate of the overall population trend to be calculated in a more practical and repeatable way than undertaking an annual whole island census, Fig 11.

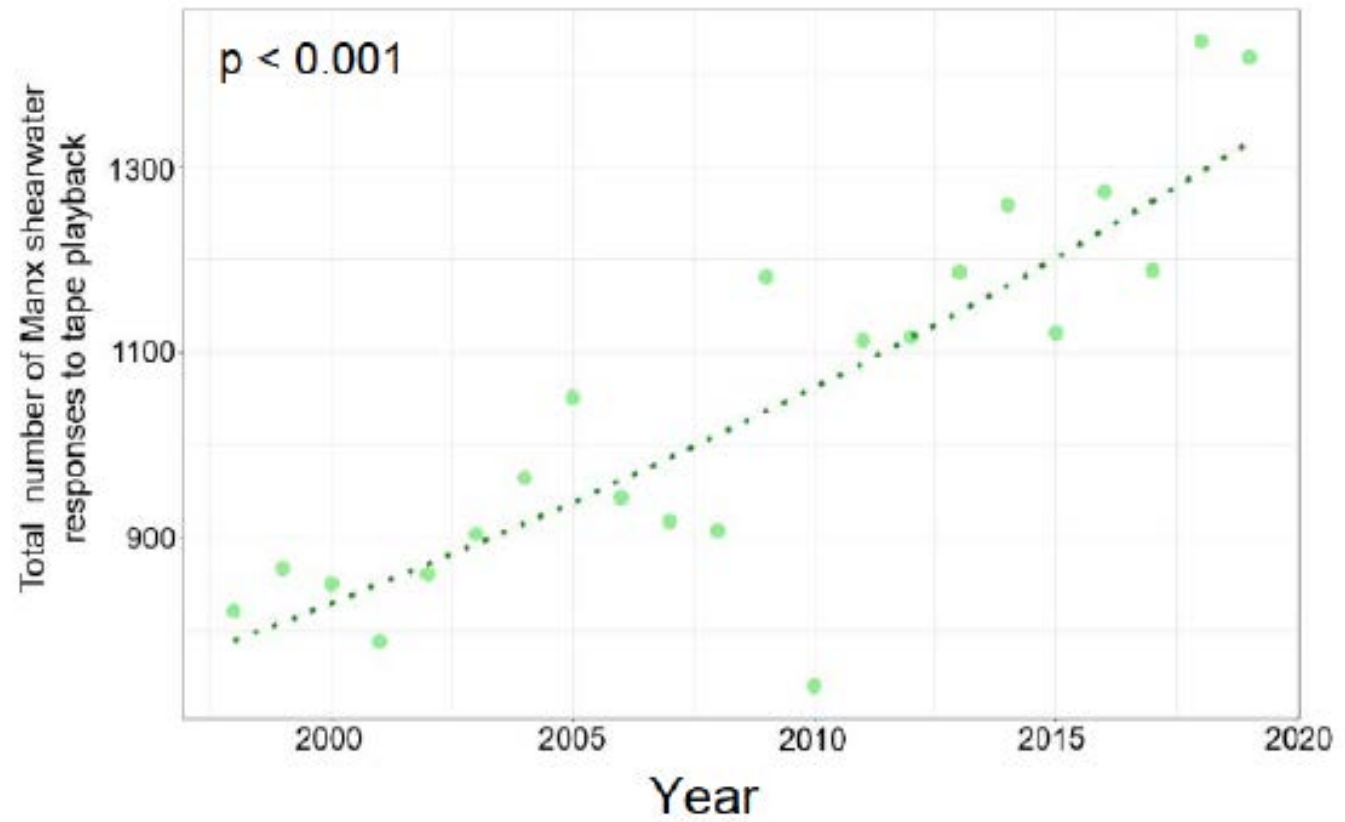

Figure 11 Manx Shearwater population estimates for Skomer Island between 1998 and 2019.

These plots have been monitored since 1998 and in that time overall responses across the island have almost doubled, this represents a highly significant increase ( $F$-stat $=48.76_{(1,19), p}<0.0001$, adj $-R^{2}=0.70$ ).

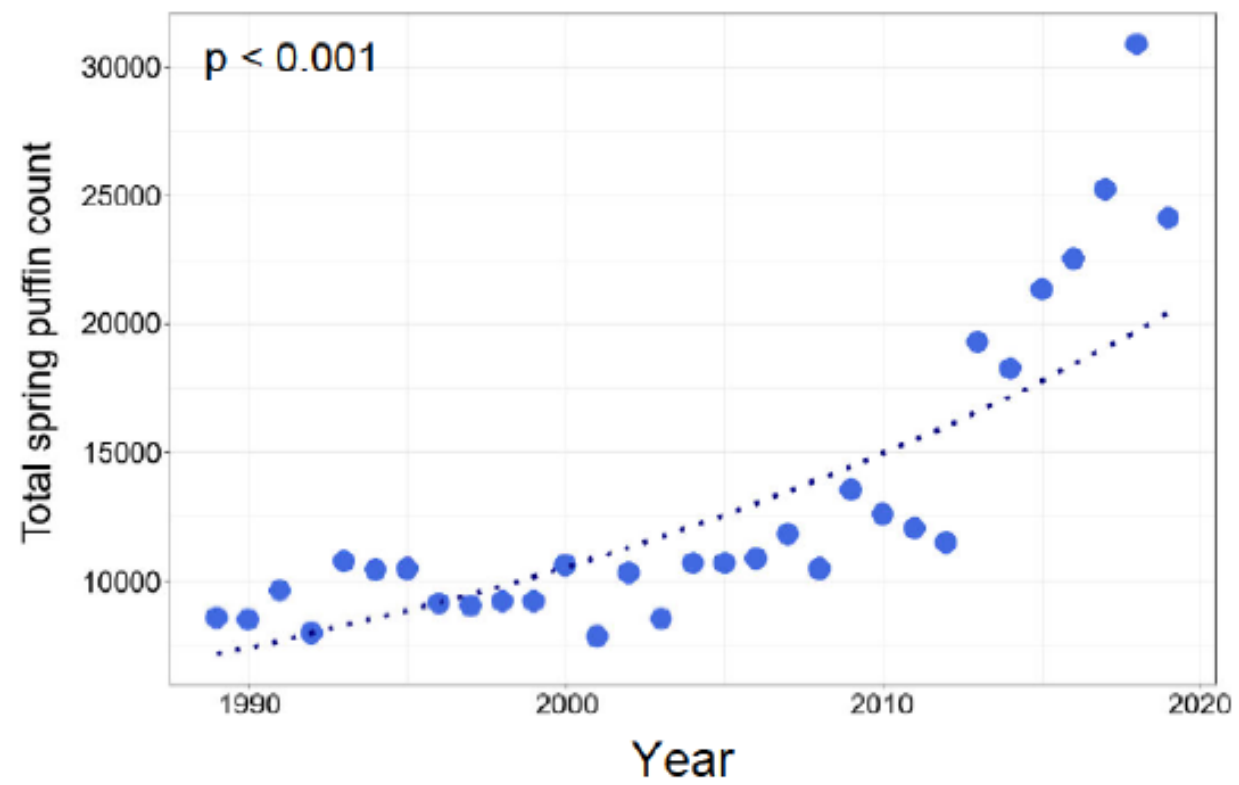

Figure 12 Total Skomer Island puffin population estimates counted on one spring evening every year between 1989 and 2019

Counts to estimate the maximum number of puffins on Skomer have been carried out every year since 1989 and in that time numbers have more than trebled. This is a highly significant increase, ( $F$ stat $=50.76_{(1,29),} p<0.0001$, adj- $\left.R^{2}=0.62\right)$, which is more notable between 2012 and 2017 where 
numbers more than doubled in just five years

Alongside this increase in shearwater numbers the puffin population is bucking UK trends and increasing at an even greater rate (Fig 12).

These estimates of the shearwater and puffin populations on Skomer both show a significant increase. Interspecific competition was not detected at this level of analysis.

\subsubsection{Puffins and shearwaters}

Previous research on Skomer has shown that puffins and shearwaters do compete for burrows in which to breed and that it is likely that puffins would have a competitive advantage at coastal locations (Ashcroft 1976). If the playback survey plots are broken down by plot it is clear that although not all plots follow the same trend most of them are increasing. Of 18 plots 12 show a significant increase (66.6\%), one shows a significant decrease (5.6\%) and five show no significant trend (27.8\%) (Fig 13). This visualisation shows that of the coastal sites 6 are significantly increasing $(66.6 \%)(C, D, J, L, O, P)$ and three are increasing but not significantly (33.3\%) (A, $H, M)$, none are decreasing. Of the inland sites six are increasing significantly $(66.6 \%)(F, G, I, N, R, S)$ one is significantly decreasing $(E)$, one shows a slight increasing trend $(\mathrm{Q})$ and one a decreasing trend $(\mathrm{B})$. If competition was playing a role it might be expected that coastal sites would not show such significant trends, or even perform better than inland sites. Puffins nest exclusively around the coast as the further they are to the sea the greater the risk of predation and kleptoparasitism. If there was a significant level of inter-specific competition between shearwaters and puffins it would be expected that shearwater population trends would differ between the coastal and inland sites. This is clearly not the case as the trends are almost identical, in fact there are more shearwaters at coastal sites. 


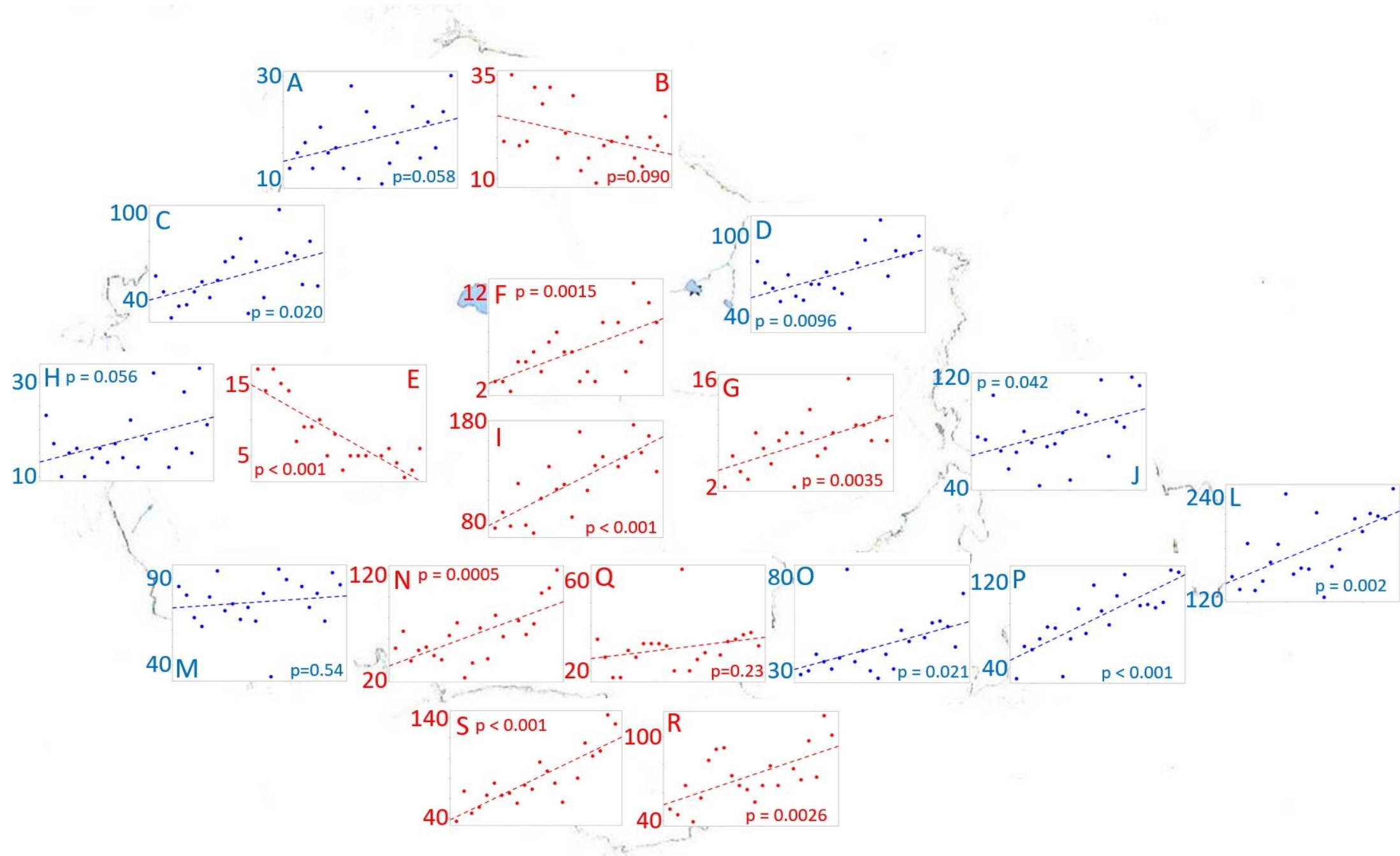

Figure 13 Manx Shearwater tape playback plots $A$ to $S$

Figure 13 shows the 18 study plots used to estimate the Manx Shearwater population on Skomer Island, tape playback surveys have been carried out every year between 1998 and 2019 (except 2013). Y-axis shows the number of responses to tape which varies widely between plots, X-axis ranges from 1998 to 2019 on all plots. 
As shown above, the total numbers of Manx Shearwater responses to tape playback and puffin population counts are both significantly increasing overall, and although not all sites are increasing, all coastal plots are. To investigate whether shearwaters are being outcompeted at coastal sites the yearly plots used for playback census were categorised as coastal or inland (Fig 14). When the number of shearwater responses is categorised by location, both show a significant, positive increase.

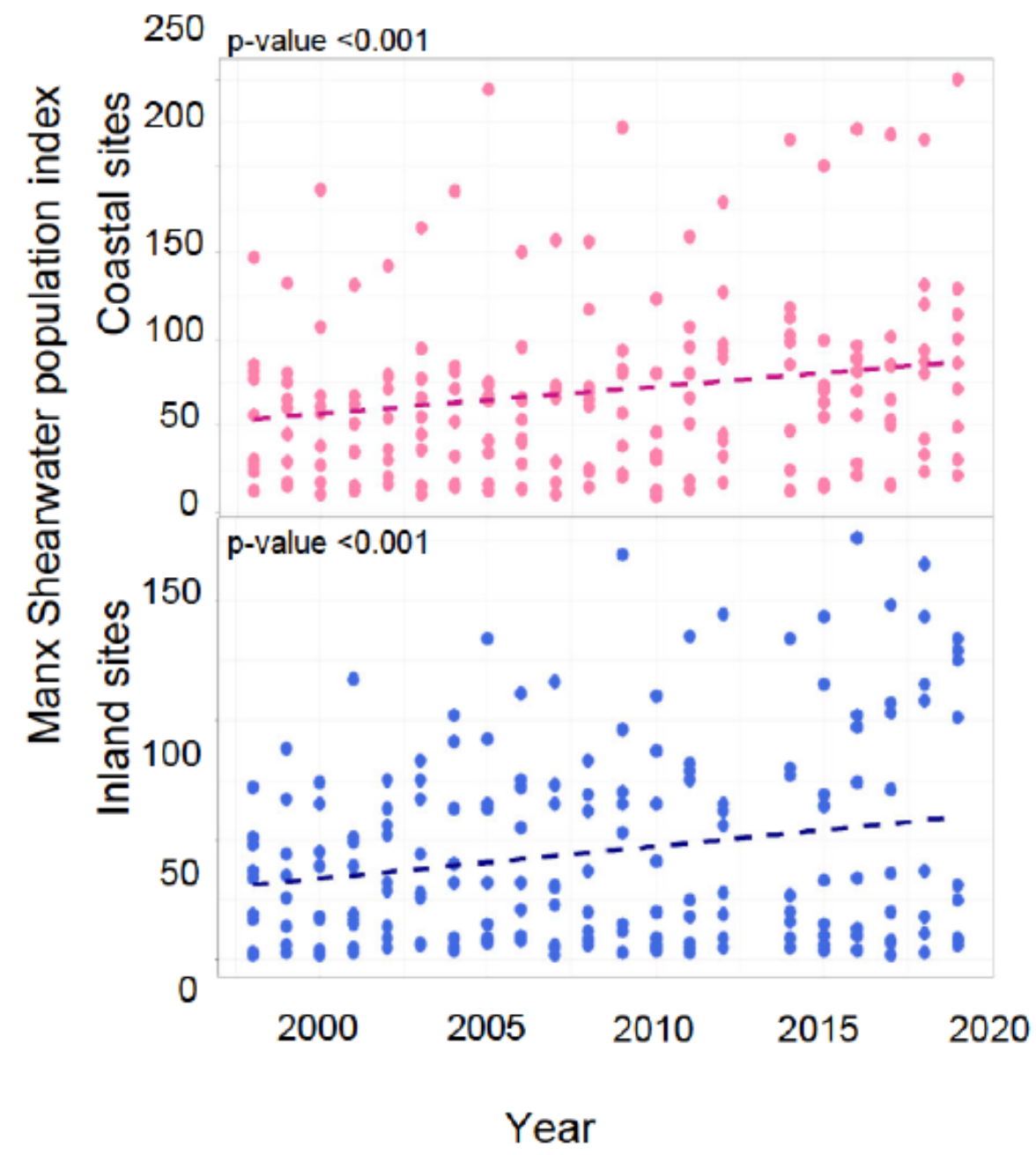

Figure 14. Manx Shearwater coastal and inland playback responses

Both sites show a significant increase in responses over time, overall coastal sites had a higher response rate than inland sites, suggesting there are more shearwaters at the coast than inland.

When each of the 18 plots is visualised in a box-plot, Fig 15, the difference in responses between plots is highlighted. In general, the plots with a lower number of responses show a greater consistency between years (plots $A, B, E, F, G, H$, and Q). 


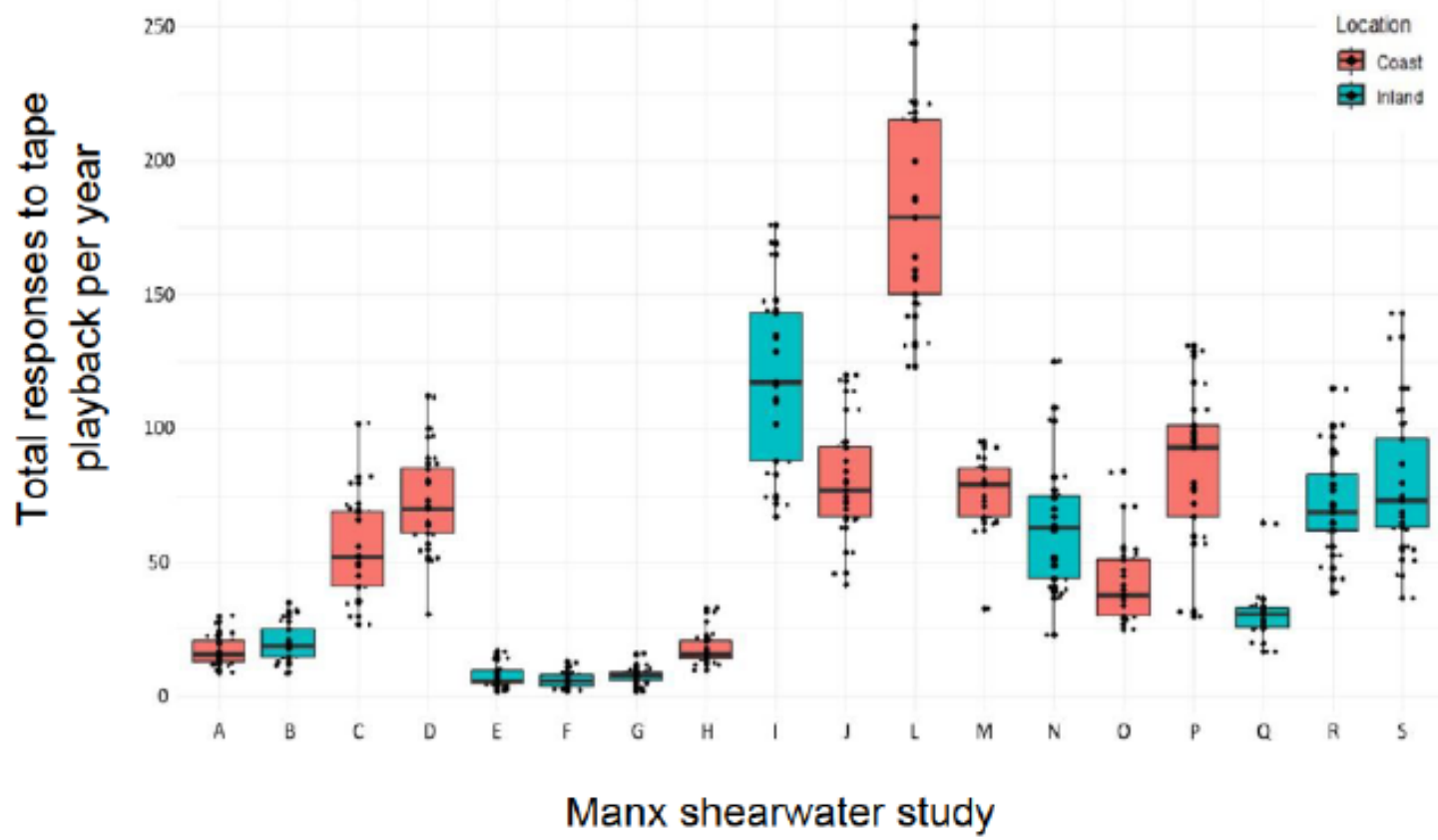

Figure 15 Boxplot: population variation between 18 Manx Shearwater sample plots and colour coded by location

Overall, there were a greater number of responses at coastal sites (parameter estimate $=14.055, p$ $<0.001, r$-squared $=0.596$ ) compared with inland sites (parameter estimate $=12.125, p<0.001, r$ squared $=0.727$ ).

If puffins were outcompeting shearwaters it would be expected that the trend in playback responses would differ between coastal and inland sites. This comparison shows that not only is this not the case but that shearwaters occur at higher numbers on the coast and are increasing at a significant rate.

\subsubsection{Manx Shearwater whole island census}

Shearwater playback plots are used as a proxy for a whole island survey as it not possible to undertake a full survey each year. The full survey has been carried out three times, 1998, 2011 and 2018. It is thought that the 1998 survey underestimated the population size, however between 2011 and 2018 there was a 10.65\% increase apparently occupied burrows. Using the playback response technique to estimate population increase for the same time period showed a $28.93 \%$ increase in the number of responses (1113 in 2011 to 1418 in 2019) which is a far higher increase. Ideally more detailed analysis would have been carried out using Puffin count data from around the island, specific Shearwater plots could have been matched with Puffin population data, however this data was not available. As shown above, although basic, there does not seem to be any obvious evidence to suggest puffins are outcompeting shearwaters as both populations are increasing. 


\subsection{Discussion}

At the level of analysis possible with the data provided, there is no evidence to suggest that puffins are contributing to the decrease in colony-level shearwater reproductive success at the Isthmus. Shearwater reproductive success has been demonstrated to be significantly higher in colonies without puffins, and there is no doubt that puffin numbers have increased across the island, and in the areas within and around the Isthmus (Ashcroft 1976).

The restricted scope of this research can only comment on the overall population trends and the overall reproductive success of both species between years. To really understand whether puffins are contributing to the decreasing reproductive success of Manx Shearwaters a detailed study needs to be carried out. Given that a working protocol is available and has been used in the past, Ashcroft 1976, this would be possible and is something that could be undertaken by a long-term volunteer as part of their training on Skomer.

What can be concluded, is that even if competition is occurring, both species are experiencing population increases on Skomer. The trend in shearwater productivity on Skokholm, where puffins do not occur in the study plots, may lead to the suggestion that puffins are playing a role on Skomer. However, they are different islands and there are a huge number of factors that were not taken into account and this result should not be considered in isolation.

\subsection{Inter-specific competition}

There is concern on Skomer that over the last 10 years or so shearwater productivity at the Isthmus colony is decreasing and that inter-specific competition from puffins competing for burrows may be a large part of the problem. It is a reasonable and logical explanation as puffins are increasing at a remarkable rate which does not conform to the national and international trends for this species (Stubbings et al. 2018). Puffins are very visible when they attend the colony, loafing around on the surface in their thousands during the evenings throughout the breeding season, and anyone who has been to the island regularly in the last few years will have noticed the increase in numbers and how the colonies have spread.

The Isthmus has been monitored as a Manx Shearwater breeding colony for over 25 years, and anecdotal evidence suggests that during this time the number of 
puffins within the colony has increased, as well as their spread from the edges of the colony into the centre. Burrow disputes are known to happen, and both species evict one another from their burrows, however the only time this is observed is during the day where confused and disorientated shearwaters are removed from a burrow. The reverse action must occur during the night and go unobserved, potentially causing observer bias contributing to the hypothesis that decreasing shearwater reproductive success is caused by Puffins, opposed to it being a natural system of competition.

Thorough research carried out in 1976 by Ashcroft looked at the relationship between puffins and shearwaters and the possibility of competition between the two species for nesting sites. Since this time the populations of both species have increased significantly, and it is therefore a reasonable assumption that any competition between the species may now be of higher intensity.

Inter-specific competition was shown to have a negative impact on productivity of both species, which was caused by a lack of available burrows, causing adults to skip breeding, but also caused loss of eggs within burrows which were damagedor removed by prospecting birds of both species (Ashcroft 1976; 1979). The conclusion of Ashcroft's (1976) work suggested that puffins may have a slight competitive advantage over shearwaters, but that competition had the potential to affect puffin population dynamics to a greater extent as post-fledging survival is lower in puffins and shearwaters breed more successfully inland where puffins will not nest.

In 2019, 43 years after Ashcroft's study (1976), it is clear that both species have not been adversely affected by competition given their current population trends. The superior competitive ability of puffins in mixed, coastal colonies and the increased productivity of shearwaters at inland nest sites may be a contributor to this increase, or it may be that there has been an increase in recruitment to the colonies as puffin reproductive success has increased by nearly $10 \%$ since the 1970 s (1973-1975 average reproductive success $=0.65,2010-2018$ average reproductive success $=$ 0.74) (Ashcroft 1976, 1979; Buche et al. 2013; Stubbings et al. 2014; 2015; 2016; 2017; 2018; Taylor et al. 2010; 2011; 2012).

The specific effects that competition is having on both species' productivity is unknown. Shearwater productivity at the Isthmus has shown a slight downward trend between 1995 and 2019, although this is not significant. This trend in productivity contrasts with the neighbouring island of Skokholm, where the 
productivity estimates come from plots without puffins (Fig 10), although there are many more differences between the Islands. The reproductive success is calculated from three separate colonies on Skokholm and there is a possibility that shearwaters on Skomer and Skokholm forage in different areas, which could have considerable impact on reproductive success (Guilford et al. 2008).

The main component of productivity that is declining is fledging success, and it seems unlikely that competition from puffins is having an effect at this stage. By the time shearwater chicks hatch puffins will already be feeding large chicks and will no longer be prospecting for burrows. Where competition may be affecting shearwaters is at the beginning of the season when both species arrive to claim a burrow, something that is not monitored currently on Skomer.

What is encouraging is that both species appear to be faring incredibly well. Puffins in particular appear to be struggling in the UK, especially in the North Sea where crashes in sand eel stocks, decreases in adult survival, increases in immature mortality and a negative association with increasing SST are causing population declines (Harris and Wanless 2011; Frederiksen et al. 2006; Lahoz-Monfort et al. 2011). Research focussed on the Celtic Sea by Lauria et al. (2012) found that puffin reproductive success over 20 years is not related to any of the climatic indices tested, and that although the effects of climate change are not fully understood it is clear the impacts being felt in the North Sea are not yet being felt here.

It is likely that there is enough space and suitable habitat on Skomer for both species to continue to increase. Puffins underwent a significant decline on Skomer, the population was thought to be in excess of 50,000 pairs in 1946 before crashing to just 5,000 in 1963 (Harris and Wanless 2011). Shearwaters are inherently more difficult to count than puffins, in 1946 shearwaters were estimated to number 25,000 pairs, which increased to 95,000 in 1971 when different methods were implemented (Brooke 1990; Corkhill 1973).

Both populations are significantly higher than they were 50 years ago, and it seems unlikely that competition between species is having an adverse effect on either of them. What is more concerning is the threats posed by climate change and although the full consequences, such as increased SST, and the associated effects are not being fully felt on Skomer, yet it seems inevitable that in the near future they will be. 


\subsubsection{Competition and reproductive success}

As demonstrated experimentally by Ashcroft, there are adults of breeding age of both species that do not have a burrow to nest in, this is a very clear indication that the competition for burrows is reducing the reproductive potential of these populations (1976). Interactions between species also directly affect productivity, shearwaters cause at least $5-10 \%$ of puffin eggs to be broken or lost during exploration and prospecting, and prospecting puffins also cause the same problems for incubating shearwaters (Ashcroft 1976). Shearwaters also show a significantly lower productivity within puffin colonies than in colonies exclusively occupied by shearwaters (Ashcroft 1976).

Ashcroft's careful monitoring of the burrows showed that burrow occupancy shifted regularly between years, with the number of evictions by puffins and shearwaters relatively equal. However, as puffin numbers started to increase during her study it was suggested that puffins may then have a slight competitive advantage. The cost of competition may have more of an effect on puffins as the rate of post-fledging survival is significantly lower than shearwaters $(30 \%)$ and therefore the $5-10 \%$ loss of eggs caused by shearwater interference may have a long-term population impact. Shearwaters high adult and post-fledging survival mean that they may be able to compensate for reduced productivity with increased recruitment back to the colony, and away from puffin occupied areas productivity is $70 \%$, this is high enough to maintain and even increase numbers.

\subsubsection{Disease and parasites}

Direct competition from puffins is not the only way in which this species can influence shearwater reproductive success, another aspect to consider is the effect of disease and parasites. After a season of field work studying both shearwaters and puffins it is obvious that puffin burrows are not as clean as shearwater burrows, with a lot more faecal matter inside the burrows of puffins. Anecdotal evidence from a field season also suggests that parasite load is far greater for puffins than shearwaters. It is common to see ticks on puffins, sometimes in very high numbers, but shearwaters do not seem to suffer as much (Personal observation).

Ticks are mostly found on shearwaters in areas where puffins and shearwaters both breed, which suggests that puffins are the source of ticks (Brooke 1990). This indirect impact of an increasing puffin population could be easily measured if all 
shearwater chicks in the study plot are systematically checked at some point during the breeding season.

\subsubsection{Possible mitigation of competition}

Multiple species using the same nesting habitat is not a characteristic that is restricted to Skomer. Bolton et al. (2004) studied Madeiran storm petrels (Oceanodroma castro) on the Azores and found that inter-specific competition may be affecting their productivity, when nest-boxes were introduced productivity increased and the population increased by $28 \%$ over two years. This paper and other similar studies have shown that the use of nest boxes can mitigate the effects of competition, especially when the species in competition are of different sizes, as bigger species can be excluded from artificial nest-boxes (Ramos et al. 1997). Part of Ashcroft's work included using artificial burrows to identify if a shortage of burrow space was contributing to competition, she found that both species readily took to the artificial burrows (1976). If further research suggests that competition is negatively affecting either species the use of artificial burrows is an option, and this is already being carried out on other islands, such as Ramsey Island. 


\section{Chapter 5 - Overall discussion}

\subsection{Future directions}

The effects of climate change are certainly more complicated than can be explained by one effect such as extreme weather (Michielsen et al. 2019; Mitchell et al. 2020). Other studies have highlighted the indirect effects of climate change on shearwaters so future studies might focus on this (as well as direct effects such as weather) in order to identify how the different forms of climate change interact and whether their effects are additive. It is likely that increases in sea surface temperature will continue to affect the marine ecosystem, and it may be that the areas around Skomer will become affected to the same extent as other areas such as the North Sea, and the impacts will become more profound (Lauria et al 2012; 2013). In such a scenario, and if extreme weather increased as predicted the effects of climate change may pose a very real threat to shearwaters on Skomer.

Going forward model averaging should be used on all 'top' models in each scenario, given the time constraints of this research it was not possible here, but this method will be used on this data in the future.

There is potential for more detailed study in this population, the identification of known age birds and the use of molecular techniques to sex individuals would allow more detailed analysis to further disentangle the demographic effects on reproductive success. In addition, using the length of time a pair has been together as a fixed effect, as used by Mauck et al. (2018), would show the direct impact of experience on reproductive success. The inclusion of other factors such as burrow identity and burrow-specific features may increase the explanatory power of these models. Multiple studies have shown that burrow quality, aspect and depth have implication for reproductive success in shearwaters and petrels (Fagundes et al. 2016; Fricke et al. 2015; Thompson and Furness 1991).

As is the case for many long-lived species, adult survival is more important for population persistence and growth than reproductive success (Jenouvrier et al. 2005; Sandvik et al. 2005). Survival in adult Manx Shearwaters is thought to be most threatened by overfishing and climate change and this may be of greater concern for the ongoing conservation of this species (Burthe et al. 2014; Perrins et al. 1973). 


\subsection{Importance of long-term datasets}

A key point that has become apparent when conducting this research is the importance of detailed long-term monitoring, especially in long-lived species with low fecundity such as seabirds where parent identity plays such an important role in reproductive success (Mauck et al. 2018; Oro et al. 2010). Chapter 3, part 1, results showed that over time shearwater productivity is not strongly associated with weather variables, and that there is no trend in the last 25 years. In the second chapter I was able to show using individual-level data based on ring recoveries and the use of the same study plot over nearly 30 years, that weather is significantly related to shearwater productivity and that pair identity is an important factor in reproductive success. In many seabirds, if adults do not reach sufficient condition to breed or if conditions are sufficiently poor, they will forgo breeding in favour of their own survival, which contributes their very high adult survival rate (Cubaynes et al. 2010). If experienced breeders skip breeding in a given year, there will be more burrows available for inexperienced birds, which may influence the overall reproductive output of the colony. Given that birds are so faithful to their breeding site it may be possible to detect breeders which are skipping years and identify if skipping is associated with environmental conditions at the colony or linked to overwintering conditions.

It is imperative that this study be continued alongside the effort to continue ringing birds to maintain a high proportion of known individuals within the colony, as without long-term studies it would impossible to disentangle the effects of environmental factors and demographic factors on reproductive success. Because field work is carried out every year to the same protocol, and thanks to the meticulous recording and maintenance of the database this research is possible. The importance and continued funding of these projects cannot be understated, and it is vital that going forward these protocols are maintained, and that all data collected is kept in all forms for future work.

Puffin monitoring on Skomer consists of population counts in early Spring and productivity monitoring during the summer. Puffin population counts are conducted in sections around the island, however in recent years the break-down of these areas was lost and the only figures available were total island counts, therefore it is not possible to accurately assess the change and spread of puffins around the island and the possible impact on different shearwater populations. It is clear from personal experience on the island and from speaking to the wardens that the puffin population 
is not evenly spread around the coast and there are significant hotspots. In the future if the break downs in puffin distribution are kept it would allow the population changes to be mapped and this data can be analysed with shearwater census data to identify whether competition may be occurring in some areas. In addition, between 2004 and 2019 North Haven puffin counts have been carried out separately, it would be beneficial to continue this work as this is the colony within which the shearwater study plot is located.

\subsection{Shearwater population trends on the Isthmus}

The population trend, in terms of numbers of breeding pairs or total number of shearwaters on the Isthmus is unknown. In each year, and in accordance with the Seabird Monitoring handbook, there is a target sample size of 100 active shearwater burrows. The number of monitored burrows ranges from 71 to 122 , with a 25 -year average of 95 . What is not taken into consideration is the amount of effort exerted by each field worker to find the number of burrows monitored each year, and therefore sample size cannot be used as a proxy for population level. This is something that could be considered when completing this field work in the future as there may be a vast difference in time spent in this task. If the effort were recorded it could provide at least a general overview of how well this colony is doing, how densely populated the Isthmus is with shearwaters and how this varies between years. When puffins are encountered in established monitoring burrows it is recorded, although these records are patchy, and it is not done in a systematic way. If this was recorded in detail the spread and density of puffin burrows within the colony could be monitored.

If Puffins numbers continue to increase it may be that the number of Manx Shearwater occupied burrows on the Isthmus decreases and it is more difficult to achieve the target of 100 burrows set out in the Seabird Monitoring Handbook (Walsh et al. 1995). A further use of the current data could be to identify the optimum number of burrow samples, i.e. the lowest number of burrows sampled that would provide the same results in terms of calculating reproductive success. Using data simulations which could be run with accumulating sub-samples of the available data, an accumulation curve could be plotted whereby the asymptote is used to identify the minimum number of burrows sampled. This process would therefore maximise monitoring efficiency by reducing the amount of fieldwork effort required. This sort of approach has been applied to other areas of seabird research, such as during the 
surveying of storm-petrels.

Although there is no direct way to measure the amount of effort put into finding shearwater burrows fieldworker effort can be assessed indirectly using encounter probability as a proxy. As shearwaters are incredibly site faithful and they have a high survival rate there is a high probability that if they have returned to breed, they will be found during productivity monitoring. Encounter probability is a reasonable estimate of the effort put in to find shearwaters, and this could be calculated in the future.

An important consideration when using this data is the role of the field worker that collects this data. During some periods there is high consistency in personnel carrying out the fieldwork, and during these times it is likely that the quality of the recording and field work itself is the same during these years. At other times there has been a higher turnover of fieldworkers carrying out the study, many of these doing this sort of work for the first time and this may lead to a greater disparity in the effort and quality of data collected.

\subsection{Moving the study plot}

It has been suggested that the study plot for Manx Shearwater reproductive success be moved as there are doubts as to whether this plot is representative of the whole island. There is basis to this suggestion as reproductive success is decreasing, however the reasons for this are unknown and the decrease is not significant. There are many factors that have not been considered in this study, or shown in others, which is why serious considerations should be made before undertaking such action.

Before any changes are made it should be considered that the decrease in reproductive success on the Isthmus is part of a natural fluctuation, or that success varies widely between habitat types, coastal vs inland, flat vs slope. It may be that as the shearwater population is increasing the island may be reaching carrying capacity and a reduction in success is caused by intraspecific competition for burrows. The intention is that the Isthmus plot will be extended to include a new plot at the Lime Kiln which has similar habitat characteristics but currently no Puffins.

This study cannot conclusively say that the study plot should be moved or remain at the Isthmus, or that there is any reason to conclude that puffin competition is having an effect on reproductive success. More research will be required to do this. 
1. Manx Shearwater reproductive success has shown a slight decrease over the study period which does not seem to be caused by weather.

2. It is likely that the indirect effects of climate change that are mediated through the food web will be a greater threat to shearwater reproductive success (Riou et al. 2011).

3. It is possible that the opposing trends shown by individual and colony-level analysis are caused by differences in demographic between each sample, and that experienced individuals can buffer the effects of climatic variability.

4. Weather, extreme or not, is not the most significant factor in determining reproductive success of Manx Shearwaters on Skomer. What is more likely is that the effects of climate change, indirect and direct, will interact to have many complex effects, especially if predictions regarding ongoing climate change are met (Michielson et al. 2019).

5. The populations of Manx Shearwaters and Atlantic Puffins on Skomer are both increasing. This study found no evidence of inter-specific competition, although more detailed research could be carried out. 


\section{Chapter 6 - References}

Aebischer, N.J., 1993. Immediate and delayed effects of a gale in late spring on the breeding of the shag Phalacrocorax aristotelis. Ibis, 135(3), pp.225-232.

Aebischer, N.J., Coulson, J.C. and Colebrookl, J.M., 1990. Parallel long-term trends across four marine trophic levels and weather. Nature, 347(6295), p.753.

Allison, S.D. and Vitousek, P.M., 2004. Rapid nutrient cycling in leaf litter from invasive plants in Hawai'i. Oecologia, 141(4), pp.612-619.

Anderson, O.R., Small, C.J., Croxall, J.P., Dunn, E.K., Sullivan, B.J., Yates, O. and Black, A., 2011. Global seabird bycatch in longline fisheries. Endangered Species Research, 14(2), pp.91-106.

Anker-Nilssen, T. and Røstad, O.W., 1993. Census and monitoring of Puffins Fratercula arctica on Røst, N Norway, 1979-1988. Ornis Scandinavica, pp.1-9.

Ashcroft, R. E. 1976. Breeding biology and survival of Puffins. - Unpubl. D. Phil. thesis, Oxford Uni.

Ashcroft, R.E., 1979. Survival rates and breeding biology of puffins on Skomer Island, Wales. Ornis Scandinavica, pp.100-110.

Avery-Gomm, S., Provencher, J.F., Liboiron, M., Poon, F.E. and Smith, P.A., 2018. Plastic pollution in the Labrador Sea: an assessment using the seabird northern fulmar Fulmarus glacialis as a biological monitoring species. Marine pollution bulletin, 127, pp.817-822.

Barton, L. 2018. MuMIn: Multi-Model Inference. R package version 1.42.1.

\section{https://CRAN.R-project.org/package=MuMln}

Bancroft, W.J., Roberts, J.D. and Garkaklis, M.J., 2005. Burrow entrance attrition rate in wedge-tailed shearwater Puffinus pacificus colonies on Rottnest Island, Western Australia. Marine Ornithology, 33(1), pp.23-26.

Beaugrand, G. and Kirby, R.R., 2018. How do marine pelagic species respond to climate change? Theories and observations. Annual review of marine science, 10, pp.169-197.

Beaugrand, G. and Reid, P.C., 2003. Long-term changes in phytoplankton, zooplankton and salmon related to climate. Global Change Biology, 9(6), pp.801-817.

BirdLife International. 2016. Puffinus puffinus. The IUCN Red List of Threatened

Species 2016: e.T22698226A86238815. $\underline{\text { http://dx.doi.org/10.2305/ }}$ IUCN.UK.2016- 3.RLTS.T22698226A86238815.en. Downloaded on 15 March 2018. 
BirdLife International. 2017. Rissa tridactyla. The IUCN Red List of Threatened Species 2017: e.T22694497A118366481. http://dx.doi.org/10.2305/IUCN.UK.20173.RLTS.T22694497A118366481.en. Downloaded on 15 March 2018.

Birkhead, T. (2014). The Seabird Wreck of 2014. [online] Ten Thousand Birds. Available at: https://myriadbirds.com/resources/essays/the-seabird-wreck-of-2014/[Accessed 29 Mar. 2018].

Blake, B.F., 1984. Diet and fish stock availability as possible factors in the mass death of auks in the North Sea. Journal of Experimental Marine Biology and Ecology, 76(2), pp.89103.

Boersma, P.D., Clark, J.A. and Hillgarth, N., 2002. Seabird conservation. Biology of marine birds, pp.559-579.

Boersma, P.D. and Rebstock, G.A., 2014. Climate change increases reproductive failure in Magellanic penguins. Plos one, 9(1), p.e85602.

Bolton, M., Medeiros, R., Hothersall, B. and Campos, A., 2004. The use of artificial breeding chambers as a conservation measure for cavity-nesting procellariiform seabirds: a case study of the Madeiran storm petrel (Oceanodroma castro). Biological Conservation, 116(1), pp.73-80.

Brooke, M.D.L., 1978. Some factors affecting the laying date, incubation and breeding success of the Manx Shearwater, Puffinus. The Journal of Animal Ecology, pp.477-495.

Brooke, M., 1990. The Manx shearwater. $1^{\text {st }}$ ed. London: T. \& A. D. Poyser.

Brown, R. Skokholm Island Warden. (Personal Communication, October 2019).

Brown, R. and Eagle, G. (2018) Skokholm Seabird Report 2018. Online report for the Wildlife Trust of South and WestWales. www.welshwildlife.org/about-us/skokholm-reports/ Brown, R. and Eagle, G. (2017) Skokholm Seabird Report 2018. Online report for the Wildlife Trust of South and West Wales. www.welshwildlife.org/about-us/skokholm-reports/ Brown, R. and Eagle, G. (2016) Skokholm Seabird Report 2018. Online report for the Wildlife Trust of South and West Wales. www.welshwildlife.org/about-us/skokholm-reports/ Brown, R. and Eagle, G. (2015) Skokholm Seabird Report 2018. Online report for the Wildlife Trust of South and West Wales. www.welshwildlife.org/about-us/skokholm-reports/ Brown, R. and Eagle, G. (2014) Skokholm Seabird Report 2018. Online report for the Wildlife Trust of South and West Wales. www.welshwildlife.org/about-us/skokholm-reports/ Brown, R. and Eagle, G. (2013) Skokholm Seabird Report 2018. Online report for the Wildlife Trust of South and West Wales. www.welshwildlife.org/about-us/skokholm-reports/ 
Büche, BI, Stubbings, EM, Boyle, D. and Perrins, CM, Yates, L. (2013) Seabird monitoring on Skomer Island in 2013.JNCC Report.

Bugoni, L., Sander, M. and Costa, E.S., 2007. Effects of the first southern Atlantic hurricane on Atlantic petrels (Pterodroma incerta). The Wilson Journal of Ornithology, 119(4), pp.725730.

Burthe, S.J., Wanless, S., Newell, M.A., Butler, A. and Daunt, F., 2014. Assessing the vulnerability of the marine bird community in the western North Sea to climate change and other anthropogenic impacts. Marine Ecology Progress Series, 507, pp.277-295.

Cam, E., Monnat, J.Y. and Hines, J.E., 2003. Long-term fitness consequences of early conditions in the kittiwake. Journal of Animal Ecology, 72(3), pp.411-424.

Camphuysen, C.J. and Garthe, S., 2000. Seabirds and commercial fisheries: population trends of piscivorous seabirds explained. Effects of fishing on non-target species and habitats, pp.163-184.

Capuzzo, E., Lynam, C.P., Barry, J., Stephens, D., Forster, R.M., Greenwood, N., McQuatters-Gollop, A., Silva, T., van Leeuwen, S.M. and Engelhard, G.H., 2018. Adecline in primary production in the North Sea over 25 years, associated with reductions in zooplankton abundance and fish stock recruitment. Global change biology, 24(1), pp.e352e364.

Carroll, M.J., Butler, A., Owen, E., Ewing, S.R., Cole, T., Green, J.A., Soanes, L.M., Arnould, J.P.Y., Newton, S.F., Baer, J. and Daunt, F., 2015. Effects of sea temperature and stratification changes on seabird breeding success. Climate Research, 66(1), pp.75-89.

Ceballos, G., Ehrlich, P.R. and Dirzo, R., 2017. Biological annihilation via the ongoing sixth mass extinction signaled by vertebrate population losses and declines. Proceedings of the National Academy of Sciences, 114(30), pp. E6089-E6096.

Chambers, L.E., Devney, C.A., Congdon, B.C., Dunlop, N., Woehler, E.J. and Dann, P., 2011. Observed and predicted effects of climate on Australian seabirds. Emu, 111(3), pp.235-251.

Clark, J.A., Robinson, R.A., Balmer, D.E., Adams, S.Y., Collier, M.P., Grantham, M.J., Blackburn, J.R. and Griffin, B.M., 2004. Bird ringing in Britain and Ireland in 2003. Ringing \& Migration, 22(2), pp.85-127.

Clay, T., Small, C., Tuck, G.N., Pardo, D., Carneiro, A.P., Wood, A., Croxall, J.P., Crossin, G.T. and Phillips, R., 2019. A comprehensive assessment of fisheries bycatch risk for threatened seabird populations. Journal of Applied Ecology. 
Cleeland, J.B., Pardo, D., Raymond, B. et al. Introduced species and extreme weather as key drivers of reproductive output in three sympatric albatrosses. Sci Rep 10, 8199 (2020). Cohen, J., Pfeiffer, K. and Francis, J.A., 2018. Warm Arctic episodes linked with increased frequency of extreme winter weather in the United States. Nature communications, 9(1), p.869.

Corkhill, P., 1973. Food and feeding ecology of puffins. Bird Study, 20(3), pp.207-220.

Coulson, J.C. and Porter, J.M., 1985. Reproductive success of the kittiwake Rissa tridactyla: the roles of clutch size, chick growth rates and parental quality. Ibis, 127(4), pp.450-466.

Courchamp, F., Chapuis, J.L. and Pascal, M., 2003. Mammal invaders on islands: impact, control and control impact. Biological Reviews, 78(3), pp.347-383.

Crawford, R.J., Makhado, A.B. and Oosthuizen, W.H., 2018. Bottom-up and top-down control of the Benguela ecosystem's seabirds. Journal of Marine Systems, 188, pp.133141.

Croxall, J.P., Butchart, S.H., Lascelles, B.E.N., Stattersfield, A.J., Sullivan, B.E.N., Symes, A. and Taylor, P.H.I.L., 2012. Seabird conservation status, threats and priority actions: a global assessment. Bird Conservation International, 22(1), pp.1-34.

Cubaynes, S., Doherty Jr, P.F., Schreiber, E.A. and Gimenez, O., 2010. To breed or not to breed: a seabird's response to extreme climatic events. Biology Letters, 7(2), pp.303-306.

Cuthbert, R.J., 2005. Breeding biology, chick growth and provisioning of Great shearwaters (Puffinus gravis) at Gough Island, South Atlantic Ocean. Emu-Austral Ornithology, 105(4), pp.305-310.

Daskalov, G.M., Grishin, A.N., Rodionov, S. and Mihneva, V., 2007. Trophic cascades triggered by overfishing reveal possible mechanisms of ecosystem regime shifts. Proceedings of the National Academy of Sciences, 104(25), pp.10518-10523.

Daunt, F., Afanasyev, V., Silk, J.R.D. and Wanless, S., 2006. Extrinsic and intrinsic determinants of winter foraging and breeding phenology in a temperate seabird. Behavioral Ecology and Sociobiology, 59(3), pp.381-388.

Daunt, F. and Mitchell, I., 2013. Impacts of climate change on seabirds. MCCIP Science Review, 2013, pp.125-133.

Davies, R.W.D., Cripps, S.J., Nickson, A. and Porter, G., 2009. Defining and estimating global marine fisheries bycatch. Marine Policy, 33(4), pp.661-672.

Dias, M.P., Martin, R., Pearmain, E.J., Burfield, I.J., Small, C., Phillips, R.A., Yates, O., Lascelles, B., Borboroglu, P.G. and Croxall, J.P., 2019. Threats to seabirds: a global 
assessment. Biological Conservation.

Dye, S.R., Hughes, S.L., Tinker, J., Berry, D.I., Holliday, N.P., Kent, E.C., Kennington, K., Inall, M., Smyth, T., Nolan, G. and Lyons, K., 2013. Impacts of climate change on temperature (air and sea). MCCIP Science Review, 2013, pp.1-12.

Easterling, D.R., Meehl, G.A., Parmesan, C., Changnon, S.A., Karl, T.R. and Mearns, L.O., 2000. Climate extremes: observations, modeling, and impacts. science, 289(5487), pp.2068-2074.

Eaton, M., Aebischer, N., Brown, A., Hearn, R., Lock, L., Musgrove, A., Noble, D., Stroud, D. and Gregory, R., 2015. Birds of Conservation Concern 4: the population status of birds in the UK, Channel Islands and Isle of Man. British Birds, 108(12), pp.708-746.

Encyclopedia.com. (2018). Extreme Weather | Encyclopedia.com. [online] Available at: https://www.encyclopedia.com/environment/energy-government-and-defensemagazines/extreme-weather [Accessed 14 Sep. 2018].

Fagundes, A.I., Ramos, J.A., Ramos, U., Medeiros, R. and Paiva, V.H., 2016. Breeding biology of a winter-breeding procellariiform in the North Atlantic, the Macaronesian Shearwater Puffinus Iherminieri baroli. Zoology, 119(5), pp.421-429.

Finney, S.K., Wanless, S. and Harris, M.P., 1999. The effect of weather conditions on the feeding behaviour of a diving bird, the Common Guillemot Uria aalge. Journal of Avian Biology, pp.23-30.

Frederiksen, M., Daunt, F., Harris, M.P. and Wanless, S., 2008a. The demographic impact of extreme events: stochastic weather drives survival and population dynamics in a longlived seabird. Journal of Animal Ecology, 77(5), pp.1020-1029.

Frederiksen, M., Edwards, M., Richardson, A.J., Halliday, N.C. and Wanless, S., 2006. From plankton to top predators: bottom-up control of a marine food web across four trophic levels. Journal of Animal Ecology, 75(6), pp.1259-1268.

Frederiksen, M., Edwards, M., Mavor, R.A. and Wanless, S., 2007. Regional and annual variation in black-legged kittiwake breeding productivity is related to sea surface temperature. Marine Ecology Progress Series, 350, pp.137-143.

Frederiksen, M., Jensen, H., Daunt, F., Mavor, R.A. and Wanless, S., 2008b. Differential effects of a local industrial sand lance fishery on seabird breeding performance. Ecological Applications, 18(3), pp.701-710.

Frederiksen, M., Wanless, S., Harris, M.P., Rothery, P. and Wilson, L.J., 2004. The role of industrial fisheries and oceanographic change in the decline of North Sea black-legged 
kittiwakes. Journal of Applied Ecology, 41(6), pp.1129-1139.

Fricke, E.C., Blizzard, K.M., Gannon, D.P. and Mauck, R.A., 2015. Model of burrow selection predicts pattern of burrow switching by Leach's Storm-Petrels. Journal of Field Ornithology, 86(4), pp.326-336.

Furness, R.W. and Tasker, M.L., 2000. Seabird-fishery interactions: quantifying the sensitivity of seabirds to reductions in sandeel abundance, and identification of key areas for sensitive seabirds in the North Sea. Marine Ecology Progress Series, 202, pp.253-264.

García-Barón, I., Santos, M.B., Uriarte, A., Inchausti, J.I., Escribano, J.M., Albisu, J., Fayos, M., Pis, J.A., Oleaga, Á., Mier, F.E.A. and Hernández, O., 2019. Which are the main threats affecting the marine megafauna in the Bay of Biscay?. Continental Shelf Research.

Gaston, A.J., Hipfner, J.M. and Campbell, D., 2002. Heat and mosquitoes cause breeding failures and adult mortality in an Arctic-nesting seabird. Ibis, 144(2), pp.185-191.

Graham, C.T. and Harrod, C., 2009. Implications of climate change for the fishes of the British Isles. Journal of Fish Biology, 74(6), pp.1143-1205.

Grant, P.R. and Nettleship, D.N., 1971. Nesting habitat selection by puffins Fratercula arctica L. in Iceland. Ornis Scandinavica, pp.81-87.

Gray, C.M. and Hamer, K.C., 2001. Food-provisioning behaviour of male and female Manx shearwaters, Puffinus puffinus. Animal Behaviour, 62(1), pp.117-121.

Grémillet, D. and Boulinier, T., 2009. Spatial ecology and conservation of seabirds facing global climate change: a review. Marine Ecology Progress Series, 391, pp.121-137.

Grémillet, D., Lewis, S., Drapeau, L., van Der Lingen, C.D., Huggett, J.A., Coetzee, J.C., Verheye, H.M., Daunt, F., Wanless, S. and Ryan, P.G., 2008. Spatial match-mismatch in the Benguela upwelling zone: should we expect chlorophyll and sea-surface temperature to predict marine predator distributions?. Journal of Applied Ecology, 45(2), pp.610-621.

Guilford, T., Meade, J., Freeman, R., Biro, D., Evans, T., Bonadonna, F., Boyle, D., Roberts, S. and Perrins, C.M., 2008. GPS tracking of the foraging movements of Manx Shearwaters Puffinus puffinus breeding on Skomer Island, Wales. Ibis, 150(3), pp.462-473.

Hanamseth, R., Barry Baker, G., Sherwen, S., Hindell, M. and Lea, M.A., 2018. Assessing the importance of net colour as a seabird bycatch mitigation measure in gillnet fishing. Aquatic Conservation: Marine and Freshwater Ecosystems, 28(1), pp.175-181.

Hanna, E., Hall, R.J. and Overland, J.E., 2017. Can Arctic warming influence UK extreme weather?. Weather, 72(11), pp.346-352.

Harris, M., Newell, M., Daunt, F., Speakman, J. and Wanless, S., 2008. Snake pipefish 
Entelurus aequoreus are poor food for seabirds. Ibis, 150(2), p.413.

Harris, M.P., 1966. Breeding biology of the Manx Shearwater Puffinus puffinus. Ibis, 108(1), pp.17-33.

Harris, M.P. and Wanless, S., 2011. The puffin. Bloomsbury Publishing.

Hatch, S.A., 1990. Individual variation in behavior and breeding success of Northern Fulmars. The Auk, 107(4), pp.750-755.

Hebbali, A. (2019). blorr: Tools for Developing Binary Logistic Regression Models. R package version 0.2.1. https://CRAN.R-project.org/package=blorr

Hennicke, J.C. and Flachsbarth, K., 2009. Effects of Cyclone Rosie on breeding red-tailed tropicbirds Phaethon rubricauda on Christmas Island, Indian Ocean. Marine Ornithology, 37, pp.175-178.

Hipfner, J.M., 2008. Matches and mismatches: ocean climate, prey phenology and breeding success in a zooplanktivorous seabird. Marine Ecology Progress Series, 368, pp.295-304. Hoegh-Guldberg, O., Mumby, P.J., Hooten, A.J., Steneck, R.S., Greenfield, P., Gomez, E., Harvell, C.D., Sale, P.F., Edwards, A.J., Caldeira, K. and Knowlton, N., 2007. Coral reefs under rapid climate change and ocean acidification. science, 318(5857), pp.1737-1742.

Huntington, C.E., Butler, R.G. and Mauck, R.A., 1996. Leach's Storm-petrel: Oceanodroma Leucorhoa. American Ornithologists' Union.

Jenouvrier, S., 2013. Impacts of climate change on avian populations. Global Change Biology, 19(7), pp.2036-2057.

Jenouvrier, S., Barbraud, C. and Weimerskirch, H., 2005. Long-term contrasted responses to climate of two Antarctic seabird species. Ecology, 86(11), pp.2889-2903.

Jensen, Ø., Dempster, T., Thorstad, E.B., Uglem, I. and Fredheim, A., 2010. Escapes of fishes from Norwegian sea-cage aquaculture: causes, consequences and prevention. Aquaculture Environment Interactions, 1(1), pp.71-83.

Jentsch, A., Kreyling, J. and Beierkuhnlein, C., 2007. A new generation of climate-change experiments: events, not trends. Frontiers in Ecology and the Environment, 5(7), pp.365374.

Jiménez, S., Domingo, A., Forselledo, R., Sullivan, B.J. and Yates, O., 2018. Mitigating bycatch of threatened seabirds: the effectiveness of branch line weighting in pelagic longline fisheries. Animal Conservation. 
Nature Conservation Committee. Updated September 2016.

Kaiser, G.W. and Forbes, L.S., 1992. Climatic and oceanographic influences on island use in four burrow-nesting alcids. Ornis Scandinavica, pp.1-6.

Kennedy, R.J., 1970. Direct effects of rain on birds: a review. British Birds, 63, pp.401-414. Keogan, K., Daunt, F., Wanless, S., Phillips, R.A., Walling, C.A., Agnew, P., Ainley, D.G., Anker-Nilssen, T., Ballard, G., Barrett, R.T. and Barton, K.J., 2018. Global phenological insensitivity to shifting ocean temperatures among seabirds. Nature Climate Change, 8(4), p.313.

Kildaw, S.D., 1999. Effect of wind on the growth rate of kittiwake chicks. Pacific Seabirds, Washington, 26.

Kulaszewicz, I. and Jakubas, D., 2018. Influence of nest burrow microclimate on chick growth in a colonial High-Arctic seabird, the little auk. Polar Research, 37(1), p.1547044.

Lahoz-Monfort, J.J., Morgan, B.J., Harris, M.P., Wanless, S. and Freeman, S.N., 2011. A capture-recapture model for exploring multi-species synchrony in survival. Methods in Ecology and Evolution, 2(1), pp.116-124.

Lauria, V., Attrill, M.J., Pinnegar, J.K., Brown, A., Edwards, M. and Votier, S.C., 2012. Influence of climate change and trophic coupling across four trophic levels in the Celtic Sea. PloS one, 7(10), p.e47408.

Lauria, V., Attrill, M.J., Brown, A., Edwards, M. and Votier, S.C., 2013. Regional variation in the impact of climate change: evidence that bottom-up regulation from plankton to seabirds is weak in parts of the Northeast Atlantic. Marine Ecology Progress Series, 488, pp.11-22.

Lebreton, L., Slat, B., Ferrari, F., Sainte-Rose, B., Aitken, J., Marthouse, R., Hajbane, S., Cunsolo, S., Schwarz, A., Levivier, A. and Noble, K., 2018. Evidence that the Great Pacific Garbage Patch is rapidly accumulating plastic. Scientific reports, 8(1), p.4666.

Lewison, R.L., Crowder, L.B., Read, A.J. and Freeman, S.A., 2004. Understanding impacts of fisheries bycatch on marine megafauna. Trends in ecology \& evolution, 19(11), pp.598604.

Liao, C., Peng, R., Luo, Y., Zhou, X., Wu, X., Fang, C., Chen, J. and Li, B., 2008. Altered ecosystem carbon and nitrogen cycles by plant invasion: a meta-analysis. New phytologist, 177(3), pp.706-714.

Lloyd, C., Tasker, M.L. and Partridge, K., 2010. The status of seabirds in Britain and Ireland. A\&C Black.

Louzao, M., Gallagher, R., García-Barón, I., Chust, G., Intxausti, I., Albisu, J., Brereton, T. 
and Fontán, A., 2019. Threshold responses in bird mortality driven by extreme wind events. Ecological indicators, 99, pp.183-192.

Lynam, C.P., Llope, M., Möllmann, C., Helaouët, P., Bayliss-Brown, G.A. and Stenseth, N.C., 2017. Interaction between top-down and bottom-up control in marine food webs. Proceedings of the National Academy of Sciences, 114(8), pp.1952-1957.

MacDonald, A., Heath, M.R., Edwards, M., Furness, R.W., Pinnegar, J.K., Wanless, S., Speirs, D. and Greenstreet, S., 2015. Climate driven trophic cascades affecting seabirds around the British Isles. Oceanogr. Mar. Biol. Annu. Rev, 53, pp.55-80.

Mangel, J.C., Wang, J., Alfaro-Shigueto, J., Pingo, S., Jimenez, A., Carvalho, F., Swimmer, Y. and Godley, B.J., 2018. Illuminating gillnets to save seabirds and the potential for multitaxa bycatch mitigation. Royal Society open science, 5(7), p.180254.

Mallory, M.L., Gaston, A.J., Forbes, M.R. and Gilchrist, H.G., 2009. Influence of weather on reproductive success of northern fulmars in the Canadian high Arctic. Polar Biology, 32(4), pp.529-538.

Matthews, G.V.T., 1954. Some aspects of incubation in the Manx Shearwater Procellaria puffinus, with particular reference to chilling resistance in the embryo. Ibis, 96(3), pp.432440.

Mauck, R.A., Dearborn, D.C. and Huntington, C.E., 2018. Annual global mean temperature explains reproductive success in a marine vertebrate from 1955 to 2010 . Global change biology, 24(4), pp.1599-1613.

McGregor, G.R., Ferro, C.A. and Stephenson, D.B., 2005. Projected changes in extreme weather and climate events in Europe. In Extreme Weather Events and Public Health Responses (pp. 13-23). Springer, Berlin, Heidelberg.

Met Office (2012): Met Office Integrated Data Archive System (MIDAS) Land and Marine Surface Stations Data (1853-current). NCAS British Atmospheric Data Centre, 13/08/2019. Michielsen, R.J., Ausems, A.N., Jakubas, D., Pętlicki, M., Plenzler, J., Shamoun-Baranes, J. and Wojczulanis-Jakubas, K., 2019. Nest characteristics determine nest microclimate and affect breeding output in an Antarctic seabird, the Wilson's storm-petrel. PloS one, 14(6), p.e0217708.

Milne, G.A., Gehrels, W.R., Hughes, C.W. and Tamisiea, M.E., 2009. Identifying the causes of sea-level change. Nature Geoscience, 2(7), p.471.

Mitchell, I., Daunt, F., Frederiksen, M. and Wade, K., 2020. Impacts of climate change on seabirds, relevant to the coastal and marine environment around the UK. 
Mitchell, P.I., Newton, S.F., Ratcliffe, N. and Dunn, T.E., 2004. Seabird populations of Britain and Ireland. $T$ \& AD Poyser, London.

Monteiro, L.R., Ramos, J.A. and Furness, R.W., 1996. Past and present status and conservation of the seabirds breeding in the Azores archipelago. Biological conservation, 78(3), pp.319-328.

Montevecchi, W.A., 2002. Interactions between fisheries and seabirds. Biology of marine birds, pp.527-557.

Morley, T.I., Fayet, A.L., Jessop, H., Veron, P., Veron, M., Clark, J. and Wood, M.J., 2016. The seabird wreck in the Bay of Biscay and South-Western Approaches in 2014: A review of reported mortality. Seabird, 29, pp.22-38.

Murphy, E.C., Hoover-Miller, A.A., Day, R.H. and Oakley, K.L., 1992. Intracolony variability during periods of poor reproductive performance at a Glaucous-winged Gull colony. The Condor, 94(3), pp.598-607.

Nagelkerke, N.J., 1991. A note on a general definition of the coefficient of determination. Biometrika, 78(3), pp.691-692.

Nakagawa, S. and Schielzeth, H., 2013. A general and simple method for obtaining R2 from generalized linear mixed-effects models. Methods in ecology and evolution, 4(2), pp.133142.

Nettleship, D.N., 1972. Breeding success of the Common Puffin (Fratercula arctica L.) on different habitats at Great Island, Newfoundland. Ecological Monographs, 42(2), pp.239268.

Nevoux, M., Forcada, J., Barbraud, C., Croxall, J. and Weimerskirch, H., 2010. Bet-hedging response to environmental variability, an intraspecific comparison. Ecology, 91(8), pp.24162427.

Newell, M., Wanless, S., Harris, M.P. and Daunt, F., 2015. Effects of an extreme weather event on seabird breeding success at a North Sea colony. Marine Ecology Progress Series, 532, pp.257-268.

Oro, D., de León, A., Minguez, E. and Furness, R.W., 2005. Estimating predation on breeding European storm-petrels (Hydrobates pelagicus) by yellow-legged gulls (Larus michahellis). Journal of Zoology, 265(4), pp.421-429.

Oro, D., Torres, R., Rodríguez, C. and Drummond, H., 2010. Climatic influence on demographic parameters of a tropical seabird varies with age and sex. Ecology, 91(4), 
pp.1205-1214.

Oswald, S.A., Bearhop, S., Furness, R.W., Huntley, B. and Hamer, K.C., 2008. Heat stress in a high-latitude seabird: effects of temperature and food supply on bathing and nest attendance of great skuas Catharacta skua. Journal of Avian Biology, 39(2), pp.163-169.

Oudi, A., Chokri, M.A., Hammouda, A., Chaabane, R., Badraoui, R., Besnard, A. and Santos, R., 2019. Physiological impacts of pollution exposure in seabird's progeny nesting in a Mediterranean contaminated area. Marine pollution bulletin, 142, pp.196-205.

Pachauri, R.K. and Reisinger, A., 2007. IPCC fourth assessment report. IPCC, Geneva, 2007.

Paleczny, M., Hammill, E., Karpouzi, V. and Pauly, D., 2015. Population trend of the world's monitored seabirds, 1950-2010. PloS one, 10(6), p.e0129342.

Palmer, T.N. and Räisänen, J., 2002. Quantifying the risk of extreme seasonal precipitation events in a changing climate. Nature, 415(6871), p.512.

Pardo, D., Jenouvrier, S., Weimerskirch, H. and Barbraud, C., 2017. Effect of extreme sea surface temperature events on the demography of an age-structured albatross population. Philosophical Transactions of the Royal Society B: Biological Sciences, 372(1723), p.20160143.

Peeler, E.J. and Murray, A.G., 2004. Disease interaction between farmed and wild fish populations. Journal of Fish Biology, 65, pp.321-322.

Perkins, A.J., Douse, A., Morgan, G., Cooper, A. and Bolton, M., 2017. Using dual-sex calls improves the playback census method for a nocturnal burrow-nesting seabird, the Manx Shearwater Puffinus puffinus. Bird Study, 64(2), pp.146-158.

Perkins, A., Ratcliffe, N., Suddaby, D., Ribbands, B., Smith, C., Ellis, P., Meek, E. and Bolton, M., 2018. Combined bottom-up and top-down pressures drive catastrophic population declines of Arctic skuas in Scotland. Journal of Animal Ecology, 87(6), pp.15731586.

Perrins, C.M., Harris, M.P. and Britton, C.K., 1973. Survival of Manx shearwaters Puffinus puffinus. Ibis, 115(4), pp.535-548.

Perrins, C.M., Wood, M.J., Garroway, C.J., Boyle, D., Oakes, N., Revera, R., Collins, P. and Taylor, C., 2012. A whole-island census of the Manx Shearwaters Puffinus puffinus breeding on Skomer Island in 2011. Seabird, 25, pp.1-13.

Piatt, J.F., Sydeman, W.J. and Wiese, F., 2007. Introduction: seabirds as indicators of marine ecosystems. Marine Ecology Progress Series, 352, pp.199-204. 
Price, C.A., Hartmann, K., Emery, T.J., Woehler, E.J., McMahon, C.R., and Hindell, M.A. 2020. Climate variability and breeding parameters of a transhemispheric migratory seabird over seven decades. Marine Ecology Progress Series, 642, pp.191-205.

R Development Core Team (2014). R: A language and environment for statistical computing. R Foundation for Statistical Computing, Vienna, Austria. ISBN 3-900051-07-0, URL http://www.R-project.org

Ramos, J.A., Monteiro, L.R., Sola, E. and Moniz, Z., 1997. Characteristics and competition for nest cavities in burrowing Procellariiformes. The Condor, 99(3), pp.634-641.

Read, P. and Fernandes, T., 2003. Management of environmental impacts of marine aquaculture in Europe. Aquaculture, 226(1-4), pp.139-163.

Richardson, A.J. and Schoeman, D.S., 2004. Climate impact on plankton ecosystems in the Northeast Atlantic. Science, 305(5690), pp.1609-1612.

Rindorf, A., Wanless, S. and Harris, M.P., 2000. Effects of changes in sandeel availability on the reproductive output of seabirds. Marine Ecology Progress Series, 202, pp.241-252.

Riou, S., Gray, C.M., Brooke, M.D.L., Quillfeldt, P., Masello, J.F., Perrins, C. and Hamer, K.C., 2011. Recent impacts of anthropogenic climate change on a higher marine predator in western Britain. Marine Ecology Progress Series, 422, pp.105-112.

Ripple, W.J., Wolf, C., Newsome, T.M., Barnard, P. and Moomaw, W.R., 2019. World Scientists' Warning of a Climate Emergency. BioScience.

Rodriguez, L.F., 2006. Can invasive species facilitate native species? Evidence of how, when, and why these impacts occur. Biological Invasions, 8(4), pp.927-939.

Rodway, M.S., Chardine, J.W. and Montevecchi, W.A., 1998. Intra-colony variation in breeding performance of Atlantic Puffins. Colonial Waterbirds, pp.171-184.

Roos, S., Smart, J., Gibbons, D.W. and Wilson, J.D., 2018. A review of predation as a limiting factor for bird populations in mesopredator-rich landscapes: a case study of the UK. Biological Reviews, 93(4), pp.1915-1937.

Sæther, B.E. and Bakke, Ø., 2000. Avian life history variation and contribution of demographic traits to the population growth rate. Ecology, 81(3), pp.642-653.

Sandvik, H., Erikstad, K.E., Barrett, R.T. and Yoccoz, N.G., 2005. The effect of climate on adult survival in five species of North Atlantic seabirds. Journal of Animal Ecology, 74(5), pp.817-831.

Santora, J.A., Reiss, C.S., Cossio, A.M. and Veit, R.R., 2009. Interannual spatial variability of krill (Euphausia superba) influences seabird foraging behavior near Elephant Island, 
Antarctica. Fisheries Oceanography, 18(1), pp.20-35.

Scheffer, M., Carpenter, S. and de Young, B., 2005. Cascading effects of overfishing marine systems. Trends in Ecology \& Evolution, 20(11), pp.579-581.

Schreiber, E.A. and Burger, J. eds., 2001. Biology of marine birds. CRC press.

Serventy, D.L. and Curry, P.J., 1984. Observations on colony size, breeding success, recruitment and inter-colony dispersal in a Tasmanian colony of Short-tailed Shearwaters Puffinus tenuirostris over a 30-year period. Emu, 84(2), pp.71-79.

Shoji, A., Aris-Brosou, S., Fayet, A., Padget, O., Perrins, C. and Guilford, T., 2015. Dual foraging and pair coordination during chick provisioning by Manx shearwaters: empirical evidence supported by a simple model. Journal of Experimental Biology, 218(13), pp.21162123.

Smith, S., Thompson, G. and Perrins, C.M., 2001. A census of the Manx Shearwater Puffinus puffinus on Skomer, Skokholm and Middleholm, west Wales. Bird Study, 48(3), pp.330-340.

Solomon, S., D. Qin, M. Manning, Z. Chen, M. Marquis, K. Averyt, M. Tignor, and H. Miller. "IPCC fourth assessment report (AR4)." Climate change (2007).

Stone, P.A., Snell, H.L. and Snell, H.M., 1994. Behavioral diversity as biological diversity: introduced cats and lava lizard wariness. Conservation Biology, 8(2), pp.569-573.

Stubbings, E.M., Büche, B.I., Miquel Riera, E., Green, R.M. \& Wood, M.J. (2016). Seabird monitoring on Skomer Island in 2016. JNCC Report.

Stubbings, E.M., Büche, B.I., Miquel Riera, E., Green, R.M. \& Wood, M.J. (2015). Seabird monitoring on Skomer Island in 2015. JNCC Report.

Stubbings, E.M., Büche, B.I., Riordan, J.A., Moss, J. \& Wood, M.J. (2017). Seabird monitoring on Skomer Island in 2017. JNCC Report.

Stubbings, E.M., Büche, B.I., Riordan, J.A., Baker, B. \& Wood, M.J. (2018). Seabird monitoring on Skomer Island in 2018. JNCC Report.

Stubbings, E.M., Büche, B.I., Wilson, A., Green, R.A. \& Wood, M.J. (2014). Skomer Seabird Report. Wildlife Trust of South and West Wales.

Sullivan, B.J., Kibel, B., Kibel, P., Yates, O., Potts, J.M., Ingham, B., Domingo, A., Gianuca, D., Jiménez, S., Lebepe, B. and Maree, B.A., 2018. At-sea trialling of the Hookpod: a 'onestop' mitigation solution for seabird bycatch in pelagic longline fisheries. Animal conservation, 21(2), pp.159-167.

Sydeman, W.J., Penniman, J.F., Penniman, T.M., Pyle, P. and Ainley, D.G., 1991. Breeding 
performance in the western gull: effects of parental age, timing of breeding and year in relation to food availability. The Journal of Animal Ecology, pp.135-149.

Sydeman, W.J., Thompson, S.A. and Kitaysky, A., 2012. Seabirds and climate change: roadmap for the future. Marine Ecology Progress Series, 454, pp.107-117.

Syposz, M., Gonçalves, F., Carty, M., Hoppitt, W. and Manco, F., 2018. Factors influencing Manx Shearwater grounding on the west coast of Scotland. Ibis, 160(4), pp.846-854.

Taylor, I.R., 1983. Effect of wind on the foraging behaviour of Common and Sandwich Terns. Ornis Scandinavica, pp.90-96.

Taylor, CJ., Baer J., Boyle, D., and Perrins, CM, 2010 Seabird monitoring on Skomer Island in 2010. JNCC Report.

Taylor, CJ., Boyle, D. and Perrins, CM, Kipling, R. (2012) Seabird monitoring on Skomer Island in 2012.JNCC Report.

Taylor, CJ., Boyle, D. and Perrins, CM, Kipling, R. 2011 Seabird monitoring on Skomer Island in 2010.JNCC Report.

Thomas, C.D., Cameron, A., Green, R.E., Bakkenes, M., Beaumont, L.J., Collingham, Y.C., Erasmus, B.F., De Siqueira, M.F., Grainger, A., Hannah, L. and Hughes, L., 2004. Extinction risk from climate change. Nature, 427(6970), p.145.

Thomas, R., Lello, J., Medeiros, R., Pollard, A., Robinson, P., Seward, A., Smith, J., Vafidis, J. and Vaughan, I. 2017a. Data analysis with R statistical software. 2nd ed.

Thomas, N., Lucas, R., Bunting, P., Hardy, A., Rosenqvist, A. and Simard, M., 2017b. Distribution and drivers of global mangrove forest change, 1996-2010. PloS one, 12(6), p.e0179302.

Thompson, K.R. and Furness, R.W., 1991. The influence of rainfall and nest-site quality on the population dynamics of the Manx shearwater Puffinus puffinus on Rhum. Journal of Zoology, 225(3), pp.427-437.

Trenberth, K.E., Jones, P.D., Ambenje, P., Bojariu, R., Easterling, D., Klein Tank, A., Parker, D., Rahimzadeh, F., Renwick, J.A., Rusticucci, M. and Soden, B., 2007. Observations: surface and atmospheric climate change. Chapter 3. Climate change, pp.235-336.

Underwood, L.A. and Stowe, T.J., 1984. Massive wreck of seabirds in eastern Britain, 1983. Bird Study, 31(2), pp.79-88.

Veitch, C.R., Clout, M.N., Martin, A.R., Russell, J.C. and West, C.J., 2019. Island invasives: scaling up to meet the challenge. Occasional Paper SSC, (62). 
Walsh, P.M., Halley, D.J., Harris, M.P., Del Nevo, A., Sim, I.M.W. and Tasker, M.L., 1995. Seabird monitoring handbook for Britain and Ireland: a compilation of methods for survey and monitoring of breeding seabirds. JNCC/RSPB/ITE/Seabird Group.

Walther, G.R., Post, E., Convey, P., Menzel, A., Parmesan, C., Beebee, T.J., Fromentin, J.M., Hoegh-Guldberg, O. and Bairlein, F., 2002. Ecological responses to recent climate change. Nature, 416(6879), p.389.

Weimerskirch, H. and Prudor, A., 2019. Cyclone avoidance behaviour by foraging seabirds. Scientific reports, 9(1), p.5400.

Wickham, H., 2016. ggplot2: elegant graphics for data analysis. Springer.

Wikelski, M., Foufopoulos, J., Vargas, H. and Snell, H., 2004. Galápagos birds and diseases: invasive pathogens as threats for island species. Ecology and Society, 9(1).

Wilcox, C., Van Sebille, E. and Hardesty, B.D., 2015. Threat of plastic pollution to seabirds is global, pervasive, and increasing. Proceedings of the National Academy of Sciences, 112(38), pp.11899-11904.

Wolfaardt, A.C., Crofts, S. and Baylis, A.M., 2012. Effects of a storm on colonies of seabirds breeding at the Falkland Islands. Marine ornithology, 40, pp.129-133.

Wooller, R.D., Bradley, J.S. and Croxall, J.P., 1992. Long-term population studies of seabirds. Trends in Ecology \& Evolution, 7(4), pp.111-114. 